\title{
Climate Change Advocacy and Ecological Modernization: The Symbolic Politics of Carbon Tax Communication in British Columbia
}

\author{
by
}

Andrew Patrick, B.A.

\begin{abstract}
A thesis submitted to the Faculty of Graduate and Postdoctoral Affairs in partial fulfillment of the requirements for the degree of
\end{abstract}

Master of Arts

School of Journalism and Communication

Carleton University

Ottawa, Ontario

April, 2013

(C) 2013, Andrew Patrick 
Library and Archives

Canada

Published Heritage

Branch

395 Wellington Street

Ottawa ON K1A ON4

Canada
Bibliothèque et

Archives Canada

Direction du

Patrimoine de l'édition

395 , rue Wellington

Ottawa ON K1A ON4

Canada
Your file Votre référence

ISBN: 978-0-494-94590-2

Our file Notre référence

ISBN: $978-0-494-94590-2$
NOTICE:

The author has granted a nonexclusive license allowing Library and Archives Canada to reproduce, publish, archive, preserve, conserve, communicate to the public by telecommunication or on the Internet, loan, distrbute and sell theses worldwide, for commercial or noncommercial purposes, in microform, paper, electronic and/or any other formats.

The author retains copyright ownership and moral rights in this thesis. Neither the thesis nor substantial extracts from it may be printed or otherwise reproduced without the author's permission.
AVIS:

L'auteur a accordé une licence non exclusive permettant à la Bibliothèque et Archives Canada de reproduire, publier, archiver, sauvegarder, conserver, transmettre au public par télécommunication ou par l'Internet, prêter, distribuer et vendre des thèses partout dans le monde, à des fins commerciales ou autres, sur support microforme, papier, électronique et/ou autres formats.

L'auteur conserve la propriété du droit d'auteur et des droits moraux qui protege cette thèse. $\mathrm{Ni}$ la thèse ni des extraits substantiels de celle-ci ne doivent être imprimés ou autrement reproduits sans son autorisation.
In compliance with the Canadian Privacy Act some supporting forms may have been removed from this thesis.

While these forms may be included in the document page count, their removal does not represent any loss of content from the thesis.
Conformément à la loi canadienne sur la protection de la vie privée, quelques formulaires secondaires ont été enlevés de cette thèse.

Bien que ces formulaires aient inclus dans la pagination, il n'y aura aucun contenu manquant. 


\begin{abstract}
This thesis explores communication of the carbon tax and climate change policy in British Columbia (B.C.), Canada, by various environmental advocates and organizations from January 1, 2006 through August 31, 2012. It adopts a form of argumentative discourse analysis espoused by Maarten Hajer in its examination of two discourse coalitions organized around the principles of both "weak" and "strong" ecological modernization (Christoff, 1996). The analysis works from a conception of the carbon tax as a product of deliberative interplay and details the shifting communicative dynamics that have helped shaped the significance of policy over time. By examining various written texts, I argue that communication about the B.C. carbon tax was largely dominated by a weak ecological modern discourse coalition. The study concludes with discussion on the potential implications for future advocacy efforts in the province, emphasizing the role of communicative practice in the "green public sphere".
\end{abstract}

Keywords: climate change, carbon tax, communication, discourse coalitions, Maarten Hajer, ecological modernization, environmental movement, British Columbia. 


\section{Acknowledgments}

My time at Carleton has offered an incredible wealth of new experiences and knowledge for which I am deeply grateful. I would like to thank the staff and faculty in the Communication Studies department for their generous support and insight into communication scholarship, and for making my experience as engaging and enjoyable as it was challenging.

I have benefitted immensely from the guidance of my thesis supervisor, Professor Chris Russill, who has offered new and exciting perspectives on my research with every discussion. I am also thankful for the encouragement and assistance of Professors Josh Greenberg, Eileen Saunders, Ross Eaman, Michael Dorland, and Kirsten Kozolanka. To my fellow graduate students, I could not have progressed as I have if it were not for the wide-ranging discussions and feedback you have shared in so many different instances. Your friendship is greatly appreciated.

To my family and friends, I owe a deep debt of gratitude. The unwavering love and support of my parents, Ruby and Jim, as well as my siblings, Jenn and Matt, has been invaluable and I would not have been able to accomplish what I have without their help. I am also indebted to my aunt and uncle, Donna and Ben, for their care and advice.

Finally, I would not be at this point in my life if I did not have the strength and spirit of my partner Tiffany enlivening me at every turn. Tiffany, your love and creativity have inspired me in so many ways and I aspire to give back even more. I am continually honoured to share this path alongside you.

A special thank you to the Ontario Graduate Scholarship Program, whose financial contribution helped make this research possible. 
Dedicated to the memory of Maureen Woods

To Aunty Moe. 


\section{Table of Contents}

Abstract - (ii)

Acknowledgments - (iii)

Dedication - (iv)

Table of Contents - (v)

Chapter One - Introduction (p. 1)

Chapter Two - Environmentalism and Climate Change Advocacy in British

Columbia (p. 10)

- 2.1 - Timeline: Environmental Advocacy and the Carbon Tax in B.C. (p. 11)

- 2.2 - Literature Review: B.C.'s Carbon Tax and Communication (p. 19)

Chapter Three -Theoretical Framework (p. 25)

- 3.1 - Ulrich Beck: Risk Society, Reflexive Modernization and the Subpolitics of Climate Action (p. 25)

- 3.2 - Ecological Modernization: Competing Visions for the Future (p. 32)

- 3.3 - Environmental Movements, The Green Public Sphere, and Media (p. 39)

Chapter Four - Research Methodology and Methodological Issues (p. 47)

- 4.1 - Discourse Coalitions and Methodological Framework (p. 49)

- 4.3 - Methodology: Communication and the B.C. Carbon Tax (p. 54)

- 4.4 - Data Collection and Materials (p. 55)

- 4.5 - A Note on Environmental Organizations and Actors (p. 61)

Chapter Five - Discourse Analysis: Results and Discussion (p. 62)

- 5.1 - Setting the Discursive Context: An Illustrative Example (p. 63)

- 5.2-Discourse Coalitions and the Strength of Ecological Modernization (p. 67) 
- 5.3 - Storylines: "Weak" Ecological Modernization Coalition (p. 68)

- 5.4 - Storylines: "Strong" Ecological Modernization Coalition (p. 74)

- 5.5 - Practicing Symbolic Politics: Movement, Media and State (p. 83)

- 5.6 - Shaping a Reformed Carbon Tax and the Ascendancy of Natural Gas (p. 90)

Chapter Six - Conclusion (p. 95)

Appendix One-Discourse Coalitions: Environmental Organizations and Actors (p.

110)

Appendix Two - Search Terms (p. 118)

References - (p. 119) 


\section{Chapter One}

\section{Introduction}

Why has there not been a "storming of the Bastille" over climate change? This rather provocative query, posed by German sociologist Ulrich Beck (2010, p. 254), may indeed reach beyond the bounds of this humble thesis, but it is admittedly a question that has sat in the back of my mind since reading it. After letting its weight sink for a moment, a torrent of counter-provocations usually come to mind; "Is climate change really the type of problem that calls for such a "revolution"? If so, revolt against who or what? What sort of revolution would this look like? What understanding of climate science and political change does this imply? What would be the consequences of thinking about climate change in this way?". Such a question is not often the starting point for attempts to address climate change and the constellation of interconnected challenges it presents for myriad societal interests (cf. Hulme, 2009), and perhaps for good reason.

For Beck (2010), however, this question begets still more questions: "Where is the support for ecological changes supposed to come from, the support which in many cases would undermine [people's] lifestyles, their consumption habits, their social status and life conditions in what are already truly very uncertain times?" (p. 255). To which he answers, "from below": meaning that the significance of climate change must be deliberated on in innumerable ways by a majority of different cultural groups in order to animate it in a more creative, participatory and conflictual light. Otherwise "climate politics is doomed" (p. 255). This is the process modern society must go through in order to confront the omissions of its own guiding mantras that have thus far created the 
insidious byproducts that now threaten to undermine its very existence. Climate change, from this view, is the ultimate side effect of an incomplete and ongoing process of modernization.

To be clear, there is much more to Beck's theory, but it is not entirely apparent that this premise is correct, or at least it does not seem to be the dominant wisdom employed to answer the threat of global warming in many places around the world. Though often times climate advocates acknowledge that an enormous transformation in the infrastructural arrangements of modern societies must be undertaken, by and large it is just as commonplace for political resolve to be sought in more calculated and controlled communication strategies that attempt to leave preexisting social and political life relatively intact. A technological breakthrough might occur, for example, with the proper government policy program in place, if only the public would just support it. From these vantage points, a more active vision of citizenship in a climate-altered world is not as necessary as getting the right technical policy changes in place to make the shift to a zero-carbon future. Much climate change communication in practice has spent a considerable amount of persuasive energy implicitly making this case: that action on global warming can abide by the dominant relations of power in societal institutions, keeping the "messiness" of a more engaged democratic politics at bay. Yet this is central to Beck's argument: the avoidance of (what he sees as) the inevitable societal change that climate change will bring has put the cement shoes on climate advocacy in preparation for its political dance with a very different sort of destiny.

I am not throwing unflinching support behind Beck's theoretical approach, but I find it a compelling entry point into what may, upon first glance, appear a rather confined 
area of study - tax reform. More specifically, the following thesis research will focus on communication issues surrounding the carbon tax in British Columbia (B.C.), Canada, from the years 2006 to 2012, while paying particular attention to the role of various environmental advocates and organizations in provincial environmental politics. Starting in 2008, the B.C. carbon tax became an important political symbol and a cornerstone in the provincial government's program to address global warming. Consequently, it is prudent to examine in more detail some of the social effects it may have had on the climate policy community and broader environmental movement, with an eye towards how these groupings may have affected the broader shape of climate change debate in the province.

Next to cap-and-trade market mechanisms, carbon taxes have been among the most prominent and commonly cited mitigation measures in the policy toolbox for fighting global warming, aiming to "internalize" the projected costs of climate change on society by putting a price on carbon emissions. ${ }^{1}$ They have been supported by an impressive collection of unlikely allies, including numerous environmentalists and economists alike. It is sometimes surprising to find that carbon taxes are advocated both on behalf of environmental activists like David Suzuki and Bill McKibben, as well as by CEOs representing Alberta's vilified oil patch (Dembicki, 2012), or the International Monetary Fund (International Monetary Fund, 2012).

Yet carbon taxes have typically occupied a contradictory role in much public debate about climate change. Many proponents have emphasized that carbon taxation offer governments a relatively quick and straightforward way to address climate change

1 Other common policies include cap-and-dividend, government regulation, and spending on research and innovation. 
commitments with little comparative cost to the broader economy. ${ }^{2}$ In its simplest form, the rationale rests on the notion that as the price of carbon-intensive goods and services increases, aggregate demand decreases, thus helping to make activities that are lesspolluting more cost-competitive and attractive.

However, despite any administrative ease and design efficiencies offered by carbon taxes, they are often said to be cursed: orphaned at birth into a socio-political sphere degraded by decades of neoliberal policy rule that has weakened the public value of governments and nurtured a populist communicative context hostile to new taxes. ${ }^{3}$ As a consequence, the threat of opportunistic political attacks preying on the latent anxieties of the general public has loomed large in much policy discourse on carbon taxes. Indeed, one does not have to look far to find examples that reinforce the seriousness of these concerns, though carbon taxes are hardly alone in their vulnerability here. ${ }^{4}$ The broader state of public discussion and engagement on climate change is often noted to be limited by a number of important challenges in various media-spheres ${ }^{5}$, not least of which has been a vocal and committed network of climate denialists supported in part by a powerful set of institutional interests (see Oreskes \& Conway, 2010; Knight \& Greenberg, 2011). Though climate change may indeed be a critical issue for broad cross-sections of society to grapple with, it is noteworthy that advocacy has frequently struggled to get past

\footnotetext{
${ }^{2}$ Often very little procedural innovation and complexity is necessary to institute carbon taxes, especially in comparison to the administrative hurdles involved in setting up new carbon markets under cap-and-trade systems. In B.C.'s case, the carbon tax was announced in February of 2008 and was up-and-running less than six months later on July 1, 2008.

${ }^{3}$ A more commonly used vernacular casts the problem in more straightforward terms, where cynical politicians manipulate the public to score cheap political points.

"This argument might hold for most climate policies introduced into such a political environment. In a Canadian setting, the most recent attacks by the ruling Conservative Party of Canada on the federal NDP cap-and-trade platform as a "carbon tax" (Galloway, 2012), echoes the narrative used in the 2008 federal election campaign which saw the Conservatives frame the Liberal "Green Shift" carbon tax as a "tax on everything" (Harrison, 2012, pp. 393-398).

${ }^{5}$ See Anderson (2009) for overview of some of these limitations. For a Canadian media context see Young \& Dugas (2011). More recent analysis of traditional media outlets points to a continued stagnation in overall news coverage (Fischer, 2013).
} 
debates about whether or not the phenomenon is real and, if so, whether it is caused by human activity.

This background further underscores the importance of scholarly attention to climate policies that have been implemented into official government legislation. In this respect, the British Columbia carbon tax deserves consideration, in part because it remains the most significant example of a carbon tax to date in North America. Examining how the policy has been framed in communication may therefore illuminate some of the argumentative dynamics that helped define the political terrain that both enabled and limited the scope of societal change that has unfolded over the past several years. The primary intent of this research is to study the efforts of advocates and organizations that pushed for climate action within the environmental community, as they often contributed considerable political energy to public debate and offered important perspectives on the meaning of the policy that were not available elsewhere. Following Dryzek et al. (2003), I take the position that social movements play a transformative role in politicizing issues like global warming through deliberative action in the "green public sphere" (cf. Torgerson, 1999), potentially bringing about broader discursive and democratic change in political cultures and expert policy circles.

It would be rare to find a policy program that was universally accepted by an advocacy community, and despite finding prominence in environmental debate in the province, the carbon tax in British Columbia was no different. Through struggles to define the meaning of policies like the carbon tax, actors worked to influence audiences and mobilize support around a given understanding of the policy's wider social significance. In this sense, my theoretical approach takes a social constructivist view 
towards climate change politics, focusing on the variety of claims made for climate action and their implicit socio-political consequences.

Furthermore, and following Hajer's notion of discourse-coalitions (1995, pp. 4272), I suggest that climate change communication is often characterized by a wide range of seemingly disparate actors expressing common cause through a variety of unifying storylines, despite potentially contradictory interests and subject-positions which are continually negotiated in the argumentative process itself. Examining how this process unfolded in relation to systems of institutional power in practice can help illuminate some of the challenges and opportunities faced by different advocates as they made their case for appropriate action. A critical part of this study will involve attention to the discourse of ecological modernization, which is often cited as a dominant communicative frame structuring environmental politics, and one which is sometimes interpreted by scholars through the lens of Beck's theories on reflexive modernization and risk society (Hajer, 1995; Dryzek et al., 2003; cf. Mol, Sonnenfeld \& Spaargaren, 2009).

In practice, ecological modernization is typically expressed in terms that dissolve antagonisms between traditional "environment vs. economy" conflicts by arguing that incorporating environmental concern into economic activity leads to greater societal benefit. Thus by "internalizing" the costs of climate change into the price of goods and services, society can take advantage of a "win-win" situation by becoming more ecologically rational and economically efficient. Scholars often note that this approach attempts to solve ecological problems created by modern institutions, by refining the operations of these institutions in accordance with the principles of ecology. Thus, the solutions to climate change are to be found in more modernity, not less: in a renewed 
science and technology sector focused on carbon emissions abatement working with "green businesses" in innovative market relationships guided by liberal democratic government oversight.

Carbon taxes are but one example of how such a broad and encompassing theory might begin to be crystallized into more specific policy proposals. However, part of the allure of such a discourse draws from this very indeterminacy. A large number of seemingly different visions for society can be advanced under its banner, enabling multiple futures to be constructed from similar metaphors and narrative reference points. In this respect, the socio-political consequences of ecologically modern discourse are an open question and one for empirical research and discussion. They depend on the specific cultural and historical background from which communicative acts are made meaningful through their production and reproduction in social life.

Special attention will be paid to the ways in which expressive regularities in discourse-coalitions have been related to the institutional context of power: a dimension for which Christoff"s (1996) distinction between "weak" and "strong" eco-modernist discourse will be used. Addressing climate change poses major challenges for the institutional arrangements of modern society as the forebears of any potential or impending ecological crisis. In this sense, the hazards of global warming, as well as its possible ameliorative solutions, are potentially, though not necessarily, socially explosive: a notion guiding much of Beck's theoretical work. This volatility, however, depends foremost on the ways in which arguments are constructed and defined in communication to seem authoritative, legitimate and appealing. If both climate science and policy action are characteristically beset by scientific and technical complexities 
informing risk analysis and value judgments (cf. Hulme, 2009), then the ways in which arguments are constructed to create the appearance of such certainty and authority deserve open scrutiny and discussion on the assumptions that may be guiding policy decisions and shaping future societal change.

The following chapters will proceed first with an overview of political events in B.C. that led to the introduction of the carbon tax and its first four years of operation, including a review of existing scholarly analysis of the B.C. carbon tax (Chapter Two). From there, I will examine the relevant theoretical literature informing the study, including research related to ecological modernization, environmental discourse and Beck's sociological approach (Chapter Three). This will be followed by an overview of the methodology that helped guide the study, an explanation of the discourse analytic approach and justification of some of the interpretive choices and considerations made during the research process (Chapter Four). This will also be punctuated by reflections on the potential benefits and limitations of the methods used, explicating what the research can and cannot offer. The next chapter (Chapter Five) will involve a detailed analysis and discussion of actual carbon tax discourse as it emerged from the sample for the time periods given, elaborating on some of the patterns and dynamics of communication found throughout the study. Both the relevant practical and theoretical issues will be discussed leading into the concluding chapter (Chapter Six), which will focus on relevant questions for further academic research and implications for future advocacy.

The centre of gravity grounding my thesis work will be an understanding of power as something that is achieved through the creative process of communication in connection to the social and historical context from which it emerges. This may seem like 
a subtle point, but I will attempt to show that such an approach offers important insights into the politics of climate change discourse in British Columbia. Modifying Hajer (1995, p. 4) slightly: this is what the carbon tax conflict was (is) about. In the context of debate about the B.C. carbon tax, I will suggest that an argumentative approach to environmental political analysis offers the fullest account of both the opportunities and limitations the policy offered to each actor or group in the environmental community.

In this sense, the B.C. carbon tax can be seen as an artifact of deliberation that held separate socio-political consequences for the different parties involved in the struggle to define its significance. Analyses that point to one clear and unwavering definition of what the carbon tax was (is) risk reifying a realist interpretation of the policy and bracketing out key factors that helped influence the course of political change throughout the study period. A more nuanced understanding of the communicative dimension of environmental politics can hopefully provide the basis for a more focused rhetorical project which could encourage deeper and wider reflection on what sort of future is being brought about in the name of climate action. 


\section{Chapter Two}

\section{Environmentalism and Climate Change Advocacy in British Columbia}

The carbon tax in British Columbia has occupied a powerful and contested position in provincial climate change politics since it was unveiled as the centerpiece of the B.C. Liberal Party's Budget on February 19, 2008. Despite being part of an array of different climate initiatives, the policy itself quickly became a highly charged symbolic target as the opposition New Democratic Party (NDP), themselves known as the progressive alternative to the Liberal's right-of-centre political coalition, campaigned to "axe the tax" in June of that year, and continued the offensive throughout the provincial election in May, 2009. As the carbon tax became an official political priority for both parties it garnered significant media attention and brought a variety of environmental actors and organizations into the spotlight as key contributors in a broader public debate.

The following chapter will proceed first with a brief account of some of the pivotal events that led to the implementation of the B.C. carbon tax in 2008 , and the subsequent political struggle over the direction of climate change politics in the province until August, 2012. Scholarly literature about the policy will then be reviewed to bring depth to this account and set the stage for later analysis. My overall aim is to frame a general narrative about the B.C. policy context that draws from these academic perspectives and illuminates some of the more formative political factors that helped influence climate change communication for carbon tax advocates over time. Furthermore, I hope to highlight a number of gaps remaining in the existing research, which my study will address in more detail in later chapters. 


\section{1 - Timeline: Environmental Advocacy and the Carbon Tax in B.C.}

British Columbia has a rich history of environmental activism and social movement mobilization that has played an influential role in its various cultural and political landscapes. High-profile environmental conflicts have often become a central feature of B.C. politics, from the birth of Greenpeace and their voyages to stop American nuclear testing in Alaska, to the so-called "War in the Woods" battles of Clayoquot Sound and the Great Bear Rainforest. Government decisions have often been met by resistance from environmentalists in a wide variety of forms, including direct action campaigns, civil disobedience, mass arrests, international media boycott strategies and multi-stakeholder agreements, among others. ${ }^{6}$

Academic literature examining climate activism in the province is less robust than research focused on more traditional environmental conflicts. However, there remain a number of accounts directly relevant to the development of the Liberal government's climate policy and the "about-face" which moved global warming to the centre of the political agenda (see next section; Sodero, 2011; Harrison, 2012; Gunster, 2010; Shaw, 2011; Peet \& Harrison, 2012). By considering these bodies of research along with historical analyses of past environmental clashes, valuable perspectives on the discursive interactions that helped animate climate change discourse surrounding the carbon tax can be reconstructed.

\footnotetext{
${ }^{6}$ For more historical background on BC environmentalism and social movements see Zelko (2004), Wynne (2004) Van Huizen (2011), Bernstein \& Cashore (2000), Braun (2002), Shaw (2004), Berman \& Leiren-Young (2011), and Carroll \& Ratner, (2007).
} 
Scholarly and popular accounts generally note a dramatic turnaround in government climate policy led by Premier Gordon Campbell beginning around February 13, 2007 with the provincial Speech from the Throne. Prior to this point the Liberals were well known for being environmental laggards and luke-warm on the climate change file, even opposing Canada's entry into the Kyoto Protocol. However, with the throne speech announcement, the Liberals signaled the beginning of a number of climate directives, which would later include a revenue-neutral carbon tax in the 2008 Budget plan announced in February of that year. ${ }^{7}$ The tax itself would be applied to greenhouse gas emissions from the combustion of fossil fuels in the province, which covered roughly three quarters of total provincial emissions. Revenue-neutrality meant that all monies raised by the government through the carbon tax were to be recycled back to citizens through tax returns and credits for low-income individuals, therefore leaving the government's fiscal balance sheet "neutral". Through a series of legislation, B.C. would soon go from "laggard to leader", according to some in the environmental community, and would draw acclaim from a wide variety of voices both within and beyond the province (Pembina Institute, David Suzuki Foundation, \& ForestEthics, 2009; Hume, 2009; de Place, 2008).

In June, 2008, the government released its Climate Action Plan, which detailed a suite of policies projected to meet 73 per cent of its legislated GHG reduction target. The remainder was to be made-up through policy recommendations delivered in August, 2008, by an expert panel of environmentalists, climate scientists, entrepreneurs, First

\footnotetext{
${ }^{7}$ Other Liberal policies included legislated GHG emissions targets of 33 per cent reduction from 2007 levels by 2020 (roughly 12 per cent below 1990 levels); a new government ministry connected to the Premier's Office called the Climate Action Secretariat; a commitment to join the regional Western Climate Initiative cap-and-trade system to put a price on emissions not covered by the carbon tax; a $\$ 14$ billion transit plan spent with federal and municipal monies up to 2020; a low-carbon fuel standard and vehicle emissions regulations similar to those enacted in California; and various commitments to renewable energy and energy efficiency. For more detail see British Columbia Ministry of the Environment (2008).
} 
Nations representatives, and politicians, called the Climate Action Team. ${ }^{8}$ The carbon tax itself, came into force in the interim on July 1,2008 , amid increasing public backlash as gas prices in the province reached an all-time high and the NDP anti-tax campaign, launched a month earlier, ${ }^{9}$ gathered steam. The carbon tax rate started at $\$ 10$ per tonne $\mathrm{CO} 2 \mathrm{e}^{10}$, or roughly 2.3 cents per litre of gasoline, and was scheduled to increase by $\$ 5$ per tonne for each successive year, until reaching $\$ 30$ per tonne CO2e on July 1, 2012. The original idea of pricing carbon through a carbon tax had previously been circulated in various environmental policy circles, including those initiated under the NDP government in the 1990s. ${ }^{11}$ In 1998, an American environmental think-tank called Northwest Environment Watch (later the Sightline Institute) issued a paper promoting revenue-neutral tax shifting, which had some influence across the border in B.C. (Durning \& Bauman, 1998; cf. Sodero, 2011). ${ }^{12}$ A subsequent paper, authored by academics at Simon Fraser University, more specifically promoted environmental tax shifting in British Columbia, which helped further establish the legitimacy of the policy in the province (Taylor, Jaccard, \& Olewiler, 1999; cf. Sodero, 2011). A year later, a separate policy brief was published by the B.C. division of the Canadian Centre for Policy Alternatives (CCPA), which countered these previous narratives about the benefits of tax shifting, and instead defended the role of government regulation and spending in

\footnotetext{
The team was originally announced in November, 2007 (see B.C. Climate Action Team, 2008).

${ }^{9}$ The party had previously expressed opposition to the Liberal carbon tax even prior to its official announcement. On January 13, 2008, NDP leader Carole James wrote an op-ed suggesting such plan would be unfair to citizens (see James, 2008). Harrison (2012, p. 393) notes the NDP supported carbon taxation just a few months earlier in November, 2007. The NDP also expressed their opposition to the carbon tax by voting against its official legislation in May, 2008.

${ }^{10}$ This represents carbon dioxide equivalent emissions ( $\left.\mathrm{CO} 2 \mathrm{e}\right)$, which serves as a baseline for all greenhouse gas emissions calculated in terms of their "global warming potential" in relation to carbon dioxide. Different fuel types sold in B.C. release different amounts of various greenhouse gases and so must be translated into a common metric of $\mathrm{CO} 2 \mathrm{e}$.

"See Sodero (2011, p. 1476). Harrison (2012, p. 393) also notes the NDP supported carbon taxation a few months before the Liberal's 2008 Budget announcement.

${ }^{12}$ One of the study's authors, Alan Durning (2008) claims that in 1998 a soon-to-be Premier Gordon Campbell told him that he would institute a revenue-neutral carbon tax during his second term in office based on his reading of the Tax Shift policy paper.
} 
conjunction with environmental taxes (Marshall, 2000). ${ }^{13}$ It is unclear whether this had much influence in policy circles at the time, but resistance to the "tax shifting" aspect of the Liberal carbon tax would eventually gain prominence within environmental and political networks in B.C. after 2008.

In any case, numerous environmental groups had made concerted efforts to strengthen government climate policy and oppose ongoing carbon-intensive development throughout 2006 and 2007. Part of this advocacy included promoting carbon taxes. Other efforts included opposition to two coal-fired power plant projects, government subsidies to the oil and gas sector, the Gateway transportation corridor on the Lower Mainland, and proposals for offshore oil drilling, among many others. ${ }^{14}$ While the Liberal government would effectively prohibit new coal plants in 2007 and adopt a number of ideas proposed by the various groups, many environmentalist demands went largely unfulfilled.

Nearly all groups expressed clear opposition to these contradictions in policy action between the government's newly formed 2007 climate agenda and its continued promotion of fossil fuel-based energy infrastructure and transport corridors. Despite this near unanimity, these issues would eventually become key points of contention within the environmental community in later disputes over the Liberal carbon tax agenda, especially during the 2009 provincial election. For those who allied more with the Liberal climate plan, their expressed opposition to the policy contradiction often became subordinate to

\footnotetext{
${ }^{13}$ The significance of this tension with respect to the design of the tax and proper way to conceive the role of the public sector will be discussed throughout Chapter Five. The CCPA would eventually become a key opponent of the revenue-neutrality of the tax.

${ }^{14}$ See Sierra Club BC (2006); Matthaus (2006); Pembina Institute et al. (2007); Bruce, Campbell \& Matthaus (2007); BC Sustainable Energy Association [BCSEA] (2007); and Genovali (2007); cf. Canadian Centre for Policy Alternatives [CCPA] (2008a).
} 
statements of qualified support for government climate policies, foremost of which was the carbon tax. ${ }^{15}$ This dynamic will be examined in further detail in Chapter Five.

Qualified support for Liberal policy was more or less enthusiastic depending on the time period and context in question. Though clearly the environmental community was not homogenous in their response to government policy, there were periods of broad agreement. Environmentalist communication ${ }^{16}$ remained relatively unified, first in a phase of cautious skepticism at the outset of the 2007 Liberal climate policy turnaround, then by a period where qualified or ambivalent support for the government climate program was more commonplace throughout much of 2008.

However, divisions in the environmental movement became more pronounced in the lead-up to the 2009 election in May, despite previous stages characterized by a more consistent and collaborative advocacy. An increasingly publicized rift had developed, most pointedly around grassroots concerns about privatized run-of-river hydro (ROR) power development in local communities, which had been escalating since the Liberal's Energy Plan in 2002 (Shaw, 2011). The NDP, for their part, had officially adopted the grassroots call to put a moratorium on private ROR development by late March, 2008, further delineating the split along partisan lines (Hume, 2008).

These tensions peaked in the months preceding the provincial election, as three environmental groups_-Pembina Institute, David Suzuki Foundation, and ForestEthicsheld a press conference lauding the Liberal carbon tax and climate change agenda, while critiquing the NDP approach as "a step backwards" (Pembina Institute et al., 2009;

\footnotetext{
${ }^{15}$ For an early example of this tension see Pembina et al. (2008). This joint release praised the release of the Climate Action Team's report. After lauding the carbon tax, the groups noted, "Notwithstanding the many positive steps, the coalition did note the Climate Action Team did not address some existing contradictions between the government's energy and transportation policies and its goal of reducing greenhouse gas emissions. Increasing oil and gas production and large-scale highway expansion projects will make it more difficult - and perhaps impossible - to achieve the province's legislated greenhouse gas reduction targets".

${ }^{16}$ This is a term I use to mean any act of communication expressed by non-governmental environmental advocates or groups.
} 
Campbell, Bruce \& Smith, 2009). In addition, prominent green leaders like David Suzuki (Bailey, 2009), Tzeporah Berman (Ward, 2009) and Mark Jaccard (Zehr, 2009a; Jaccard, 2009 a) added fuel to the fire by heavily criticizing the NDP climate platform. ${ }^{17}$

Harrison (2012, pp. 398-399) notes that the defense put forth by these advocates was partly a response to the defeat of the federal Liberal Party plan for a similar carbon tax following the 2008 Canadian national election six months earlier. British Columbia is home to a number of significant actors in the environmental movement at a national level, and in many instances, the B.C. carbon tax was explicitly conceptualized as a "model" for climate policy elsewhere. However, any plans to that effect met with resistance from other environmentalists who previously collaborated with these same actors, but who ultimately found greater alignment with grassroots and NDP causes. ${ }^{18}$ Following the re-election of the Liberal Party in May, 2009, the NDP officially dropped their call to "axe the tax" in the summer of that year, eventually advocating reform of the policy, which would include making it "fair and effective", as well as dedicating revenues to climate initiatives instead of committing to revenue-neutrality (Littlemore, 2009; Brethour, 2012). In November, 2009, the Liberal government assembled a Green Energy Advisory Task Force to solicit advice on provincial energy policy and build social license in affected communities, including those impacted by privatized ROR developments. The panel enlisted some of the same laudatory environmentalists who defended the Liberal climate change agenda during the election, including Tzeporah Berman, Matt Horne of the Pembina Institute, and James Hoggan,

\footnotetext{
${ }^{17}$ Further expert critique of the NDP climate platform was given by Sustainable Prosperity saying it was the "weakest policy in Canada" and would create "huge instability and doubt" for the market (Hume, 2009). A group called the Conservation Voters of BC recommended an "Anybody But Carole" voting strategy for the electoral riding held by NDP leader, Carole James (Lavoie, 2009). "Appendix One lists actors and environmental groups that tended to align with one another in "discourse coalitions", a term I will explain in much greater detail in Chapters Four and Five.
} 
chair of the David Suzuki Foundation and co-founder of the climate change website DeSmogBlog. The recommendations, released in April, 2010, were soon followed by the Clean Energy Act in June, 2010, which aimed at turning B.C. into a "clean energy powerhouse" by focusing on energy export opportunities, and removed further independent oversight of renewable energy projects (Shaw, 2011; Hoberg, 2010; Green Energy Advisory Task Force, 2010; Bill 17 - 2010: Clean Energy Act, 2010).

Though the carbon tax remained an important topic of environmentalist concern in B.C. after the 2009 election, political attention and media coverage generally lessened for the remainder of the study period. ${ }^{19}$ Premier Gordon Campbell officially resigned from office in March, 2011, and was replaced by Liberal Premier Christy Clark, whose administration has generally shown less enthusiasm for Campbell's original climate strategy. ${ }^{20}$ Under the Clark government, the Liberals officially launched a public review of the carbon tax to decide how the government would move forward following the last scheduled price increase to $\$ 30$ per tonne CO2e in 2012 (Bailey, 2012).

The substance of much climate advocacy about the carbon tax eventually became concentrated on four points of reform to the structure of the tax itself, and further solidified in an online campaign during the input period of the government review process (www.betterfuturefund.ca; Bruce \& O'Connell, 2011; Horne, Bruce, Glave, \&

\footnotetext{
19 As a rough indicator of this, a search using the keywords "carbon tax" and "British Columbia" was performed in Canadian Newstand Complete, which returned 533 results from the dates January 1, 2006, through September 31, 2012. The majority were published in 2008 ( 359 texts), tapering down in 2009 ( 84 texts), and leveling off for the rest of the research period. Less than 30 texts for each year were found for the 2010-2012 period. Only nine texts were returned for 2007 and none for 2006. Though texts were distributed relatively evenly throughout each year, over 60 per cent of texts from 2009 were published in the April and May lead-up to the provincial election. This general trend is corroborated in my research sample of blog posts, policy documents and independent media.

${ }^{20}$ This is in line with popular arguments suggesting that the political force behind the carbon tax was largely dependent on the decisions of Premier Campbell (see Harrison, 2012; Sodero, 2011; \& Gunster, 2010). It is also noteworthy that Campbell himself later accepted the position of federal high commissioner to the United Kingdom where he has lobbied against European low-carbon fuel standards that would discriminate against polluting sources of fuel, such as those from the Alberta tar sands (Dembecki, 2011). Furthermore, Campbell's resignation is commonly attributed to widespread public backlash to his implementation of the Harmonized Sales Tax, which was also sold as a revenue-neutral replacement for previous sales taxes.
} 
Dauncey, 2012; Sierra Club et al., 2012). ${ }^{21}$ These policy points had previously taken shape by at least late 2008 (see Pembina Institute, 2008b) ${ }^{22}$, and were expressed more consistently throughout the remainder of the study period. Recommendations usually included increasing the carbon price beyond $\$ 30$ per tonne $\mathrm{CO} 2 \mathrm{e}$, expanding coverage of the tax to include non-combusition emissions from industry, ${ }^{23}$ increasing compensation for low-income families, and using carbon tax revenue to fund emissions reduction projects.

Equally concerning to climate advocates was the rapid expansion of natural gas production in the northeast of the province where technological innovations led to a booming industry, facilitated in part by the extraction process known as hydraulic fracturing ("fracking"). Though emissions from the oil and gas sector were a significant concern for a wide-range of environmentalists prior to the 2007 Throne Speech, the magnitude of the problem became increasingly engrossing to a number of actors with government approvals of projects like the Encana Cabin Gas plant in February 2010. One estimate predicted the plant would become the largest single-point source of emissions in the province by adding roughly 2.2 megatonnes (Mt) CO2e per year to the provincial emissions inventory, most of which would not be covered by the carbon tax (Horne, 2010; M. Lee, 2010a). ${ }^{24}$ In comparison, a common estimate of emissions reductions expected from the carbon tax was $3 \mathrm{Mt} \mathrm{CO2e,} \mathrm{assuming} \mathrm{the} \mathrm{price} \mathrm{stayed} \mathrm{at} \$ 30$ per tonne

\footnotetext{
${ }^{21}$ This online campaign was organized primarily by three groups as part of the original sample including BCSEA, David Suzuki Foundation and Pembina Institute. However, the other two founding groups represent partnerships with at least three sampled organizations including Dogwood Initiative, Sierra Club BC and ForestEthics, among a number of similar groups not represented in the research. Furthermore, a coalition of environmental groups and unions echoed the calls for a Better Future Fund in the submission to the carbon tax review, which also included Wilderness Committee (Sierra Club BC et al., 2012).

${ }^{22}$ Note, however, that this policy document stopped short of recommending a move away from revenue-neutrality towards dedicated spending on climate initiatives (see Pembina Institute, 2008b, p. 4)

${ }^{23}$ Generally, these are emissions are defined as those not burned, but released during the production and processing of cement, aluminum, lime, natural gas, and landfill waste.

${ }^{24}$ The Cabin Gas plant estimate also did not include figures for "upstream emissions" that were thought to result from the new production capacity begetting further natural gas extraction (Horne, 2010).
} 
post-2012 (see British Columbia Ministry of Environment, 2008, pp. 19-20). In an op-ed in the Vancouver Sun, resource economist Mark Jaccard estimated that processing capacity to match the natural gas sector's exploitation potential would make the government's emissions targets "virtually impossible" (Jaccard, 2010).

In February, 2012, the government moved natural gas exploitation to the centre of its economic agenda by releasing the Natural Gas Strategy, which included proposals for three Liquid Natural Gas (LNG) processing facilities on the northern coast near Kitimat, B.C., to take advantage of price differentials in Asian markets (British Columbia Ministry of Energy and Mines, 2012). Shortly thereafter, Premier Clark publicly suggested the government would reevaluate the way it accounted for its GHG emissions by looking beyond provincial borders to potential reductions facilitated by B.C. natural gas exports thought to have replaced higher-emissions fuels in other jurisdictions, like China (Hunter, 2012). In June 2012, the government reclassified natural gas used to power LNG processing plants as "clean" under the Clean Energy Act on the grounds that it functioned as a "transition fuel", displacing higher-carbon energy burned elsewhere (Bailey \& Stueck, 2012; cf. Stephenson, Doukas, \& Shaw, 2012).

\section{2 - Literature Review: B.C.'s Carbon Tax and Communication}

Scholarly appraisal of the B.C. carbon tax has focused on different aspects of the policy setting that offer important insights into separate and overlapping areas regarding the origin, design, and implementation of the tax, as well as its overall significance for academic research. I will first map out where these accounts converge and how they 
differ, to provide a clearer picture of how my own analytical project adds further depth to this discussion, especially in relation to the environmental movement and communication. From there I will sketch out some of the remaining gaps in research and how my study addresses some of these areas in connection with my chosen theoretical framework, which will be explained in the next section.

Broadly speaking, research on the B.C. carbon tax has portrayed many features of the political story and genesis of the carbon tax in much the same manner as the account given above. It is often noted that the Liberal climate agenda was a surprising political event in that it represented a significant step towards a more encompassing climate agenda from a party that previously had a dubious record on the environment. This policy reversal has been shown to be a function of the top-down decision-making that characterized much of the Liberal climate program. Both Sodero (2011) and Harrison (2012) demonstrate that Liberal climate policy was driven primarily by the decisions of Premier Gordon Campbell, who was empowered by the centralizing authority afforded by the provincial majoritarian parliamentary system, at times against the will of his own caucus members.

Harrison (2012; cf. Peet \& Harrison, 2012) in particular argues that the arrival of the carbon tax was due, at least in part, to the "good policy" motives of the Premier overcoming "good politics" ${ }^{25}$ The argument here is that although the carbon tax was indeed an economically efficient and environmentally effective policy instrument ("good policy"), it was likely to inspire backlash from the electorate, and thus not a smart

\footnotetext{
${ }^{25}$ Harrison (2012) also cites a number of other reasons for Campbell's normative commitment to "good" climate policy, including the successful implementation of California's Global Warming Solutions Act, increased environmental attention as indicated through public polling data, a second significant parliamentary majority, the birth of his grandchild, and the pine beetle epidemic in B.C. which devastated much of the provincial forest sector (p. 389; cf. Sodero, 2011). However, the majority of these reasons seem to suggest that action on global warming had potential to deliver "good politics".
} 
political choice ("good politics"). As I will elaborate later on in Chapter Five, this assessment is consistent with many of the arguments made by environmental actors that had defended the policy publicly, especially in the lead-up to the 2009 election.

Gunster (2010) argues that Liberal government communication of the carbon tax itself helped inspire public backlash by framing the policy in a manner that addressed audiences primarily as self-interested consumers, as opposed to engaged civic actors with a common interest at stake. ${ }^{26}$ From this view, the Liberal climate agenda was a technocratic endeavour, designed and implemented with minimal participation from the public, and imposed on the electorate through a "decide, announce, defend" style of oneway communication (p. 206). ${ }^{27}$ Individuals were encouraged to consider the tax in terms of its revenue-neutrality by government spokespeople who emphasized the money citizens could make through greener consumer choices and corresponding tax cuts. ${ }^{28}$ Instead of inspiring collective calls for action in the face of a looming climate crisis, Gunster argues this communicative strategy fueled a reactive "hardship frame" (pp. 198201; cf. Peet \& Harrison, 2012), which gathered strength in mainstream media coverage, where individuals emphasized their lack of choice in changing their current carbonintensive lifestyles. Although the Liberal frame of tax cuts and consumer choice may have fit well with conservative ideological tendencies, it ultimately constrained the political and deliberative possibilities available to advocates hoping to convince the public of the value of the carbon tax.

\footnotetext{
${ }^{26}$ Sodero's (2011, p. 1478-1479) informants also point to poor communication strategy as contributing to public backlash, but offers little further elaboration.

${ }^{27}$ See also Hajer's (2003) analysis of "nature development" in the Netherlands as a "conceive-decide-implement" approach to policymaking (p. 92).

${ }_{21}$ Gunster (2010) also suggests that dedicating carbon tax revenues to climate programs, instead of tax cuts, would have opened new communicative contexts from which audiences could reevaluate the policy as a collective ameliorative measure in the fight against climate change.
} 
Both Gunster and Harrison differ here in terms of the conceptual role assigned to both the public and communication processes. Whereas Gunster calls for more extensive citizen participation in climate change politics, Harrison's main conclusions are that carbon taxes "seem most viable where a party leader is personally strongly committed, his or her party already holds a majority in a parliamentary system, the measure can be passed between elections, and the party can deflect attention from the issue in the next election" (2012, p. 404). Barring this, policy makers are advised to pursue "carbon pricing by stealth" $(2012$, p. 404).

These assessments sit awkwardly beside Gunster's claim that " it was the failure (or refusal) to invoke the language of personal sacrifice in the framing of the carbon tax that was largely responsible for its hostile reception" (2010, p. 189). Gunster's commitment is to change the conditions for "good" politics, which is a position that involves a more expansive challenge for climate advocates wishing to fight for "good" policies like the B.C. carbon tax. ${ }^{29}$ In contrast, Peet and Harrison (2012) suggest governments should emphasize the tax-cutting dividends returned to citizens in a more visible fashion, and consider changing the name of the policy by removing the word "tax". They recommend pre-testing communication strategies on populations deemed unlikely to support the tax initially, to generate familiarity and understanding of its beneficial policy attributes (Peet \& Harrison, 2012, p. 118).

One important area left underdeveloped in these accounts is the role played by environmental groups. General claims about the beliefs or statements of "environmentalists" are often noted, but no systematic appraisal has yet been carried out

\footnotetext{
${ }^{29}$ This tends to cohere with Meyer's (2010) account of the environmental politics of "sacrifice". Of course, these accounts make the normative commitment that carbon taxes are good policies for addressing climate change (see Chapter Four).
} 
on environmental organizations and actors involved in public discourse surrounding the B.C. carbon tax. Sodero (2011) dedicates limited analytical attention to the role of environmental groups in the policy process, while Gunster (2010) tends to portray them as a unified constituency, whose passionate and thoughtful defense of the carbon tax was based on ecological grounds and the findings of climate science (pp. 205-206; cf. p. 188). ${ }^{30}$ Harrison (2012, p. 399) states "the environmental community was virtually unanimous in embracing the carbon tax", while suggesting the decision to support the Liberal climate agenda was contentious given the stronger positions held by the NDP on ROR hydro power and other environmental issues (cf. Peet \& Harrison, 2012, p. 100). Environmental actors differed primarily in their assessments of whether or how to support the NDP given their campaign to "axe the tax".

Shaw (2011) offers the most detailed contribution in this respect, focusing specifically on the rift that developed within the environmental community over ROR hydro. She suggests that disputes among environmentalists derived less from conflicted political loyalties than from a flawed conception of climate change as an "emissions" problem. For Shaw, climate change is best understood as an "energy" problem, meaning it is enmeshed in the ways in which societies choose to develop, distribute and alter the energetic flows of ecosystems.

In this respect, decisions about energy are fundamentally political decisions that impact our ability to address climate change in a manner that can be more or less socially equitable and ecologically impactful. Shaw argues that environmentalists defending the carbon tax and the Liberal climate agenda operated under an "emissions reduction"

\footnotetext{
${ }^{30}$ Gunster does touch on the role of environmental economist, Mark Jaccard, as a key proponent of the government's focus on revenue-neutrality. As will be explained in Chapter Four, my account includes Jaccard as an important part of the environmental community and the discourse coalition supporting "weak" ecological modernization.
} 
frame, which separated the entanglement of renewable energy development from its greater social and ecological consequences. This abstraction may have helped make climate action more amenable to dominant economic and political discourse, she argues, but it ran the risk of exacerbating social and ecological problems in the process, and ended up splitting the environmental community. ${ }^{31}$

Comparing these various accounts of the carbon tax creates a useful backdrop from which to situate my own analysis. I hope to expand the scope of research related to the environmental movement in B.C. by bringing together a different set of theoretical and methodological understandings of climate change communication. In addition, I will draw upon a different array of data for consideration focused more explicitly on the carbon tax. I will first examine the sociological theories of Ulrich Beck, before moving on to scholarship on ecological modernization discourse, environmental movements and the "green public sphere" (Chapter Three). The findings elaborated in this present section offer valuable perspectives on the carbon tax debate and some of the key events that helped shape environmental politics in the province. However, I will demonstrate that an argumentative discourse analytic approach (Chapter Four) offers important insight into the ramifications of policy debate on both the environmental community and broader public deliberation on climate change in the province. I now turn to the theoretical foundations informing my study.

\footnotetext{
${ }^{31}$ The distinction between the two understandings of climate change can be seen in the writing of prominent advocates of carbon pricing who write, "[e]nvironmentalists are all too often focused on energy rather than emissions... whereas the better way to solve the GHG problem is to focus on emissions" (Simpson, Jaccard, Rivers, 2008, p. 149; cf. M'Gonigle, 2009a \& b; M'Gonigle \& Anderson, 2009).
} 


\section{Chapter Three}

\section{Theoretical Framework}

This chapter will outline a number of theoretical concepts guiding my analysis, including those elaborated by German sociologist Ulrich Beck, as well as scholarship on ecological modernization discourse, environmental movements and the green public sphere. My presentation will proceed first with a broad depiction of Beck's macro-theoretical framework, and move towards meso-theoretical levels of analysis in preparation for the methodological discussion of Chapter Four. I will highlight a number of important synergies held between these various theoretical works in order to situate my analysis of the B.C. carbon tax.

\section{1 - Ulrich Beck: Risk Society, Reflexive Modernization and the Subpolitics of}

\section{Climate Action}

Ulrich Beck's theories have been widely applied to issues of environmental governance and communication. In his depiction of contemporary modern society, Beck details what he describes as the radical transformation of industrial society as it is reflexively remade in the image of "risk society" (Beck, 1993; 1995a \& b; 1999; Beck, Bonss \& Lau, 2003). First modern industrial societies, Beck argues, were typically driven by naturalized notions of rational progress through the institutions of science and industry; endless economic growth propelled by the exploitation of nature as an infinite resource and advanced technological development; and hierarchical orders of expert and lay 
knowledges. Risk society, in contrast, emerges through a confrontation with the unintended consequences of operationalizing the guiding mantras of first industrial modernity. As Beck (1995b) states, "the 'invisible hand' turns into the 'invisible saboteur"' (p. 8). Through the process of reflexive modernization, industrial society is forced to deal with the potentially catastrophic side effects of its own foundational premises, which threaten to undermine the basis for its own authority and continued operation.

This confrontation is said to come about through an autonomous onslaught of risks manufactured by the expert systems of industrial modernity. These risks are continually encountered and dealt with in any number of ways but are never fully overcome by the institutions of first modernity (Beck, 1999, p. 28; Beck, Bonss, \& Lau, 2003). This is not to say that risks are necessarily reflected upon in broader society and Beck distinguishes the processes of reflexivity (a self-confrontation with the side-effects of modernity) from reflection (modernity becoming the object of public, political or academic debate). Risks, in Beck's schema, have both a materiality and an immateriality that is mediated and contested in social discourse (1999, p. 4; 2010, p. 260-262). In this respect, risks become visible, or culturally intelligible, as different actors attempt to define their meaning in relation to broader systems of social and institutional power.

It is through the combination of both reflexivity and reflection that industrial modernity begins its reorientation towards a greater process of self-transformation (Beck, 1999, p. 34). Through the blind innovations of first modernity, society encounters the reflex-like byproducts of its own success that now threaten its very existence. At the same time a growing public awareness or reflection on this situation takes hold and 
society is said to become self-critical by questioning the decision-making authority that underpins its own precarious situation. The development and proliferation of reflective critique represents an existential threat to the institutions of first modernity, which work to "veil the hazards" of reflexive modernization (Beck, 1995, p. 101; cf. Cottle, 1998).

Climate change, from this perspective, can be seen as an emblematic risk of second modernity and risk society. Fossil fuels have energized the icons of global industrial capitalism and its models of endless economic growth and prosperity. But a creeping public awareness about the potentially catastrophic risks of business-as-usual greenhouse gas emissions has now become a prominent source of contention, offering the potential to unsettle existing relations of societal power. Modern institutions act to control and minimize these damages primarily through what Beck terms the "relations of definition"- the ways in which uncertain risks are represented within public discourse in relation to systems of power and authority. Communication about climate change is entwined within these relations as part of the legal, epistemological and cultural power matrix that organizes risk politics (Beck, 2010, p. 259).

Beck conceives the process of reflexive modernization as shifting the focus of public concern from how to properly distribute social "goods" among its constituentsmaterial wealth, full employment, social welfare, legal rights, etc.- to how to distribute social "bads"- such as nuclear radiation, holes in the ozone layer, and climate change. These "bads" are spread out across time and space, transcending the traditional jurisdiction of the nation-state, often as scientifically mediated constructions characterized by high degrees of uncertainty (cf. Hulme, 2009). Old class divisions and alliances of capital become unstable as these "bads" threaten different social, cultural and 
economic interests in an uneven and unpredictable manner. Conflicts of accountability break out between groups over how the consequences of climate risks are to be distributed, legitimized or averted altogether, hence shifting long-standing political dynamics as new coalitional alliances are formed.

The increasing complexity of risk and reflexivity brings to the forefront the role of specialized experts and counter-experts who engage in debate to define the dominant meaning of each new hazard (Cottle, 1998, pp. 13-15). This new contestation of specialized knowledges begins the demonopolitization of expertise and engages what Beck calls the "subpolitical" realm (cf. Bulkeley, 2001a, pp. 432-436). In risk society, subpolitics refers to political activity that has unhinged itself from the bounds of traditional modern institutions. For Beck (1999), "subpolitics means the shaping of society from below" (p. 39), and represents a critical opening for change in modern societies.

To retain their grip on power, state political institutions are thrown into coalitions with actors and groups outside the conventional domain of representative politics, in order to maintain some semblance of legitimate control over decision-making power. As Beck (1999) states:

What is characteristic of the subpolitics of world society are precisely ad hoc 'coalitions of opposites' (of parties, nations, regions, religions, governments, rebels, classes). Crucially, however, subpolitics sets politics free by changing the rules and boundaries of the political so that it becomes more open and susceptible to new linkages - as well as capable of being negotiated and reshaped. (pp. 39-40) 
These linkages offer opportunities for social movements and counter-experts in particular to challenge the inadequacy of the prevailing institutional mandates through the relations of definition. By inducing public reflection on the future direction and radical incompleteness of modernity, these actors can force questions of "how we want to live" center-stage through various communicative practices in different media-spheres. Both environmental degradation and protest are symbolically mediated in this sense and so media become a key site in the transformational process of reflexive modernity.

However, there remains a tension in Beck's conception on the role of media and social movement communication in "unveiling the hazards" of modern industrial development. In part, this can be related to what Cottle (1998, pp. 10-12; cf. Mythen 2007, p. 800) describes as his "ontological/epistemological slippage": risks are both real and socially constructed and society is both reflexive and reflective on its path towards risk society. Beck frequently notes that industrial society is its own worst enemy, caught in a perpetual process where new, dangerous risks are manufactured, which constantly threaten to undermine the credibility and authority of the institutions that legitimize them. This can at times leave the precise role and importance of counter-movements in the process of delegitimation and risk dramatization through media representation unclear. For example, Beck states:

The environmentalist critique is biting, corrosive, because it wants to preserve the things that conservatives in every camp put at stake, in open self-contradiction, with reckless industrialization policies...Thus whoever argues and demonstrates against legalized 'normal' poisoning need not fight, as if in a second French Revolution, for the victory of principles that are supposed to change the world. $\mathrm{He}$ 
or she need 'only' make the accusation that is on everybody's lips - that the claim purely and simply coincides with the reality of its contrary. It is precisely this 'socially scandalous' aspect of hazards which entices the mass media with the promise of high circulation levels and viewing figures, and leads journalists to ask trenchant questions and to produce 'headline news'. (1995, pp. 99-100)

Such a claim can seem to downplay the complex role mass media corporations often play in legitimating dominant institutional relations of power and defusing the "social explosivity" of risk represented by social movement communication (cf. Gitlin, 1980; Anderson, 2000 \& 2003; Cottle, 1998). Mainstream media coverage of climate change has often struggled to establish the issue as a serious public priority, let alone as a site of reflection on the future of modernity, and the simple allure of "socially scandalous" headlines have by no means led to trenchant public critique in any straightforward sense. How climate risks are made "visible" through the contestation of knowledge claims will be examined further in the following sections, focusing particular attention on theories related to ecological modernization discourse, environmental movements and the green public sphere.

Still, Beck's sweeping theoretical tracts, limited empirical analysis, and liberal use of poetic narrative have contributed to a number of confusions and scholarly criticisms (see Mythen, 2007; Cottle, 1998; Hier, 2008). Mythen (2007, pp. 799-801), for example, notes a number of potential shortcomings to Beck's work. He states that Beck's perspective "assumes an improbable uniformity of cultural experience" (p. 801) with respect to the interpretation of risks. Similarly, he notes that risks are not all perceived as negative prospects to be avoided, and in many cases may be culturally attractive. 
Likewise, he critiques Beck for focusing too much attention on the worst-case scenarios of risk accidents.

While there may be some merit to these critiques, Beck makes clear on a number of occasions that "[hazards] are subject to historico-cultural perceptions and assessments which vary from country to country, from group to group, from one period to another" (1995b, p. 91). His catastrophic view of risk has more to do with the notion that in an increasingly globalized and technologically-mediated world that continually churns out life-threatening hazards, eventually the least likely event occurs in the long run (1995b, p. 1). Beck's provocation is more systematic, and in many senses precautionary, as he asks, "what do probabilistic safeguards - and thus the entire natural- scientific analysis - have to contribute to the assessment of a worst-case scenario whose occurrence leaves the theories intact, but annihilates life?" (1995b, p. 69). ${ }^{32}$ In this sense, Beck's approach is less about foretelling the future than about establishing the structural context on which processes of social change and conflict take place in light of the systematic generation of risks.

I argue that Beck's theoretical work, though at times underdeveloped, can still offer compelling conceptual territory from which to base the study of climate change policy and communication in British Columbia. More specific theoretical formulations and empirical findings related to ecological modernization discourse can address how some of these processes might work in practice, and how they might be studied further in

\footnotetext{
${ }^{32}$ A related precautionary sentiment regards his conception of public reflection and a renewed, empowering form of democratic politics in risk society. Beck (1995a) writes, "The secret elective affinity between the ecologization and the democratization of society in not being recognized. The long-term policy toward threats should be: slowing down, revisability, accountability, and, therefore, the ability for consent as well; that is to say, the expansion of democracy into previously walled-off areas of science, technology and industry. The opportunities of risk society are not being recognized or utilized. What is important is to exploit and develop the superiority of doubt against industrial dogmatism. The goal is not a turning back but rather a new modernity, which would demand and achieve self-determination, and prevent its truncation in industrial society" (p. 17).
} 
the case of the B.C. carbon tax. I turn now to some of the theoretical debates on ecological modernization and further elaborate on some of the connections with Beck's writing.

\section{2 - Ecological Modernization: Competing Visions for the Future}

Research on ecological modernization is a diverse body of work that has struggled to clarify its own research agenda and theoretical approach to environmental policy. Part of this confusion has stemmed from the various ways in which the concept has been interpreted and used to describe the empirical phenomenon it purports to analyze. Yet despite this polysemy, there remain a number of basic commonalities in the scholarly literature from which to build a workable theoretical approach to the study of climate policy communication. For the purposes given here, I will differentiate between what Christoff (1996) refers to as "weak" and "strong" ecological modernization: a distinction I will explain in more detail shortly.

In its most general articulation, ecological modernization describes an approach to environmental protection that restructures the political economy of modern industrial societies to account for issues of ecological degradation. Ecological concerns are integrated into the operations of modern institutions through a plethora of different policy arrangements that recognize "the environment" and "the economy" as mutually reinforcing categories. Pricing carbon pollution, for example, aims to "internalize the costs" of climate change on the economy and reduce greenhouse gas emissions. It can 
therefore be seen more generally as an exemplary instance of ecological modernization policy discourse.

Though the structural character of environmental deterioration is a central concern for the practice of ecological modernization, the overall approach to policy change is often said to be largely reformist in its attempts to redirect modern institutions and political economy towards greater ecological rationality. This is typically expressed through the language of efficiency and anticipatory policy logic with the maxim that "pollution prevention pays". Environmental protection is said to be a positive-sum endeavour, offering market opportunities that "decouple" economic growth from wasteful activities, thus purporting to overcome the radical environmentalist critique that there are "limits to growth". Addressing the ecological negligence of industrial society in this manner allows for new relationships between governments, markets, scientific organizations and civil society, which lead to a more holistic approach to economicenvironmental processes.

Though the term "ecological modernization" is commonly held to have entered the political realm and social science literature in the early-1980s with the parallel activities of Martin Jänicke and Joseph Huber in Germany, much of its historical roots originate a decade earlier. ${ }^{33}$ Maarten Hajer (1995, pp. 73-104) has traced the development of ecological modernization as a dominant policy discourse in environmental politics to the counter-cultural movements, expert think tanks and intergovernmental organizations of the 1970s and early-1980s. Hajer demonstrates an unlikely confluence of radical treatises and technocratic policy papers that would eventually form the basis for a number

\footnotetext{
${ }^{33} \mathrm{Mol}$ and Janicke (2009) note that though ecological modernization found a place in the government policy of Northern European countries at this time, similar developments had been established in Japan in the 1970s.
} 
of discursive innovations leading to the UN Brundtland Report in $1987 .{ }^{34}$ Publications like the Club of Rome's Limits to Growth, on the one hand, and E.F. Schumacker's Small is Beautiful and Edward Goldsmith's Blueprint for Survival, on the other, showed a set of distinct social agendas that nonetheless shared significant overlap in their definition of the modern environmental dilemma. The discourse of environmental limits, neoMalthusian survivalism, and lifestyle politics helped constitute much of the environmental movement at the time, but would soon give way to a less publicized shift in policy discourse towards a reformist middle-ground at expert institutions like the Organization for Economic Co-operation and Development and the United Nations Environment Programme.

For Hajer, the formative conditions that led to the emergence of ecological modernization discourse were marked by considerable ambiguity, which allowed two different sets of actors with different subject-positionings to borrow ideas and phrases while creating new politically feasible "discourse-coalitions" (a concept explained further in Chapter Four). Despite their differences, both the radical-egalitarian and hierarchical, expert-driven discourses would find converging views in key areas like technological application and comprehensive planning, among others. However, this alliance would at times prove tenuous, characterized by tension between its various factions, both in the practice of environmental politics and in theoretical debates in social science.

An important concern for many scholars has been the potential for ecological modernization to be co-opted by the hegemonic interests of industrial power, leaving it window-dressing for business-as-usual development to continue in the name of

\footnotetext{
${ }^{34}$ Note that not all accounts take the Brundtland Report and the concept of sustainable development as synonymous with ecological modernization. Both Dryzek (1997, pp. 123-152) and Mol, Spaargaren \& Sonnenfeld (2009) distinguish ecological modernization as a more specific concept that is less amenable to the multitude of definitions that have characterized the career of sustainable development.
} 
"progress". This point connects debates about the proper relationship between technological innovation and elite-driven policy change, and democratic and deliberative decision-making in the process of social change. Attempts to clarify the supposed balance between reformative and revolutionary changes needed as a corrective to modern industrialism have cast doubt on how flexible the institutions of modernity really are. Indeed, Mol and Jänicke (2009; cf. Buttel, 2009) note the evolving nature of academic research on ecological modernization theory, having moved from an early phase focused on the capacity of technological fixes and innovation in capitalist liberal democracy, to a later period which recognized the limitations of socio-political processes working from within these bounds.

Among other scholars, they note the diversity of approaches to ecological modernization theory. Buttel (2009), for example, has divided academic work in this field into four separate areas of study. The most relevant body of research for the purposes of this study is the social constructivist approach to policy discourse led by Maarten Hajer (1995; 1996; 2003) and John Dryzek (1997, Dryzek et al., 2003). This approach focuses most succinctly on the processes of communication and the context of social power in which ecological modernization discourse gains its practical historical and cultural relevance. Both Mol (1996, pp. 315-319) and Buttel (2009) have noted that this theoretical program fits awkwardly alongside other ecological modernization research, at times viewed as hostile to, or even separate from the field altogether, especially with respect to the concept of reflexivity.

Hajer (1996; cf. 1995) notes three separate divisions in ecological modernization discourse. The first and most dominant is "techno-corporatist" and is characterized by an 
optimistic account of industrial society's ability to incorporate ecological concern through the processes of "institutional learning". From this view, ecological modernization is a moderate social project conceptualized in technical terms and implemented by elite policy-makers, scientists and engineers beyond the reach of wider public input and participation. In this sense, it echoes Beck's notion of "veiling the hazards", where a more broad-based, reflexive engagement with risk definition remains muted or put on hold. Environmental groups themselves have largely discarded radical social critique in favour of hierarchical management and a professionalized organizational structure, and are progressively integrated into state decision-making bodies.

The second interpretation of ecological modernization critiques the first as a "technocratic project". It finds close affinity with radical environmental discourse and is suspicious of the capacity for industrial consumer capitalism to exhibit "institutional learning". Its approach to ecological politics centers on the importance of democratic social choice in civil society, and takes issue with the dominance of policy experts in discussions about ecological modernization.

The third approach, and Hajer's suggested corrective for both of the previous interpretations, is ecological modernization as a reflexive "cultural politics". Here the goal is to encourage deliberative comparison of different environmental discourses in the process of clarifying policy options and the assumptions of cultural value often hidden in talk about "the environment". This third option is anti-objectivist in its orientation in that all claims to knowledge, whether they are scientific, economic, or otherwise, are given space to be considered and challenged in order to be better understood as a particular 
vision for the future of society in relation to certain conceptions of nature and technology. It is concerned foremost with focusing the rhetorical activities of environmental discourse and enabling open public debate about the direction of modern development in hopes of making it more reflective and inclusive.

Hajer's schema closely resembles Christoff's (1996) classification of "weak" and "strong" ecological modernization, though Christoff frames his dichotomy in more explicit normative terms. Weak versions of ecological modernization correspond with Hajer's "institutional learning" approach, where societal transformation is narrowly conceived as technocratic, economistic, instrumental, and nationally-focused (Christoff, p. 490). By contrast, stronger versions encourage the development of multiple alternative ecological modernities that help discipline and restrain the unitary and instrumental character of globalized industrial capitalism according to a more encompassing ecological rationality. ${ }^{35}$ Strong eco-modernism is rooted in local cultural and ecological knowledge, but connected through common recognition of key institutions, technologies and deliberative communicative practices that work to protect the integrity of ecosystems. $^{36}$

Christoff argues that the processes of modernization typically reorganize what were previously intimately known social relations and institutions-including understandings of "place" (immediate experience of location) and local time (according to the seasonal rhythms, for example) -into more abstract or "disembedded"

\footnotetext{
${ }^{33}$ The dichotomy here is not as absolute as might be inferred. Christoff (1996) explains, "It is essential to note that weak and strong features of [ecological modemization] are not always mutually exclusive binary opposites. Some features of weak or narrow [ecological modernization] are necessary but not sufficient preconditions for an enduring ecologically sustainable outcome" (p. 491). ${ }^{36}$ Strong eco-modernism remains "modern" in the sense that it depends upon these institutions, technologies and practices, while still critiquing them for their environmental omissions. The discipline of ecology itself, Christoff (p. 495) points out, is a part of an abstract body of scientific knowledge and practices that depend on the transmission of scientific information among an international community of actors. This interpretation can be complicated still further by Torgerson view (1997, p.25-26).
} 
associations, which are distant or separate from immediate experiences (p. 491) ${ }^{37}$ Weak versions to ecological modernization are unable to resist these forces in a way that is sufficiently "ecological", given their penchant for framing the environmental challenge in economistic terms. ${ }^{38}$ Such a conceptual approach rests too comfortably with hegemonic industrialism and risks legitimizing continued exploitation of the environment, without sufficiently subjecting these aims to public deliberation. In this respect, and following Beck's dichotomy, weak ecological modernization "[accepts] that modernization has become more reflexive, but only in the narrow and instrumental sense of improving environmental efficiency, rather than in the broad and reflective manner of ecological critique which fundamentally questions the trajectories of industrial modernity" (Christoff, 1996, p. 496).

Christoff clearly favours strong ecological modernization as the strategy most likely to promote lasting cultural transformations to reduce material consumption and bring about rapid structural transformation, both nationally and internationally. It is communicative and open, democratic and deliberative, and in this sense most closely related with Hajer's notion of "cultural politics", as well as much of Beck's work. However, Christoff's (1996) account can portray the conflict of environmental politics in rather broad terms as being "between the environment movement on the one hand and governments and industry on the other" (p. 490).

I will further explain Hajer's notion of discourse coalitions, in addition to his discourse analytic approach as a means to complicate this dichotomy and fit it more

\footnotetext{
${ }^{37}$ Harvey's (1999) examination of the environmental justice movement can be read in light of this process. A key challenge involves moving beyond particularist, place-based politics to "adopt a politics of abstraction capable of reaching out across space" (p. 184) and radicalizing the discourse of ecological modernization.

38 To further emphasize this point, Christoff (1996) states, "An ecological critique that recognizes and respects the importance of the cycles upon which the biological world depends, and which seeks to re-embed our relationship to nature in a local place and to redefine the relationship in ecological terms, often stands in opposition to the transcendent, abstracting features of modernity (and its industrial manifestations) while still to some extent depending upon its conceptual framework" (p. 494).
} 
succinctly within Beck's notion of subpolitics in Chapter Four. For now, I will examine some of the challenges climate advocates face in their work to create policy change given some of the tensions elaborated through ecological modernization research. If, following Beck, environmental movements play crucial roles in advancing a more critical reflection on the direction of modern development in light of global warming, it is worthwhile exploring how this change might come about in more detail. In this respect, my study follows the deliberative political theory of Torgerson $(1999 ; 1997)$ and Dryzek et al. (2003) on the importance of environmental movements based in civil society and a critical public sphere separate from the operations of the state.

\section{3 - Environmental Movements, The Green Public Sphere, and Media}

A significant issue affecting theories of green politics, especially with respect to weak and strong varieties of ecological modernization, relates to how political change happens. How can a sufficiently ecological set of policy programs be implemented in government operations? Is this the primary goal of ecological politics? ${ }^{39}$ What might be the role of democratic participation in bringing about broader social change on an issue like climate change? In many respects, weaker approaches to ecological modernization tend to operate through assumptions of an oligarchic political order that depends upon semiauthoritarian action in the administrative sphere (Torgerson, 1999, pp. 11-12; p. 141). From this perspective, it might be argued that top-down climate policy like the Liberal carbon tax could well prove effective in rescuing modern society from the threat of

\footnotetext{
${ }^{39}$ Torgerson's (1999) approach to the environmental politics complicates questions as to whether there is one clear goal to environmental politics. By this he invokes Hannah Arendt's celebration of the intrinsic value of political action itself, as a form of artistic expression, and pushes back on the common conception of environmental politics as largely instrumental.
} 
climate crisis without deeper engagement on the part of the broader public. Such a prospect may seem plausible, but it is not one that has gone unchallenged. As Torgerson (1999) suggests, "[proposals] for an authoritarian response to environmental problems make sense only if one assumes a successful challenge to established authoritarian power. Where could such a challenge possibly come from, apart from democratic social movements?" (p. 12).

Torgerson sees the "green public sphere" as the key location where deliberative political action in the environmental movement is practiced and potentially connected to the domain of policy discourse in the administrative sphere. Key to this perspective is the notion that, despite the self-image of policy professionalism as a relatively unitary and authoritative voice of apolitical reason (monological), administrative actors are connected in "a network of relationships-both conflictive and cooperative-in which informal connections are at least as important as formal ones and where dialogical tendencies belie the monological image" (Torgerson, 2010, p. 2). This may seem like an obvious point, but it is important to Torgerson's theoretical approach, and is complimentary with both Hajer and Dryzek's work as well, as I will show in a moment.

Much of Torgerson's conceptual point is aimed at addressing Habermas' claim that "discourses do not govern", which is a theoretical product of his bifurcation of both "system" and "lifeworld" (see Torgerson, 2010). In Habermas' view, the governing structures of democratic state institutions are best conceived as a "system", which largely operates on a principle of closure in order to implement the policies dictated by debate originating in civil society and the lifeworld. This is what it means to "govern": at some point discussion and difference are put to an end and policy is enacted in law. For 
Torgerson, this explanation is insufficient, as it does not adequately explain the way policy communities actually operate, which is to say, through discourse. Both policy discourse in the administrative sphere and public discourse constituted in the public sphere "govern" on this account, and of most particular interest here is the interconnection between the two in their border regions (cf. Torgerson, 1997).

Following a similar line of reasoning, Dryzek et al. (2003) construct an account of environmental movements as they aim to create a "green state"; one in which deliberative action in civil society changes public policy and wider political culture, leading to the incorporation of ecological imperatives into the core of government institutions. The critical concern for environmental actors, in this regard, is attaching the movement's defining interest to the center of the state's economic agenda, primarily by challenging its legitimation imperative. ${ }^{40}$ Incorporating climate change concern through policies like the B.C. carbon tax into the periphery of state operations, by contrast, is a dangerous prospect for movements, as they risk co-optation without affecting substantial policy change. This might mean the government applies the policy to a limited sector or portion of emissions instead of across the entire economy, at sufficient price, and in conjunction with a wideranging suite of other policies that drive transformational change towards a zero-carbon society. The means by which movement actors can work to avoid such a scenario will depend on each specific political context, but of paramount importance is the maintenance of a vibrant, independent green public sphere, which can stand as a counterbalance to unfettered state (or corporate) power.

\footnotetext{
${ }^{40}$ According to Dryzek et al. (2003) there are a number "imperatives" that make up the central tasks of the modern state in governance: domestic order, survival, revenue, and legitimation (pp. 1-2 \& 12-14).
} 
Dryzek et al. (2003) caution that the allure of being included in state decisionmaking means participating in a constrained discursive arena and risks depleting civil society and movement vitality. This can narrow the number of positions available for expression in the polity as a whole and reduces civic resources for policy innovation. ${ }^{41}$ Furthermore, it can undermine the ability of the social movement to present an oppositional stance to dominant institutional actors and inspire a state of broader selfcritical reflection throughout different segments of society. A crucial task for social movements, according to deliberative theorists like Dryzek and Torgerson, is to change the political agenda and problem definitions with which environmental issues are conceived. Such an endeavour parallels Beck's theory on subpolitics and reflexivity, where manufactured risks ignite confrontation between official institutional authorities, social movements and counter-experts within the relations of definition (cf. Dryzek et al., pp. 169-171).

However, social movements face a number of vexing challenges in their quest to change the political conversation. Movements often find themselves locked in an asymmetric relationship with mass media corporations, where their dependence on favourable news coverage initiates a decidedly ambivalent "movement-media dance" that can lead to a "politics of spurious amplification" (Gitlin, 1980, p. 285). In this sense, advocates are often forced to confront a media logic that generally operates according to rhythms and communication requirements can be at odds with the more sensitive requirements of deliberative democratic politics. ${ }^{42}$ Mass media coverage offers the potential to broaden the scope of movement politics and influence, but can also constrain

\footnotetext{
${ }^{41}$ Toke (2011) has shown social movement actors to be important innovators, not only in the policy realm, but also in the development of alternative technologies like wind power (cf. Lovell, 2004).

"2 See DeLuca \& Peeples (2002) and their conception of the "public screen" as an amendment to the public sphere, and its potential consequences for participatory democracy and oppositional movements.
} 
the language used to contest the dominant meanings as framed by their rivals. Advocates must negotiate their interests with media workers through a number of different tactics that usually involve a set of ambiguous and uncertain trade-offs in order to increase their standing as legitimate political actors (Anderson, 2000, 2003, cf. 2009; Gamson \& Wolfsfeld, 1993; Gitlin, 1980).

Gamson and Wolfsfeld (1993,pp. 121-123) have suggested a complementary division of labour can be sought between movement actors who raise media attention through the creation of spectacle, and those who retain a guarded respectability as carriers of the movement's issue frame. However, this division can lead to potentially ruinous consequences when internal differences within the movement feed media appetite for drama and the "fall of the righteous" storyline (p. 120). As Gamson and Wolfsfeld (1993) state:

Movements frequently offer multiple frames, each identified with particular groups. Those whose action creates a broader movement standing may find that their preferred frame is poorly represented by those who become the mediadesignated spokespersons. They may attack and attempt to undercut their rivals. This internal movement contest can easily become the media's story, thereby distracting attention or blurring the preferred issue frame. A division of labor is likely to work only if there is a common frame and a willingness to subordinate concerns about who gets credit for being the messenger. (p. 123)

I will show in Chapter Five that a similar dynamic was at play in the case of the B.C. carbon tax, though I will use Hajer's conception of discourse coalitions to complicate the idea of a common understanding of the policy itself and its significance. Furthermore, the 
"split" in the environmental community in B.C., mentioned in Chapter Two, dealt with issues of much greater depth than merely who got credit as the messenger. Regardless, theorists like Torgerson and Dryzek speak to the value of diversity and deliberation in the green public sphere, but often leave analysis of these types of media dynamics unaddressed. This is an important area of concern because bringing about a broader state of critical reflection on the illegitimacy of institutional safety pledges in the face of global risk in many respects depends on mass media representation.

Dryzek et al. (2003) are concerned with increasing the likelihood of strong ecological modernization, which requires both an open and inclusive green public sphere. They suggest that social movements can choose the strategic position they take in relation to state authority based on whether the state is either inclusive or exclusive, and active or passive (pp. 6-9). Where the media system fits into this model is not always clear. Corporate mass media organizations can be highly complex and variable depending on a host of considerations and therefore representation of climate risks can also vary (see Carvalho, 2005; Anderson, 2009, pp. 173-174; Gamson \& Wolfsfeld, 1993).

Dryzek et al. (2003) argue that social movements in civil society need to cultivate an oppositional stance towards inadequate government policy action through communication in the green public sphere. Here, movement diversity offers grist for debate and reflection, which can then gather a multifaceted challenge to industrial hegemony. By expanding the scope of discursive positions available for expression, and honing arguments through active, inter-discursive comparison, environmental movements can shift the terms of debate and problem definitions on issues like climate change. Yet it remains an open question as to how these shifts are to occur given the challenges 
presented by media representation. How are these oppositional stances portrayed in the mass media? How are they interpreted and made meaningful to different sections of society? How do they eventually become seen as a legitimate threat to state irresponsibility? How is the internal differentiation of environmental discourses dealt with in the glare of a public spotlight that may at times prove hostile to its various demands?

There are obvious limitations as to what the present study is able to accomplish. However, some of these questions might be addressed by emphasizing that challenges to state legitimacy posed by a vibrant green public sphere are multifaceted, and not entirely dependent on corporate media. In this respect, green discourse might, in part, be nurtured in various "enclaves" of deliberative communication (see Dryzek \& Stevenson, 2011, p. 1870) prior to exploiting the various openings presented by larger mainstream outlets. If opportunities to encourage further deliberative engagement with climate policy as a cultural product already exist within broader media systems, then a reflexive discussion about the role environmental advocates play within these institutional dynamics could benefit the project of environmental politics in the long run.

Still, the difficulties presented to a movement based on a diverse and inclusive interplay of perspectives and practices, which simultaneously aims to transform societal institutions are significant (see Torgerson, 1997, pp. 35-39). In no small part, the outcomes of these struggles will depend on how various interests are negotiated in the process of communication. I argue that the methodological tools of argumentative discourse analysis can allow a greater understanding of how these social dynamics operate in practice and what their consequences may be for environmental politics. I turn 
now to this body of research to examine in greater detail some of these issues in the context of the B.C. carbon tax (Chapters Four and Five). 


\section{Chapter Four}

\section{Research Methodology and Methodological Issues}

My study draws from the work of scholars using an argumentative approach to discourse analysis to assess the variety of claims made by environmental actors and groups in relation to climate change and the B.C. carbon tax. Much of this research follows a postpositivist tradition that is inspired by the works of Michel Foucault and others. My methodology will be primarily informed by Maarten Hajer's analytical framework (1995 pp. 42-72; 2003, pp. 103-109; 1993, pp. 44-48; Hajer \& Versteeg, 2005). Hajer understands the policy process as part of broader argumentative struggles that help define the terms for environmental politics through the social construction of meaning. By drawing on various discourses, actors are able to construct accounts of policy problems that attempt to secure a preferred interpretation of environmental issues and position themselves in relation to a greater social order.

My presentation here will take on a deliberative style itself, as is often the case with this sort of argumentative analysis. The present chapter will proceed with an explanation of how discourse is conceived from this tradition, detailing Hajer's notion of discourse coalitions, as well as some select methodological issues for consideration. The chapter ends with a discussion on the procedural details and various texts chosen to represent carbon tax communication in British Columbia.

The discourse analysis used for this study focuses on how knowledge claims interact in a specific socio-historical setting, in order to make sense of how one understanding of the policy problem comes to dominate over another. Examining which 
claims about climate policy are validated as credible and how competing perspectives are either dismissed or ignored can offer further insight into the relational power dynamics affecting public debate. Such an analytic focus has clear consequences for policy research, as the concept of "discourse" takes on a more encompassing role in environmental politics. As Karen Litfin (1994) has observed, [as] determinants of what can and cannot be thought, discourses define the range of policy options, thereby functioning as precursors to policy outcomes. A discursive practice approach is sensitive to the interactive dynamics between knowledge and power, as well as the contextual factors that enable certain discourses to prevail in the policy process. (p. 13)

From this interpretation, discourse is seen as much more than a neutral linguistic medium in which actors express their own interests. Through the creative process of argumentation, the views and experiences of actors are shaped by the social opportunities and trade-offs that accompany any given stance taken on an issue. Communication about climate change then becomes a more complex endeavour that relies on a host of factors beyond merely what is said.

In line with this view, I use Hajer's conception of discourse, which he defines as "a specific ensemble of ideas, concepts and categorizations that are produced, reproduced and transformed in a particular set of practices and through which meaning is given to physical and social realities" (Hajer, 1995, p. 44). ${ }^{43}$ Analysis should clarify which discursive features are involved in a dispute over issues like the B.C. carbon tax, and attempt to explain how various actors mobilize bias to influence the course of debate in

\footnotetext{
${ }^{43}$ Other definitions of discourse conceptualize it as "a shared way of apprehending the world" (Dryzek, 1997, p. 8) to "sets of linguistic practices and rhetorical strategies embedded in a network of social relations" (Litfin, 1994, p. 3).
} 
their favour. Researchers must decipher how questions of value are routinely transformed into questions of fact and further reflect on the power effects this may have on the policy process (Litin, 1994, p. 4; cf. Hajer, 1995, pp. 54-55). To clarify how this is generally accomplished, I turn to Hajer's concept of discourse coalitions and his three-pronged approached to studying discourse, elaborated in the section below.

\section{1 - Discourse Coalitions and Methodological Framework}

Hajer argues that environmental politics are characterized by hegemonic struggles between and within communicative networks called "discourse coalitions", which are constituted by a variety of storylines, actors and discursive practices united in a common political project $(1995$, p. 65$)$. This combination of factors creates alliances that are attractive to groups of seemingly disparate actors that are nonetheless able to work together on issues like climate change. ${ }^{44}$ Members of these groups find commonality through shared discursive reference points woven together by storylines about a given issue. Previously separate discursive domains of knowledge are integrated within each coalition to form new understandings of policy and subject positions, which then shape the course of political debate through each narrative. Storylines, in this case, are conceptualized as the "discursive cement" that binds a previously fragmented social grouping together to form new sets of relational interests in the process of communication.

In this respect, coalition members need not share a similar set of beliefs, but rather a common set of storylines that suggest a common understanding. Most actors cannot

\footnotetext{
"In this respect, Hajer's account aligns with Beck's notion of subpolitics and the "ad hoc coalition of opposites" mentioned earlier.
} 
understand a problem like climate change in all its complexity and hence the political power of a text derives from its multi-interpretability and the metaphorical quality of its narrative (Hajer, 1995, pp. 61-63). By reducing the complexity of a given problem, storylines allow "discursive closure", which truncates a variety of discourses and helps rationalize a specific take on the issue at hand.

Given these considerations, Hajerian discourse analysis is part of a deliberative branch of policy analysis that focuses on three elements of policy conflicts (2003, pp. 103-109). The first involves a detailed examination of the language and terms used to secure systematic forms of bias employed in communication. These include the gamut of generative storylines, metaphors, myths, and vocabularies that work to support each version of social and physical reality. The second element requires understanding how different groups of actors come together by way of specific storylines that support the formation of discourse coalitions. And the final element contextualizes analysis within a set of historically embedded institutional practices, which help give meaning to each discursive conflict.

These practices differ depending on the institutional context that frames their expression. For example, radical environmentalism may come with its own suite of practices, from acts of civil disobedience to clothes-swaps and Critical Mass bicycle rides, just as market environmentalism may be reproduced through professional board meetings and the exchange of detailed knowledge about renewable energy start-up companies (see Dryzek, 1997). Similar acts of communication will have different social consequences depending on the practical institutional context from which they are made meaningful. 
A number of points about these component parts of discourse analysis bear further mention. The concept of storylines is often used in different analytical frameworks and is central in Hajer's approach (cf. Dryzek, 1997; Litfin, 1994). By connecting different domains of knowledge together, these narratives help overcome social fragmentation by suggesting coherence and unity in a complex array of discursive fields that themselves draw from more developed institutional traditions. They position actors in a social and moral order (as victims or heroes, for example), reorder understandings of the policy problem, and offer important forms of agency for different groups of actors.

However, identifying the discursive features that bind these coalitions together is a demanding endeavour, especially given the diversity of environmental storylines that are typically expressed in a given context. Hajer notes that emblematic environmental issues, like climate change, may draw on discourse about law, economics, the natural sciences, and political philosophy, among many others, often in a single instance of communication. Different scholars have outlined a number of separate, and at times overlapping, conceptual maps of the potential environmental discourses that have typically animated environmental politics (see Dryzek, 1997; Dryzek \& Stevenson 2011; Bäckstrand \& Lövbrand, 2007 \& 2006; Brulle, 2008 \& 2009; Teräväinen, 2010; Doulton \& Brown, 2009; Smart, 2013).

Interpretive choices of classification in the research process therefore depend on a degree of closure themselves. My point is to highlight this particular aspect of scholarly inquiry as potentially problematic, but one that is largely unavoidable and not confined to my study alone. Indeed, these complications could potentially apply to the practice of deliberative analysis of environmental politics more generally. However, as both Hajer 
(see 1995, pp. 66-67) and Dryzek (see 1997, pp. 197-201) have noted, different discourses often find affinity or complementarity with one another, suggesting that the degree of this overlap is not only functional for the practice of environmental politics, but also open to further scholarly debate. I can offer little immediate resolve to this issue, other than to suggest that a heavy focus on the exactness of each choice for classification risks missing the overarching analytical goal of providing a more holistic understanding of how environmental politics functions in a specific context.

A second area of clarification involves how actors are treated in the reconstruction of discourse coalitions. Hajer emphasizes that actors in coalitions share a common discourse, and not necessarily shared beliefs or interests, or even understandings. As Dryzek notes,

[the] impact of discourses cannot be reduced to just the impact of interests and organizations that subscribe to them; indeed, it is quite conceivable that impact may be felt in the absence of any such indentifiable organization(s). Discourses take effect in [a] largely impersonal fashion, if they can indeed manage to change the language that significant numbers of people use in talking about the environment. (Dryzek, 1997, p. 38)

This view has repercussions for the study of environmental discourse where coalitional members are joined in fluid relationships, not all of which may be as straightforward as the traditional conception of a "coalition" may suggest. Actors are able to express similar discursive positions in alliance with one another without being socially connected or personally acquainted. That said, there are limits to actors' ability to simply choose their positioning within these groupings. In Hajer's argumentative model "social action 
originates in human agency of clever, creative human beings but in a context of social structures of various sorts that both enable and constrain their agency" $(1995$, p. 58$) .^{45}$ In this sense, greater sensitivity towards the social and institutional contexts in which communication takes place is necessary, and Hajer draws attention to this area of analysis in part through his conception of discourse coalitions.

Hajer's analytic approach is well regarded and has been influential in the field of environmental policy analysis. His original study (Hajer, 1993 \& 1995) drew from his graduate research and consisted of extensive literature reviews, historical surveys, document analyses and interviews with key policy actors. A review of literature on discourse coalitions and Hajerian discourse analysis has shown a fair degree of fidelity to this methodological approach, often combining some mix of textual analysis and interviews, with some exceptions (cf. Smart, 2011 \& 2013; Thomas \& Littlewood, 2010; Teräväinen, 2010; and Fogel 2007).

Previous research following Hajer's methods have varied in terms of their breadth and depth of analysis, which in turn has depended on the timeframe, political context, and specific policy discourse examined. Discourse coalitions identified by researchers, including their key discursive features, cast of characters or constituent storylines, have differed with respect to amount of detail given and the degree of reasoning used to explain each interpretive choice.

On one end of the spectrum, for example, Winkel et al. (2011) examined climate discourse in sustainable forestry policy in Germany with great specificity, highlighting individual storyline elements and key chronological policy developments that have

\footnotetext{
${ }^{45}$ Both Litfin (1994, pp. 22-23) and Dryzek (1997, p. 20) stake out similar positions in their interpretations of Foucault's position on the power of discourses and the role of the subject.
} 
shaped two key discourse coalitions (cf. Smith \& Kern, 2009). Others have offered more procedural detail to their study, combining textual analysis with coding software to identify themes and quotations that are then reassembled into discourses that constitute each coalitional grouping (Teräväinen, 2010). Still others have traced discourse more generally and have been less explicit in outlining their procedure and interpretive methods (Thomas \& Littlewood, 2010; Fogel, 2007). In addition, some studies have combined Hajer's analysis with other approaches, including Sabatier's framework on advocacy coalitions, though Hajer distinguishes his approach from Sabatier's (Hajer, 1995, pp. 68-72; cf. Winkel et al., 2011; Bulkeley, 2000; and Lovell, 2004; cf. Litfin, $2000)^{46}$

\section{3 - Methodology: Communication and the B.C. Carbon Tax}

As previously mentioned, an important shortcoming of social scientific research on the B.C. carbon tax to-date is that it lacks comprehensive examination of environmentalist communication and its potential consequences for climate change politics in the province. The characterizations of environmentalist positions that do exist tend to be underdeveloped, overly unified, and unable to offer insight on how positions have changed over time. Furthermore, no studies have been found employing argumentative discourse analysis in the context of B.C. climate change politics.

The method used in this study is primarily guided by Hajer's approach to analyzing discourse coalitions by examining the terms and practices actors and organizations

\footnotetext{
${ }^{46}$ Though Hajer acknowledges a number of overlapping areas of agreement between the two approaches, he takes issue with Sabatier's focus on "beliefs" and his individualist ontology. Hajer argues Sabatier's framework uses a problematic conception of language as a neutral medium that merely expresses these a priori beliefs. Instead, he suggests that language and the social context in which communication takes place help to constitute these beliefs (cf. Sabatier, 1988).
} 
employed in the struggle to make meaning of the B.C. carbon tax. Research attention focuses on public communication of environmental actors through a variety of media texts. Particular consideration was given to differences and interrelations between common storylines, metaphors, concepts, and other rhetorical devices, to explore how particular framings have made some elements of the policy context appear fixed and appropriate, while others were seen as problematic. The practical institutional context in which coalitional statements were made was also highlighted to better understand the social setting that helped shape coalitional dynamics in the province. The following section explains in further detail the procedural process and methodological considerations taken into account during data collection and analysis.

\section{4 - Data Collection and Materials}

The study is based on a compilation of texts intended to represent a spectrum of environmental discourse in mainstream media, selected alternative media, advocacy websites, and policy documents. The analysis focuses on 13 environmental organizations and four select individuals, including Sierra Club BC, Pembina Institute, David Suzuki Foundation, ForestEthics, Sustainable Prosperity, Sightline Institute (formerly Northwest Environment Watch), PowerUP Canada, Voters Taking Action of Climate Change, British Columbia Sustainable Energy Association (BCSEA), Canadian Centre for Policy Alternatives (CCPA), Dogwood Initiative, Raincoast Conservation Foundation, and Wilderness Committee (formerly Western Canada Wilderness Committee). Individual advocates considered included Simon Fraser economist Mark Jaccard, University of 
Victoria environmental lawyer and co-founder of Greenpeace Michael M'Gonigle, cofounder of ForestEthics and PowerUP Canada Tzeporah Berman, and environmental activist David Suzuki. These organizations and advocates were chosen after an extensive preliminary investigation ${ }^{47}$ on the carbon tax debate in B.C. showed them to be either frequent contributors to public discourse on climate policy or important dissident voices who may have been influential in the overall make-up of a potential group of discourse coalitions.

Following Dryzek (1997, p. 9), I assert that climate discourse and environmental communication encompasses a wide variety of actors, some of which may not see themselves as "environmentalists" and may even be hostile to such a characterization. ${ }^{48}$ The term "environmental organization" was also interpreted broadly to include "green think tanks" dedicated to the analysis and promotion of climate policy, as well as grassroots or membership-based environmental non-profits and professional charities that focus on a variety of more traditional conservation-oriented issues like wilderness preservation or biodiversity loss, in addition to climate change advocacy. These classifications are consistent with both Beck and Hajer's theories on subpolitics and competitive coalitional alliances.

News items were searched through Canadian Newstand Complete, which covers major newspapers, at a national, provincial and local level within British Columbia. ${ }^{49}$ Alternative or independent presses were searched online and include The Tyee, the

\footnotetext{
${ }^{17} \mathrm{My}$ interest in communication about the B.C. carbon tax has been a research priority since at least late-2010, but my focus on the environmental community in particular solidified near the start of 2012 . My investigations involved searching Canadian Newstand Complete and various independent media sites for news articles, examining provincial government documents, searching the websites and blogs related to different groups, and reading scholarly accounts of the policy.

"I use the term "advocate", "actor" and "activist" interchangeably, though the latter is used less frequently as it connotes a more radical orientation in discursive outlook and practical activity, and so is less applicable to more conservative constituents of discourse coalitions.

${ }^{49}$ A list of search terms is provided in Appendix Two.
} 
Georgia Straight, Vancouver Observer, Rabble.ca, Public Eye Online and DeSmog Blog.

These publications were chosen after a preliminary search revealed they often offered a

forum for environmental advocates to voice a diversity of perspectives in more depth

than was typically given in the major publications. The data include news articles, op-eds, news releases, policy papers, and website text from the various groups. ${ }^{50}$ The search ranged from January 1, 2006 until August $31,2012 .^{51}$ This roughly corresponds with Sodero's (2011) analysis, which notes a critical shift in government climate policy leading to the announcement of the carbon tax in February, 2008, and continues until its final increase on July $1,2012$.

Primary analysis centered on texts acquired with the terms "British Columbia" and "carbon tax". A preliminary search in Canadian Newstand Complete returned 531 results. The majority were published in 2008 (359 texts), tapering off in 2009 ( 84 texts), and leveling off for the rest of the period (2010-2012 returned less than 30 texts for each year). ${ }^{52}$ Only nine texts were returned for 2007 and none for 2006 . The news organizations with the most frequent contributions were The Globe and Mail (78 texts), The Vancouver Sun (41 texts), The Canadian Press (28 texts), and Times-Colonist (21 texts). ${ }^{53}$

\footnotetext{
${ }^{50}$ For text related to Canadian Centre for Policy Alternatives the groups blog Policy Note (www.policynote.ca) was searched in addition to the home site. Additionally, the website Progressive Economics Forum (www.progressive-economics.ca) was searched after a preliminary examination showed it to be a valuable site for CCPA advocates to express views about climate change and the carbon tax.

"Public discussion and media attention has generally increased in tandem with each increase in the carbon price (implemented each year on July 1) and so I have chosen August, 31,2012, as the end date to capture dialogue that may have arose as a result. Furthermore, environmental groups submitted proposals to the provincial government by this time for the provincial government's carbon tax review and so this end date allowed for the inclusion of these texts to be considered in the sample.

52 It is difficult to get an accurate distribution of these texts by type of publication. The majority of the Canadian Newstand sample was classified as "news stories" (439), with a sizable number classified as "commentary" or "editorial" (77 and 65 texts, respectively). However a rough examination of some of these categories shows some cross-over between classifications.

${ }^{53}$ The largest metropolitan area in British Columbia is Vancouver whose media market is dominated by two Postmedia outlets: The Vancouver Sun, which is generally seen to represent more "liberal" viewpoints, and The Province, which is known as a more of a "conservative" outlet. It is worth noting that from the years 2006-2012, the search brought back only 12 results for The Province. Canada's other national newspaper is National Post, which turned 13 results for this same period.
} 
It is not surprising that the most highly active periods were during the initial public announcement and roll out of the tax. Though texts were distributed relatively evenly throughout each year, over 50 per cent of texts from 2009 were published in April and May, in the lead-up to the provincial election. This general trend is corroborated in the research sample of blog posts, policy documents and independent media.

However, these numbers give a rough picture of carbon tax discourse as covered in the mainstream press at a national, provincial, and local level. Environmentalist communication was a smaller portion of the texts drawn from Canadian Newstand Complete sample, and actors were typically represented in either op-eds or as interviewees in larger news pieces. When other search terms were included to encompass a more detailed sample of environmentalists and groups the distribution of relevant texts shifted somewhat (see Appendix Two for search terms used). The Vancouver Sun led mainstream media outlets, publishing 42 texts, with the Times-Colonist and the Globe and Mail following behind with 21 and 16 pieces published. ${ }^{54}$

To get a more detailed sample of environmental discourse, texts were gathered from independent and alternative media sites, as well as from the websites of advocacy groups. The most robust cache of news publications was found at The Tyee (34 texts), with other important contributions coming from the Georgia Straight (18 texts), Public Eye Online (16 texts), and DeSmog Blog (13 texts). It is difficult to give a greater sense as to the depth of coverage and amount of attention given to climate issues relevant to the carbon tax from these numbers alone. Some publications, like The Tyee, tended to give more generous space to a host of environmental issues, often playing different advocates'

\footnotetext{
${ }^{54}$ A significant number of publications came from different local and distant newspapers, serving different cities and towns across the province, or larger centers across Canada, such as the Toronto Star, the Edmonton Journal or the Ottawa Citizen, for example.
} 
claims off each other, or publishing lengthy environmentalist commentary. Others, like DeSmog Blog, often featured commentary from bloggers or reported on other news reports, with comparatively less space for advocates' own voices.

Throughout the sample, texts that allowed environmental actors to articulate their positions in their own words were given more consideration than reporting on these actors by other authors. A number of aspects of news coverage and representation were considered as well, including type of publication (op-ed, blog post, submission to government committee), page number, rhetorical construction of argument, frequency of cross-reference, etc.. Most texts were closely read multiple times and were organized sequentially by time period and by author, highlighting key themes, metaphors, and storylines.

Similarly, documents created by different groups were considered in relation to their organizational mandate and intended purpose, whether texts were "fact sheets" meant for broader public distribution, or detailed policy documents focused on specific areas of government oversight, for example. In this respect, some of the most active groups were found to be Pembina Institute, Canadian Centre for Policy Alternatives, David Suzuki Foundation and Sierra Club. However, this is a rather difficult metric to convey in any straightforward manner. Some groups frequently published comprehensive policy reports, often in coalition with one another. ${ }^{55}$ Still others released smaller commentary pieces on government legislation to media and supporters, or made numerous contributions as sources for journalists in news stories. ${ }^{56}$ In addition, influential

\footnotetext{
${ }^{\text {ss }}$ Actors from Pembina Institute and CCPA would be the most obvious examples here. David Suzuki Foundation also contributed in this manner, though larger policy documents often focused more on federal policy making. Both these groups also acted as important facilitators of coalition media statements and documents.

${ }^{36}$ Some groups, like Pembina Institute, contributed both larger policy documents, as well as smaller commentary pieces, and were frequent contributors to news stories. Actors at David Suzuki Foundation were commonly cited in news stories, but did not release as
} 
advocates like Mark Jaccard repeatedly found wider audience through op-ed pieces in the Vancouver Sun, whereas actors with less media standing were confined to blog posts on group websites.

Additional policy documents produced by the provincial government were also studied, including the Climate Action Plan (2008), the Speech from the Throne (20062012), Budget announcements (2006-2012), Climate Action Team Report (2008), Green Energy Advisory Task Force Report (2010), and the Clean Energy Act (2010). ${ }^{57}$ Analysis was limited to written text for reasons of practical convenience.

While interviews were not conducted formally, reported interview data in Harrison (2012) and Sodero (2011) fill out the analysis. This is a potentially significant shortcoming, especially as it regards more oppositional environmental voices and groups that are more ambivalent towards dominant media conventions, making their inclusion a challenge (see Anderson, 2003 \& 2000; Greenberg \& MacAuley, 2009; Greenberg, Knight \& Westersund, 2011). Furthermore, it may be difficult to infer some of the relational dynamics in actor networks from the study of media texts alone. Despite these limitations there remain a number of important insights to be gained from studying public communication in this manner, especially considering the potential repercussions for the state of the green public sphere, both within the province and beyond.

\footnotetext{
many large policy reports at the provincial level, at least in the same manner as CCPA, for example. Others, like Kevin Washbrook of Voters Taking Action Against Climate Change, was a modest source in news stories and contributed to various policy reports from other groups, though VTACC did not create any policy documents on their own.

${ }^{37}$ Other important government actions that have affected climate change policy in British Columbia were also consider including the government's 2012 decision to suspend further increases to the tax until further government review, Premier Christy Clark's suggestion that the government may rewrite provincial climate change targets, and the recent announcement to amend the Clean Energy Act to include natural gas used for powering the proposed Liquid Natural Gas terminals in north-western British Columbia.
} 


\section{5 - A Note on Environmental Organizations and Actors:}

It is also important to acknowledge that organizations differed on a number of operational levels and approaches to advocacy, which made considering each group's mandate a crucial part of analyzing their approach to carbon tax communication. For example, some groups are dedicated to issues related to climate change more than others; some are smaller member-based groups, located within the province who direct their energies more locally and which depend on the work of volunteers; some are professional think-tanks focused primarily on policy advocacy and design; and some are provincial chapters of larger national charities. More detail on each group and their place in the respective discourse coalitions is provided in Appendix One. It should also be noted that this research concentrates on the environmental community in particular. A wider analysis might consider a more detailed examination of oppositional discursive responses to the tax by the broader public, political parties or business associations. ${ }^{58}$

\footnotetext{
38 This could relate to the NDP's 'Axe the Tax' campaign or to what Gunster (2010) refers to as the 'hardship frame' (pp. 198-201), for example.
} 


\section{Chapter Five}

\section{Discourse Analysis: Results and Discussion}

The aim of the discourse analysis presented here is to more clearly decipher the degree to which conflicts about the carbon tax and climate change in B.C. may have represented efforts to maintain, or challenge, a politically workable discourse coalition centered around the concepts and storylines of ecological modernization. My argument is that environmentalist communication tended to reinforce a discourse of "weak" ecological modernization, often in conjunction with the governing Liberal Party. This relationship would shift over time and was periodically challenged by "stronger" varieties of ecomodernism, sometimes connected to more radical environmentalist practices (Dryzek, 1997, pp. 147-152 \& 153-193; cf. Harvey, 1999).

Evaluating the relative strength of eco-modernist discourse will be an important focus in the pages to follow. For the most part, environmentalist communication about the carbon tax avoided a more confrontational stance to challenge prevailing institutional power, though various degrees of resistance were nearly always present. I suggest that a consistent strong discourse coalition never fully formed in a manner equal to the prevailing weak one. ${ }^{59}$ Further discussion in the concluding chapter will focus on the opportunities and limitations of such findings for future advocacy and scholarly work.

The current chapter proceeds first with an examination of a selected event from the research sample to introduce some of the discursive terrain covered in the chapter. Subsequent sections provide a detailed look at some of the storylines and discursive features of both the weaker version of ecological modernization, as well as those stronger

\footnotetext{
39 Actors and organizations that tended to align with one or the other discursive poles are categorized in Appendix. One.
} 
variants, with special focus on the ways in which they tended to interact together. The communicative practices of various actors and groups are then further divided along these lines and compared in relation to dominant forms of institutional power, including systems of state, media and corporate authority. The chapter concludes by reflecting on some of the changes in carbon tax communication following the 2009 election, when much of the political attention began to wane and developments in the oil and gas sector came to take precedence.

\section{1 - Setting the Discursive Context: An Illustrative Example}

"s"If [Liberal Leader Gordon Campbell] goes down because of axe the tax, the repercussions are the carbon tax will be toxic for future politicians... No politician will raise it. That's why environmentalists are so upset."”

David Suzuki, quoted in The Globe and Mail (Bailey, 2009)

"...if "Super, Natural British Columbia"-the birthplace of Greenpeace-can't add a few cents to a litre of gas...then what hope is there that we privileged (spoiled?) industrialized nations will lead a charge to save the developing world from drought, starvation and inundation?"

Tzeporah Berman, This Crazy Life: Living Our Environmental Challenge (Berman \& Leiren-Young, 2011, p. 255)

In December, 2009, during the UN climate conference in Copenhagen, a coalition of 10 Canadian environmental organizations presented B.C. Premier Gordon Campbell with an 
"Economy Wide Pricing" award to "recognize "acts of climate leadership" by municipal and provincial governments across the country" (Kimmett, 2009b). The award was delivered to Campbell by renowned environmentalist Tzeporah Berman at a ceremonial gala, marked by a photo-op of the two unlikely allies shaking hands. Though it seems to have garnered little attention in mainstream print media, the event offers a valuable entry point into the symbolic politics of environmental discourse in the province and the coalitional dynamics constructed through the concepts of ecological modernization.

Despite the lack of press from larger news organizations, the award made a splash in independent and online publications, and helped raise the ire of a number of local B.C. environmentalists. The event itself fit snugly within a narrative of disconnect that had been building for some time within grassroots-circles in the province's environmental movement. Many of the groups presenting the Copenhagen award had not been active in B.C., and a number of other participating organizations had provoked a split in the environmental community eight months earlier with similar actions during the 2009 provincial election. ${ }^{60}$

The refrain, not altogether unfamiliar to environmental movements elsewhere, centered around storylines that emphasized the corrupting power of institutional collaboration. It was argued that the more professionalized green groups and think tanks, garnered prestige and legitimacy in the official corridors of power, while negotiating compromised policy that would ultimately fall short of what was needed. In the process they forfeited their accountability to a more critical and independent base within the green public sphere. With such a loss of democratic control, the prominent groups represented a threat to the success of the movement and were themselves part of the

\footnotetext{
${ }^{60}$ Here I am primarily referring to the debates over privatized ROR hydro development mentioned earlier.
} 
machinery of power, complicit with the perpetrators of the ecological and climate crisis. The groups too often functioned as government "validators", and their morally dubious media spectacles represented a "greenwashing", which pitted superficial symbolism against substantive policy action. ${ }^{61}$ The Copenhagen event was largely seen as a public relations exercise, and a dangerous one at that. ${ }^{62}$

The more established groups countered these critiques in a number of ways, which will be detailed in the next section, but a few points deserve mention here. First, the above storyline illustrates a forceful narrative that was at times associated with a more radicalized brand of environmental discourse that played a small, but important, role in shaping the overall argumentative dynamics within the movement. Second, a significant part of the carbon tax story involved struggles over the proper trajectory for environmental movement, or more broadly speaking, about "the appropriate role and relationship of nature, technology and society" (Hajer, 1996, p. 247).

In this regard, a key point of struggle became the concept of "climate leadership". Examining how this term was employed in communication illustrates important discursive terrain for understanding the carbon tax debate. Presumably, the Copenhagen coalition indeed staged Premier Campbell's carbon pricing award with the aim of turning the media spotlight onto the carbon tax as a success story that could encourage other politicians and publics to follow suit. What many carbon tax supporters consistently lauded was bold "climate leadership" in a world where a reactive (or tractable) public was averse to any new tax proposal. For a politician to stand behind good climate policy

\footnotetext{
${ }^{61}$ Indeed, environmental representatives were used as official government validators. See Palmer (2008).

${ }^{62}$ For examples of this type of response see The Canadian Press (2009), Tieleman (2009a \& b), and I. Lee, (2009).
} 
like the carbon tax was to risk "political suicide", and so justified sympathetic public support (cf. J. Simpson, 2008; Burrows, 2010; Jaccard, 2008b).

This was a very prominent aspect of carbon tax communication in British Columbia, and implicit in its formulation was the idea that the political success or failure of the tax could become almost contagious (Bailey, 2009, April 18; Berman \& LeirenYoung, 2011, p. 255; cf. J. Simpson, 2009). A prime justification for supporting the policy was not only because it would reduce provincial carbon emissions (a drop in the bucket by total global standards), but rather that it could serve as a template or model to inspire similar action by other jurisdictions. ${ }^{63}$ If the carbon tax failed in B.C., a haven for all things "green" and progressive, it would spread its politically toxic legacy elsewhere and "poison the well" through its broader symbolism (Berman, 2009).

This was a common perspective offered by a majority of the dominant voices in the environmental community. From this reading, the symbolism under consideration was hardly inconsequential or immaterial "greenwash", though it may have been more difficult to articulate a convincing guarantee that others would be compelled to follow suit. It often meant calling on vague or uncertain intuitions that an electoral victory for the B.C. Liberals would translate into stronger climate action outside provincial borders. In this sense, supportive arguments for the carbon tax became heavily dependent on their social construction and how they were rhetorically fixed in communication as a significant and stable social reality.

\footnotetext{
${ }^{63}$ To be clear, environmentalists did defend the carbon tax on the basis of its potential to reduce provincial emissions, but the notion that the policy held importance outside provincial borders was a consistent theme (see Hsu, Bauman, 2012; de Place, 2010b; de Place \& Bauman, 2012). Climate scientist Andrew Weaver (2009) likewise imbued the BC carbon tax with international political significance, foretelling, "[rest] assured, in the lead-up to Copenhagen, the world will be watching the B.C. election". Indeed, according to Rabe \& Borick (2012, p. 366) the policy had been official examined by six state legislatures in the United States.
} 


\section{2 - Discourse Coalitions and the Strength of Ecological Modernization}

With this in mind, the following section outlines a number of the more common storylines, metaphors and conceptions that helped frame debate about the carbon tax and climate action in B.C., as well as the actors who gave voice to them. My primary goal is to sketch some of the key communicative dynamics that shaped the make-up of a dominant discourse coalition, which I argue centered around a weak version of ecological modernization and remained relatively stable throughout the study period. Consideration will be given to the various discursive practices used to bring meaning to these storylines in the subsequent section, with particular focus on arguments about the proper role of environmental actors in relation to corporate, state, and media institutions.

Though I suggest weaker forms of ecological modernization tended to hold prominent influence over the climate debate, this was periodically challenged by stronger discursive variants that questioned many of the assumptions carried within the dominant coalition and sought to expand or change the context for political action. Many of these expressions struggled against the more technocratic tendencies in the coalition, in order to redefine the appropriate democratic social and moral order for the environmental movement and its approach to the carbon tax and climate policy. As a consequence, they were also more likely to be connected with, or constituted by, radical brands of environmentalism that emphasized deliberate or direct forms of democratic participation (cf. Dryzek, 1997, pp. 147-152).

However, a concerted and consistent challenge to the dominant discourse coalition remained relatively marginal, though a number of groups made forceful appeals, 
some of which, I argue, carried wider currency over different time periods. ${ }^{64}$ Still, weak

eco-modernist discourse generally took precedence within the environmental community and tended to be in closest alignment with the government's climate program. Actors expressing these views were most likely to sit on government panels or be referenced in official communication materials and reports. ${ }^{65}$ Moreover, they also tended to be quoted most frequently in mainstream media outlets, both as sources in story pieces as well in op-eds, and they often issued detailed policy briefs and reports that further helped establish their credibility and legitimacy as expert contributors to public debate.

I will first outline a simplified version of some of the more common weak ecomodern storylines, followed by an examination of the stronger variants. Tables summarizing both the general make-up of aligned actors who typically contributed to both of these trends are included in Appendix One for reference, in addition to general interpretive reasoning behind each choice in classification.

\section{3 - Storylines: “Weak" Ecological Modernization}

In its most simplistic form, the discourse of weak eco-modernism is based on a theme of efficiency and a largely instrumental set of arguments, often based on the cost-benefit analyses of environmental economics. In this sense, the discourse comes to represent

\footnotetext{
64 The most notable example here involves the split over privatized ROR hydro development and the government's removal of local oversight, which brought a number of complaints to the surface regarding the structure of the environmental community and the dominant position afforded to the professionalized groups (Shaw, 2011; Tieleman, 2009a; The Canadian Press, 2009). Other instances of critique were less concentrated, but often challenged both the structure of the tax and the overall scope of the government's climate plan based on norms of social equity and justice. Often these included arguments for an increased role from the public sector and participation and deliberation from the public-at-large in choosing climate policy solutions. Advocates here were often associated with the CCPA Climate Justice Project.

${ }^{65}$ One of the most prominent actors in this regard was economist Mark Jaccard, whose environmental consulting firm provided technical analysis and modeling that would form the basis of the govemment's Climate Action Plan (British Columbia Ministry of Environment, 2008) and who sat as Special Advisor to the Climate Action Team. His company's work was widely cited and circulated in environmental circles, especially as a benchmark for the preferred schedule of carbon price increases for the tax past 2012 (see Pembina Institute \& David Suzuki Foundation, 2009; and David Suzuki Foundation, 2008).
} 
Hajer's (1996) “institutional learning" approach: that societal institutions can alleviate the ecological crisis by incorporating environmental concern within their operations as preventative measures, in this case through pricing carbon emissions, with minimal change to the existing social order.

A foundational storyline in the B.C. carbon tax debate was that society could no longer afford to use the atmosphere as a free garbage dump (Horne, 2007; David Suzuki Foundation, 2008; Simpson, Jaccard, \& Rivers, 2007, p. 199). In this framing, the costs associated with climate change were too great to remain external to the market price of carbon-intensive activity. Internalizing these costs required putting a price on carbon that was applied throughout the economy and sufficient enough to encourage green behavior and make polluting activities cost-prohibitive. The carbon price would then gradually rise over time to give consumers and businesses time to adjust their investments and lifestyles accordingly.

Generally speaking, these tenets were rarely challenged, although there were important exceptions. A derivative of this narrative was the notion that a carbon tax creates a powerful market incentive through price signals, which stimulate innovation and allow individuals and companies the flexibility to adjust their actions according to their own particular circumstances (see Bruce, 2008). This view was sometimes counter-posed against a vision of government regulations as bulky, indiscriminate, and inefficient, though many actors qualified their statements by explaining that regulations were an important tool in the policy mix (see Green, 2007). Still, the carbon tax was often said to be foundational to any effective climate agenda and so worked to establish its meaning 
and hierarchy in the openness of climate policy choice (see Pembina Institute et al., 2009; Jaccard, 2008b).

In addition to these concerns, advocates attempted to show the plausibility of continued GDP growth alongside a strong price on carbon (see Horne, Bruce, \& Smith, 2012). Carbon taxes were said to be cost-effective means at addressing climate change with minimal, or even positive, economic impacts. This was accomplished by pointing to other nations with carbon taxes, as well as through reference to reports based on modeling and situated in a Canadian context (Bruce, 2008; Pembina Institute \& David Suzuki Foundation, 2009; David Suzuki Foundation, 2008). In this regard, communication about the carbon tax attempted to neutralize any critique that strong action on climate change would negatively affect the government's broader economic agenda, and instead offered a discursive space that allowed existing power arrangements and cultural systems to retain their legitimacy and remain largely untouched. The storyline was sometimes crystallized into the win-win mantra, "good for the climate and good for the economy" (Mather, Olewiler, \& Elgie, 2007; Pollon, 2011; Horne, Bruce, \& Smith, 2012). Advocates attempted to show the tax was already working through anecdotes of real world examples in B.C., statistical data, or common sense appeals to the notion that as fossil fuel prices increased, people would use less of them (Elgie, Rivers, Olewiler, 2010; Sustainable Prosperity, 2012; Campbell, Bruce, Smith, 2009). Many of these claims were likewise challenged, either by pointing to the small price added to fossil fuels in relation to shifts in marketplace (Rees, 2008; Shaffer, 2009a \& b), or to the idea that demand for fossil fuel use like gasoline was "inelastic", meaning it was not 
affected much by increases in price because of the lack of alternatives (M. Lee, 2006; Griffin Cohen, 2008).

As mentioned earlier, a prime concern for advocates of the carbon tax was that the policy would be politically unpalatable to the general public. Hence an important source of collective attention was devoted to selling a tax-averse citizenry a policy they knew little about, that was foisted upon the provincial agenda largely at the behest of the Premier, and in a political context where cynicism towards politicians ruled the land (cf. Gunster, 2010; Harrison, 2012). This communicative pressure was perhaps even more acute because the provincial climate agenda was borne into the vacuum of political inertia and uncertainty at both national and international levels (see Sodero, 2011, pp. 1477; Harrison, 2012). ${ }^{66}$

A key rhetorical resource for advocates seeking to persuade the public about the value of the carbon tax was designed into the policy itself in the form of its revenueneutrality. If citizens could accept that the carbon tax was not adding any additional tax revenue to government coffers, but instead was returned in sum to taxpayers through tax cuts and credits, the policy would gain popularity. This notion was supported both through reference to public opinion polls that suggested that carbon taxation would be a political winner if offset by tax reductions (Mather, Olewiler, \& Elgie, 2007; Jaccard, Rivers, \& Keith, 2007) and by common sense appeals to the inherent rationality of the policy design. The carbon tax was "not a tax grab", but a "tax shift" (David Suzuki Foundation et al., 2008). ${ }^{67}$

\footnotetext{
${ }^{66}$ Campbell himself framed this as both a moral responsibility and as an economic opportunity following his return from failed talks at Copenhagen, explaining that, "[sub-national] governments need to be bold, innovative and show leadership that can drive nationallevel change" (Campbell, 2009).

${ }^{67}$ See Gunster (2010) for theoretical discussion on this aspect of the Liberal government communication strategy. As the tax schedule progressed it became increasingly clear that the tax cuts and credits amounted to net revenue loss for the government. The carbon tax
} 
Whether revenue-neutrality was meant to minimize negative economic impact or intended primarily as a political communication tool to allay public fears remained an ambiguous feature of argumentative interplay. The weak eco-modern carbon tax discourse was premised on the notion that "nobody likes a tax", which was an idea connected to narratives emphasizing the need to support courageous political leadership and good policy. In some senses, this aspect of communication speaks to deeper assumptions about the proper role for climate advocates in relation to the general public and the preexisting social order, which echoes academic debates about climate change, public relations and social movements (see Lakoff, 2010; Brulle, 2010; Brulle \& Jenkins, 2006).

It was largely taken for granted that "[citizens] concerned about climate change don't take to the streets with "carbon taxes now" placards," (Jaccard, 2008b). Given the apparent lack of grassroots climate activism and that the Liberal's climate agenda was initiated as a surprising top-down endeavour, the context for communication was largely set. Thus, the moral work of promoting "good policy" like the carbon tax remained largely up to economic and environmental experts. ${ }^{68}$ Though this may have been seen as problematic by some actors, it marked an important difference with some of the stronger eco-modernist advocates, who envisioned a more extensive role for public deliberation and participation in the crafting of local policy solutions (cf. Canadian Centre for Policy Alternatives [CCPA], 2008a).

\footnotetext{
was "revenue-negative" and to some this represented an "economic boon" (Elgie, Rivers, Olewiler, 2010), and was celebrated as a "great deal for individual taxpayers" (Jaccard, 2011). Still, others emphasized this as a negative outcome: the carbon tax was "increasing social inequality, while squandering revenues on expensive corporate income tax cuts" (M. Lee quoted in CCPA, 2011). ${ }^{68}$ The role of experts remained a prominent feature of carbon tax communication. Rhetorical appeals referencing expert consensus about the value of carbon pricing were common. For example, a coalition of groups defending the carbon tax noted, "[leading] economists and environmental experts agree: seeing that cost, and making it real, will give us new incentives to change the technologies and habits that created global warming in the first place" (David Suzuki Foundation et al., 2008).
} 
A number of carbon tax defenders eventually expressed frustration at the lack of success communicating the rationale for revenue-neutrality to the public, only to focus more on "the specifics, rather than the rhetoric" (Olewiler quoted in S. Simpson, 2008, June 28). From this perspective, delivering the facts of the policy's merits was meant as an antidote to misinformation that had distorted debate about the carbon tax and climate policy, more generally (David Suzuki Foundation et al., 2008; Jaccard, 2008b). Presumably, this too met with limited success in broader public debate and eventually new narratives that favoured spending tax revenue on climate initiatives began to gain strength. ${ }^{69}$

Though a large part of environmentalist defense of revenue-neutrality was directed at obstinate public resistance to the policy, bolstered by an NDP countercampaign, it served contradictory discursive purposes within the environmental community itself. Endorsements of revenue-neutrality tended to reinforce the idea that "tax-and-spend" government was bad and should be avoided, which contributed to a problematic frame for those working to ensure enough funding was available for a wider societal transformation (cf. Gunster, 2010). For example, in their responses to the policy recommendations of the Climate Action Team in 2008, a group of ten organizations stated, "Maintaining revenue neutrality is not critical from our perspective, and we would support the government being open to different uses for the revenue...our main concern is that the overall provincial budget makes sufficient climate change investments." (BC Sustainable Energy Association [BCSEA] et al., 2008b, p. 5; cf. David Suzuki Foundation, 2007).

\footnotetext{
${ }^{69}$ Counter-narratives on government spending will be examined in further detail later on. Evidence of limited success selling revenueneutrality comes from Gunster (2010) and his analysis of public resistance through the "hardship frame" (pp. 198-201; see also Sodero, 2011, p. 1478). Exit polling analysis also suggests the Liberals won the 2009 election, for example, in spite of the carbon tax (Etchell \& Hoberg, 2009).
} 
To be clear, even weaker streams of eco-modernist discourse were sensitive to the value in diverse policy mechanisms, including increased government spending and regulations (Green, Harrison, Richards, \& Olewiler, 2008; Pembina Institute, 2008b). Environmentalists were often more concerned about the overall mix of funding for climate programs than they were about singing the praises of the free market or denouncing government excesses. Even articulations with the most fidelity to Liberal government talking points expressed this ambiguous relationship in rather contradictory terms. For example, in an op-ed prior to Budget 2008, a spokesperson for the Sierra Club B.C. emphasized that a revenue- neutral carbon tax "won't add any money to government coffers and should even leave [British Columbians] with more money in [their pockets]" (Matthaus, 2007b; cf. Matthaus, 2007a; Gunster, 2010, pp. 194-195). However, this same article promoted increased government regulations, spending, and royalty rates on oil and gas companies, to fund various climate initiatives, including a 40-year transportation plan.

\section{4 - Storylines: “Strong” Ecological Modernization}

Throughout the sample there was significant discursive overlap between what I have described as both weak and strong variants of ecological modernization. ${ }^{70}$ Identifying and categorizing examples of different discourses was further complicated by shifting coalitional arrangements and joint statements, which more often than not supported the carbon tax, if not always in its current form. However, this ambiguity made the decision

\footnotetext{
${ }^{70}$ This is not surprising given Christoff's argument, mentioned earlier, that the two are not binary opposites and that often aspects of weak eco-modern discourse are necessary, but not sufficient, precursors for stronger variants (1996, p. 491).
} 
as to whether or not a separate discourse coalition ever fully-formed to challenge the dominant weaker version a demanding analytical task. Indeed, it served to highlight the openness of definition and deliberate choice in the research process itself, as well as the danger in potentially reducing too much discursive variety into a methodologically tidy continuum based on the binary of "weak" vs. "strong".

That said, there a number of reasons why this binary is a valuable heuristic in understanding climate change communication in British Columbia. The primary concern in this analysis focuses less on identifying whether or not there emerged a distinct or stable "strong" eco-modernist coalition. Instead, it highlights the argumentative interplay of a variety of discursive combinations related to climate change and the carbon tax that helped set the opportunities and limits for actors jockeying for policy influence. Though commonalities in stronger eco-modern critiques depended on a number of similar discursive features, what set them apart from their weaker analogues often involved a more socialized vision of environmental politics.

On a practical level this involved a diverse set of actors with various subjectpositions struggling to define what the concepts and storylines of ecological modernization in B.C. should entail. Consequently, much communication about climate change became a battleground over the extent to which apparent ecological imperatives were to be incorporated into the centre of societal institutions (cf. Dryzek et al., 2004). Though there were a number of contentious points of difference within the environmental community, ultimately some form of eco-modernist discourse became the more or less explicit assumption tying most actors and arguments together. 
Expressions of stronger ecological modernization were more dispersed in the research sample and not as unified as those representing weaker forms, but they nonetheless shared a number of common concepts and storylines about climate change and the carbon tax. Perhaps most obviously, they were more likely to challenge the legitimacy of both the government, as well as the dominant social and moral order tasked with finding solutions to the climate crisis. In Beck's terms, these discursive framings were more likely to attempt an "unveiling of the hazards" by questioning the "rules, institutions, and capabilities which specify how risks are to be identified in particular contexts" (2010, p. 259).

An important part of this involved interrogating corporate political economy, especially the continued influence of the fossil fuel industry on government policy (see Mann, 2008). This materialized in a number of ways with a variety of different metaphors and storylines supporting a broadly critical and antagonistic view towards this sector. At times, these storylines came to represent significant points of difference between environmentalists and were used rhetorically to show that a particular actor was either aligned with progressive climate activism or not.

Prior to the introduction of the carbon tax, environmentalists campaigned together in opposition to a variety of Liberal policies, which enabled the expansion of carbonintensive development and infrastructure (Pembina Institute et al., 2007; Bruce, Campbell \& Matthaus, 2007; BCSEA, 2007; cf. David Suzuki Foundation, 2007). The most pointed examples here included objections to government subsidies for the oil and gas industry, the Gateway transportation project, and proposals for offshore oil drilling. These policies were widely condemned by actors aligned in both weak and strong discursive camps, and 
continued to be so throughout the study period (see BCSEA et al., 2008a). However, the relative emphasis placed on each of these objections became important points of contention, especially during the 2009 election campaign, suggesting a difference in priorities implicit in each discursive strategy.

Those actors who often took a weaker eco-modern stance were critiqued for their defense of Liberal climate policy, which was said to translate into de facto support for the very energy policies they had previously advocated against (Genovali, 2009; M. Lee, 2009; Holman, 2009a \& b). After detailing a litany of potential threats from the fossil fuel industry, one advocate concluded, "Having put an inordinate amount of emphasis on rescuing the carbon tax, the environmental movement in B.C. comes out of this election a paler shade of green as it just might have cut off its nose to spite its face" (Genovali, 2009). Another explained that the mistake of supporters lay in "putting a single headlining issue like the carbon tax out front when effectively dealing with climate change requires a multifaceted approach" (Holman, 2009b) ${ }^{71}$ Crucially, these statements still defended the importance of carbon taxation, while instead insisting that it be "aligned with a suite of policies and initiatives that work in concert, not in contradiction" (Genovali, 2009).

Paradoxically, actors in the weaker camp likewise emphasized these same points (see Zehr, 2009b; Robinson, 2009; cf. Pembina Institute, 2007). For instance, days after delivering a contentious pre-election news conference in which they defended Liberal climate policy, the Pembina Institute issued a press release explaining their "serious concerns regarding the Liberals' energy plan, which [included] opening new gas fields

\footnotetext{
"This notion, that the symbolic media-value of the carbon tax limited effective climate advocacy, will be examined in greater detail in the following section.
} 
and developing an energy corridor across Northern British Columbia" (Pembina Institute, 2009a; see also Zehr, 2009b; cf. Pembina Institute \& West Coast Environmental Law, 2009). Likewise, Tzeporah Berman emphasized, "I'm not saying the B.C. Liberals are good just because of the carbon tax...I don't support their decision on Gateway [transportation corridor]. I don't support their expanding the oil-and-gas industry in the north" (Burrows, 2009). ${ }^{72}$ Indeed, these had been important advocacy issues that previously involved both sides in coalition (cf. Pembina Institute et al., 2007; BCSEA, 2007). ${ }^{73}$ However, a key difference that distinguished groups from one another was the willingness to tolerate Liberal policy contradictions to prioritize the "leadership" frame that the carbon tax came to represent.

Stronger eco-modernist advocates also tended to question the logic of official carbon accounting rules that considered only emissions originating from within provincial boundaries and suggested expanding the carbon tax to include emissions from fossil fuel exports (Sierra Club BC, 2011; CCPA \& Sierra Club BC, 2011; M. Lee, 2009; Horne, 2012a; Dogwood Initiative, 2011). This became an increasing concern, especially as the expansion of the natural gas industry and the proposed liquid natural gas (LNG) terminals on the North coast threatened to overwhelm legislated climate targets. New

\footnotetext{
${ }^{72}$ She continued by explaining, "I'm saying that [the Liberal] climate strategy and their commitment to conservation efficiency and an economy-wide price on carbon and their commitment to expand the renewable-energy sector is leadership. I'm not saying that I agree with all of their platform..." (emphasis added, Burrows, 2009).

${ }^{73}$ One critique associated environmentalist defense of Liberal policy with "sucking up to large industrial polluters" and exclaimed, "as far as fighting climate change, the government's fixation on expanding freeways and bridges - I don't know how the Hell you'd ever support that program as a way to fight climate change" (Holman, 2009a). One of the groups being critiqued, the David Suzuki Foundation, was a founding member of the Livable Region Coalition, and worked together with the same advocates as part of a larger grassroots coalition opposing the Gateway transportation project (see Colebourn, 2008; Langley Times, 2007; see also http:/(www.livableregion.ca/about.html). Indeed, just two months earlier a number of soon-to-be divided groups released a media advisory in the lead-up to the 2009 provincial Budget announcement stating their commitment to "cross-budget consistency", which effectively meant a phase-out of subsidies to the oil and gas sector, allocations for species-at-risk, closed-containment salmon farming, and marine protected areas along the Pacific coast (David Suzuki Foundation et al., 2009b; David Suzuki Foundation, 2009).
} 
metaphors and storylines began to cast fossil fuels as a powerful drug and the province as both an addict and a dealer (M. Lee, 2010b; CCPA, 2010b; Dogwood Initiative, 2011). ${ }^{74}$

This frame therefore set aside internationally-accepted rules in carbon accounting practices to recast the moral context for responsible climate action in more globalized terms. It did not matter where in the world fossil fuels were burned: provincial climate action could not be ethically sound if it depended on a political economy that profited off the export of a "dirty" pollutant. Most pointedly it was asked, "what if it turns out that beautiful BC is running the resource economics equivalent of a meth lab?" (M. Lee, 2010b).

Likewise, a similar metaphor cast carbon emissions as a "toxic" pollutant that required more urgent government intervention. For example, in a blog post published for the Dogwood Initiative, one advocate questioned the notion of pricing carbon emissions altogether, instead writing, "The proper way to eliminate toxic substances is to ban them" (Stainsby, 2009a). This storyline was often driven by a strong moral sense of urgency regarding the threat of catastrophic climate change; skepticism towards the field of conventional economics (often by focusing on the uncertainty involved in setting an adequate carbon price); and a positive view towards government regulation and a strong public sector in ameliorating the risks of global warming. ${ }^{75}$

A separate policy, known as cap-and-dividend, was also proposed that was thought to be more effective at reducing emissions and satisfied the concerns and criteria

\footnotetext{
${ }^{74}$ Advocates compared the expected emissions reductions from the carbon tax to the expected emissions output from burning provincial fossil fuel exports to dramatic effect: $3 \mathrm{MT} /$ year vs. $105 \mathrm{MT} / \mathrm{year}$, respectively (see M. Lee, 2010b). Far from heralding the death of the carbon tax, this helped justify a deeper transformation in the provincial economy with the carbon tax as the central engine driving a "fair and effective" transition to a carbon-neutral BC (CCPA \& Sierra Club BC, 2011; CCPA, 2012b; M. Lee, 2011).

${ }^{75}$ These perspectives were connected in statements like, "Dealing with toxins is not a matter for economics and the market", as well as, "Regulation, unlike taxes, can be based on our collective morality and values and on the best available scientific information about our planet - in this case, information about global warming. Our values, I hope, place the highest importance on the well being of all peoples on earth..." (Stainsby, 2009a). Other versions told of a history of government regulations as effective tools in dealing with other toxic substance (cf. Griffin Cohen, 2008).
} 
of actors occupying this discursive position. Though many of the arguments supporting this policy and the "toxicity" metaphor were seemingly antithetical or incompatible with support for the carbon tax, a number of actors and groups still found ways to advocate for both simultaneously (Heyman \& Campbell, 2009; Sierra Club BC, N.D.; Horter, 2009a; cf. Dogwood Initiative, N.D.). Still, these positions exerted a relatively marginal influence in the overall discursive make-up within the environmental movement, though the focus on exports and the "drug addiction" metaphor became more common beginning in $2010 .^{76}$

The threat of dangerous climate change, usually defined as two degrees Celsius global warming over preindustrial averages, played a more pronounced role in stronger eco-modernist discourse, though most actors touched on this risk in some fashion (cf. Russill \& Nyssa, 2009; Boykoff, Frame, \& Randalls, 2010). Groups highlighted the possibility of overshooting the threshold for runaway changes to the global climate. This was expressed through technical policy papers in partnership with academic scientists calculating specific global "carbon budgets" and then extrapolating various scenarios for divvying ethical responsibility for reducing provincial carbon emissions (CCPA, B.C. Government and Service Employees' Union [BCGEU], \& Sierra Club BC, 2008; Stainsby, 2009b; Horter, 2009b). This often combined discourses about climate science, global inequity and climate justice to push for stronger provincial emissions targets and extended moral consideration to people in developing nations.

Likewise, social inequity became the focus of policy papers highlighting the disparity in emissions between British Columbians at different income brackets, hence

\footnotetext{
${ }^{76}$ The storyline itself was a part of the discursive mix at least since the announcement of the carbon tax (see Genovali, 2008a; Berman, 2009).
} 
arguing for a more localized climate justice through fair distribution of carbon tax revenues (CCPA, 2010a \& 2008b) ${ }^{77}$ Again, this entailed a greater role for government support, and these arguments were often connected to others calling for carbon tax revenue to be spent on climate initiatives. The most forceful arguments here came from actors representing the Canadian Centre for Policy Alternatives and the Climate Justice Project. These advocates challenged the validity of revenue-neutrality by reframing it as "a political consideration above all else [that] should be abandoned" (CCPA, 2008c).

Overall, stronger eco-modern discourses were more likely to construct storylines about deeper societal transformation on the basis of explicitly moral arguments, as opposed to a more instrumental set of considerations for climate action. ${ }^{78}$ However, both camps in the discourse coalition rested on appeals to the importance of "climate leadership" in British Columbia, though common instrumentalist arguments relied more on promises of continued GDP-growth; aspirations towards competitive advantage in a globalized "green economy of the future"; or to the looming threat of trade sanctions from the United States in anticipation of stronger climate policies from the Obama administration (Dauncey, Horter, Smith, \& Berman 2009; Campbell, Bruce \& Smith, 2009). Strong eco-modernist arguments more readily challenged the authority of dominant institutional actors in moral terms that cleared discursive space for more egalitarian or collective subject-positions, and aimed more succinctly at the core of provincial economic and legitimacy imperatives.

\footnotetext{
${ }^{n}$ It bears repeating that a strong eco-modern discursive standpoint should not be conceived as something exclusive to any one organization or actor, or as something solid or unchanging. Policy discourse here is conceived as part of a dynamic and interactive process, which involves a number of complex and indeterminate social, historical and cultural processes. For instance, the group Sustainable Prosperity is here classified as a "weak" eco-modern organization, but actors from this group also espoused alternative discourses more closely related to climate justice, that focused both on the disparate effects carbon taxation had on marginalized groups, as well as local participation in policy design (see Sustainable Prosperity, 2011).

To be clear, the two were not mutually exclusive and even the most instrumental set of appeals to continued GDP growth, for example, rested in some way on moral assumptions regarding the benefits of material wealth to the broader populace.
} 
Moreover, these proponents often pushed for a more democratic and localized climate politics, assigning a greater constitutive role for public deliberation and grassroots engagement in crafting effective policy. This was sometimes linked to the idea that the fairness of a policy—as perceived by the majority of those affected by its implementation-would become a vital contributing factor to its success beyond the relatively exclusive policy-communities that helped incubate them (CCPA, 2008a; CCPA \& Wilderness Committee, 2011). The idea of fairness, transparency and public input in the policy process, was something that was espoused by a majority of advocates, but held varying influence in the shifting coalition of actors, sometimes creating points of contention during debates about ROR hydro.

Oppositional cultural critiques questioning the rationale for continued economic growth and consumer capitalism were less common, but present (M'Gonigle, 2009a \& b; Stainsby, 2009a; Rees, 2008; Genovali, Paquet, \& Macduffee, 2009; M. Lee, 2008). Still, even more radical environmental opposition often gravitated towards some sort of dissolution of the discursive opposition between "environment vs. economy", if only to redefine "the economy" in the context of ecological limits. This ecological rationality still utilized many of the institutions of modernity, aligning itself with the natural sciences, technological innovation and revitalized public institutions. Yet it remains questionable whether these discourses fit comfortably within any ecologically modern coalition, though they bore significant resemblance to Hajer's (1995, pp. 78-103) telling of the discursive tensions that originally gave rise to the concept within the environmental movement (cf. Dryzek, 1997, pp. 153-201). ${ }^{79}$

\footnotetext{
${ }^{79}$ Christoff (1996, pp. 494-495) questions the assumption that radical environmental critique is itself not often thoroughly embedded in many of the assumptions of modernity. Dryzek (1997, pp. 172-193) most clearly echoes this in his analysis of what he calls "green
} 


\section{5 - Practicing Symbolic Politics: Movement, Media and the State}

"One core task of opposition movements is to contest the prevailing definition of things, the dominant framings. They must "rectify names", they must change the way people construe the world...they must probe to discover in practice how far the principles of news "objectivity" can be severed both from the disparaging codes and from the corporate and State interests that sustain and delimit them."

Todd Gitlin, The Whole World is Watching (1980, p. 283)

"I thought I was part of a movement, not a cult."

Tzeporah Berman, quoted in The Georgia Straight (Burrows, 2009)

As previously mentioned, the coalition of environmental groups led by Tzeporah Berman at the 2009 United Nations conference in Copenhagen exacerbated an earlier rift that emerged in the environmental movement by honouring Premier Gordon Campbell with an award for climate leadership. A few days following this event, an activist was arrested after scaling a flagpole on the front lawn of the B.C. Legislature building and hanging a banner that read, "Stop the Gordon Campbell Pipeline, BC's Colossal Fossil". The pipeline in question was the Northern Gateway pipeline proposal, set to link the Alberta 
tar sands with Asian markets through the port of Kitimat, B.C., in the heart of the socalled Great Bear Rainforest. $^{80}$

In a fiery letter detailing the rationale for his stunt, Ingmar Lee explained a litany of grievances with the Campbell government's environmental policy. An important motivation for the action was to show opposition to the "due-process oriented, charitable status-quarding [sic] organizations [who] have already established themselves as collaborators with the Neocon Campbell government...”(I. Lee, 2009). According to Lee, these organizations were "shameless greenwashers of the $\mathrm{BC}$ government and the darlings of the corporate media". The Copenhagen award gifted to Premier Campbell was the "final straw that drove [him] up the flagpole".

Lee's action seems to have garnered little print media attention, even among smaller independent publications, and it is not clear that he himself had much influence on the specific make-up of the discourse coalition on ecological modernization. Yet it serves to represent a more radical articulation of environmental discourse that bears some similarities to stronger eco-modern currents in the environmental movement and speaks to the split that occurred within that community during the 2009 election.

Held in contrast, these two events highlight the different ways in which various historically-constituted discursive practices helped bring meaning to climate communication in the province. Over a decade earlier, Tzeporah Berman herself may have been scaling the pole, so to speak, as she helped get her start as an activist leading grassroots opposition to old-growth logging on Vancouver Island, which was marked by direct action, mass arrests, international media attention and boycotts (Berman \& Leiren-

\footnotetext{
${ }^{80}$ Interestingly, the Northern Gateway proposal would eventually become a very active site of conflict for environmental politics in both B.C. and at the Canadian federal level. In many senses, the project became an official national priority for the ruling federal Conservative Party and a key area of focus for environmental groups across Canada.
} 
Young, 2011; Bernstein \& Cashore, 2000). Now, through a series of transformations, she had placed herself on the other end of the so-called "realo vs. fundi" divide in the environmental movement (Saunders, 2011; cf. Dryzek et al., 2003, pp. 111-117). She was a "realo", more readily working with corporations and governments through negotiations with key power brokers for "realistic" environmental progress. This set her apart from the "fundis", who were said to hold on to a counterproductive fundamentalism that was more radical and moralistic, and which impeded more effective activism.

The storylines here resonate with the tensions found in the ecological modernization coalition supporting climate action, if in a more dramatic and divisive manner. ${ }^{81}$ Weaker eco-modern discourse tended to be reinforced and sustained by discursive practices that depended on assumptions of social hierarchy, legitimacy, expertise and authority that worked along the grain of hegemonic institutional power. As mentioned previously, the terms and storylines animating this camp largely accepted established views of social and political reality as given and advocated a reformist agenda within these restraints.

Actors in these groups were often policy professionals with backgrounds in academia, economics, the private sector, or government bureaucracy, and much of their efforts focused on creating technical climate policy reports. ${ }^{82}$ They were also more likely to sit on official government panels or contribute commentary as respected sources for mainstream media coverage (cf. Anderson, 2003). That said, any absolute distinction between other actors that espoused stronger eco-modernist positions should be cautioned,

\footnotetext{
"In Hajer's (1995) telling of the discursive innovations that led to ecological modernization, more radical environmental discourses resembling Lee's were incorporated into new communicative projects and offered more attractive subject-positionings (pp. 73-103). ${ }^{22}$ See think tanks like Sustainable Prosperity, Pembina Institute, or Mark Jaccard, for example. Some actors, including Jaccard and Alex Wood of Sustainable Prosperity, were associated with the National Roundtable on the Economy and the Environment and the C.D. Howe Institute.
} 
as many had similar backgrounds and activities, though they may have been more likely associated with unions or focused on grassroots advocacy and social justice. ${ }^{83}$

Furthermore, as mentioned earlier, actors and organizations often worked in concert issuing joint letters, news releases, press conferences, submissions to government committees, or campaigns engaging membership and the broader public to push for stronger climate policy. This was especially so both in the lead-up to the 2008 Budget announcement, which unveiled the carbon tax, and in the months following its implementation. ${ }^{84}$ For instance, in February, 2008, a coalition of 22 environmental organizations in B.C. representing a wide variety of interests and organizational mandates related to climate change and the environment submitted policy recommendations to the government-appointed Climate Action Team (BCSEA et al., 2008a). This included a carbon tax and was endorsed by a strong majority of relevant groups examined in the research sample. ${ }^{85}$

However, the shifting nature of these collaborative efforts complicated any linear retelling of carbon tax discourse over time. Though nearly all actors and groups in the sample period worked together to support the carbon tax or other climate or environmental policy at some point, these alliances were often uneven or in flux, limiting any analytical insight to the bounds of methodological choices employed here. ${ }^{86}$ To further underscore the changing make-up of these coalitions, note that follow-up responses to the government-initiated Climate Action Team report in August, 2008,

\footnotetext{
${ }^{3}$ Actors associated with the CCPA Climate Justice Project were well connected with academic institutions. A number of others had longstanding connections to unions and labour movements like BCGEU and Solidarity Coalition, including Cliff Stainsby of Dogwood Initiative and George Heyman, director of Sierra Club BC.

4 See Harrison's (2012, pp. 388-393) telling of the origins of carbon tax advocacy, which included letters from academic economists, businesses and church groups, as well as submissions to government budgetary committees, op-eds in newspapers, and letter-writing campaigns.

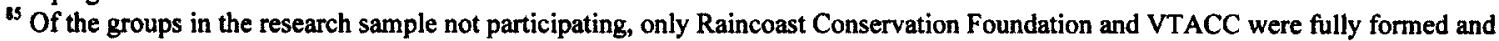
focused on B.C. at the time. The report included the general caveat that "some groups may not support all of the detailed measures as stated".

${ }^{36}$ Personal interviews or other qualitative interpretive methods might further detail the nuances of some of these dynamics.
} 
included only ten of the original 22 groups who had previously submitted policy recommendations in February, 2008 (BCSEA et al., 2008b).

That said, a clear period of division in the environmental movement arose during the 2009 election campaign. This tension was driven in part by competing understandings about the appropriate relationship between movement representatives and official purveyors of institutional power, including those of the mainstream media. Part of the rift might be understood in terms of what Carroll and Ratner (2007, p. 59) have identified as an historical "double ambivalence" between B.C. social movements and both the Liberal Party and the NDP. ${ }^{87}$ Under the provincial NDP governments from 1991 to 2001, the relationship between social movements and state power in B.C. became contradictory and disillusioning for many grassroots organizers. During this period, environmentalists and other social activists were actively integrated in official government decision-making processes, often only to resist what was later seen as a disappointing and compromised politics of inclusion or a politically ineffective "reasonableness" (p. 49).

From this perspective, the 2007 Liberal Party policy turnaround on climate change continued a previous reorientation in the relationship between the environmental movement and state politics (pp. 56-60). This shift towards an "actively inclusive" political program (Dryzek et al., 2003) initiated by the Liberal government, sought out environmental expertise from a number of actors and organizations for consideration in government decision-making bodies ${ }^{88}$ Crucially, those incorporated into official

\footnotetext{
${ }^{87}$ Carroll \& Ratner (2007, pp. 46-48) note a similar historical relationship stretches back to the neo-liberal policies of the Social Credit governments of the 1980 s and its conflicts with the Solidarity Coalition.

The most prominent examples here included the Climate Action Team and the Green Energy Advisory Task Force, which saw contributions from both Mark Jaccard and Tzeporah Berman, as well as representatives from David Suzuki Foundation and Pembina Institute. In this sense, the environmental movement became a key constituent in a broader official politic.
} 
deliberative processes tended to be less oppositional in their discursive stances towards the government and often represented weaker eco-modernist positions. ${ }^{89}$

This new working relationship was criticized by environmentalists closely aligned with both the NDP and grassroots groups from communities opposed to Liberal policies that predated the carbon tax. High-profile attacks on the NDP by popular leaders of the environmental movement, such as David Suzuki and Tzeporah Berman, for example, created significant dramatic effect in the symbolic environments of corporate mass media. Not only did these actors defend a policy that they themselves deemed "politically suicidal", they did so in defiance of their supposed natural allies on the Left and to the detriment of the NDP partisan cause. Furthermore, these attacks seemed to symbolize a discursive reordering with consequences for the democratic makeup of a movement that had often prized egalitarian practices of participatory democracy above much else (cf. Salazar \& Alper, 1999). Localized expressions of resistance were seen to be steamrolled by unaccountable, media-certified leaders in the name of a carbon tax, an admittedly important policy for many detractors, but one whose significance seemed to hold value in more decontextualized and spatially-diffuse mediascapes. ${ }^{90}$

Other storylines included the concern that locally-valued rivers were being molested by the "profit motive", represented by a ruinous "goldrush" of private development (foreign corporations like General Electric, in the case of Bute Inlet and Plutonic Power, being the most emblematic example), which had corrupted public process for the sake of energy exports to the United States (see Kimmet, 2009a). Still,

\footnotetext{
${ }^{39}$ As mentioned earlier, this does not mean these actors did not push the government for stronger climate action, as this was very consistently the case. But in context of the entire research sample they were the least oppositional in communication.

${ }^{\circ}$ David Harvey (1999) notes a similar tension in his analysis of the environmental justice movement where "The move from tangible solidarities felt as patterns of social bonding in affective and knowable communities to a more abstract set of conceptions with universal meaning involves a move from one level of abstraction--attached to place-to quite different levels of abstraction capable of reaching across a space in which communities could not be known in the same unmediated ways" (p. 183).
} 
tensions inherent in dominant media practices remained an important preoccupation. Addressing the prominent environmentalists who had defended the Liberal carbon tax, one activist exclaimed, "As the living systems of this part of the world are under the final assault by the BC Liberal Government, you make headlines" (Tieleman, 2009a).

This tension helps underscore the ambivalent relationship embodied in environmentalist communicative practices, which are often shaped by, and even dependent on, various institutional rules and criteria for participation in broader media systems (Anderson, 2003; Gitlin, 1980; Gamson \& Wolfsfeld, 1993; Greenberg, Knight $\&$ Westersund, 2011). In this case, the symbolic potency of these media representations became implicated in the image of the movement itself, and a struggle for representation began to define much climate discourse throughout this period. In a visceral sense, these "mass-mediated images were fixing...the terms for internal debate; they were helping define the [movement's] situation for it." (Gitlin, 1980, p. 31).

Advocates on both sides of the discursive divide lamented the role the carbon tax played in public debate on climate change during the election (Robinson, 2009; Barrett, 2009), but to different rhetorical ends. In its most radical articulation, critics cast defenders of the carbon tax as corporate "greenwashers" whose equivocal or ambiguous relationship with government and the media ultimately served as a political endorsement, legitimating the environmental transgressions of the Liberal government (Tieleman, 2009a). ${ }^{91}$ Still, most detractors would express their continued commitment to the carbon tax, which often meant that any differences of perspective were ultimately framed as

\footnotetext{
91 This resonates with the idea that the "symbolic" value of the tax was in opposition to "real" climate policy action. This too was picked up by Carole James when she shot back at environmentalists supporting the policy, "I understand the carbon tax is a symbol. Well, I think we need more than symbols" (Bailey, 2009).
} 
problems of emphasis in political communication and practice, as opposed to an unbridgeable discursive incompatibility.

To the more oppositional actors, this was not enough. In Berman's case, she was castigated as an environmental Judas Iscariot, even inspiring a small campaign against her appointment as climate campaigner for Greenpeace International. Much concern revolved around the appropriate conduct for leaders of the climate movement and their relationship towards those with institutional power. A creator of the "Save Greenpeace" campaign explained that "in an era of climate change, confrontational, no-compromise environmentalism has never been needed more, and yet has also never been under greater threat" (Saunders, 2011). ${ }^{92}$ From this perspective, Berman's collaborative relationship with the government, especially her appointment as a member of the Green Energy Advisory Task Force, cultivated further distrust towards the "hidden motives" behind her actions, usually involving the financial interests of her funders (Tieleman, 2009a; Burrows, 2009; Zehr, 2009c). ${ }^{93}$ Hence, a discourse of suspicion towards political economy usually reserved for corporations and government representatives found expression in a new discursive arrangement.

\section{6 - Shaping a Reformed Carbon Tax and the Ascendancy of Natural Gas}

Following the 2009 election there is evidence that tensions between groups lessened, especially with the coordinated release of a set of policy recommendations by 21

\footnotetext{
${ }^{92}$ Further to this he noted, "The philosophy of Berman and people like her is one of accepting power and attempting to persuade it, rather than confronting power and dismantling it".

${ }^{93}$ The influence of foreign funders in the BC environmental movement, especially from the United States, has a historical precedence (see Bernstein \& Cashore, 2000, p. 97), as does anti-American sentiment (Zelko, 2004; Van Huizen, 2011). Berman herself countered these critiques by suggesting her detractors were captive to union financial influence, saying "I don't care if it's built by Martians!" (Glave, 2009).
} 
environmental groups, many of which had previously been at odds with respect to ROR development in the province (see Shaw, 2011, pp. 755-757; David Suzuki Foundation et al., 2009). The completeness of this truce is unclear, and certainly antagonism still remained, as is evident in the Copenhagen climate leadership award, the results of the Green Energy Advisory Task Force process and the Clean Energy Act, as well as the "Save Greenpeace" petition. However, hostilities at least partially subsided and what little communication on the carbon tax remained honed in on four points of policy reform: continued tax rate increases passed 2012, compensation for low-income households, use of revenues to fund climate mitigation projects, and expansion of coverage to include non-combustion emissions from industry.

As mentioned earlier, these points generally came together under advocacy efforts to establish a "Better Future Fund", especially during the government's carbon tax review period in 2012 (Bruce \& O’Connell, 2011; Horne, Bruce, \& Smith, 2012; Sierra Club et al., 2012; www.betterfuturefund.ca). ${ }^{94}$ A common storyline acknowledged the carbon tax as an "important first step" towards progressive climate action, but emphasized that the task ahead required making the program "fairer and more effective" (Pembina Institute, 2012a, p. 1; Horne, Bruce \& Smith, 2012; cf. CCPA, 2012b; CCPA \& Sierra Club BC, 2011; Sierra Club et al., 2012). This often meant situating the carbon tax as one constituent part of an integrated provincial climate strategy designed to have all policies

\footnotetext{
It is interesting to note that though the four policy points found relatively consistent articulation in communication, the online public engagement effort www.betterfuturefund.ca suggested only two of the four: expanding tax coverage to non-combustion emissions, and using that extra revenue to spend on climate projects. This stands in contrast with the recommendations from stronger eco-modern groups like those at the CCPA who suggested using half of existing revenue for climate spending and half to compensate low-income households (CCPA, 2011).
} 
working together in tandem, hence attempting to rectify growth in the oil and gas sector and a lack of funding for various mitigation initiatives. ${ }^{95}$

The recommendations taken up in this revised effort had been expressed prior to the government's carbon tax review, and in many ways were already an unofficial carbon tax "campaign" that began to take shape later in 2009 and onwards. ${ }^{96}$ A number of groups had pressed some of the four points on various occasions even before the 2007 Throne Speech. Indeed, the idea that the carbon price schedule had to continue to increase was a foundational rationale for the policy in the first place. Likewise, the concern that carbon taxation could be regressive, meaning it generally hit the budgets of lower-income individuals and families harder than those with more income, was also common to carbon tax discourse and found expression in low-income tax credits given out by the government.

However, in October, 2008, an analysis from economists at the CCPA argued the Liberal program would become regressive starting in 2010, emphasizing that low-income credits would not increase in-step with the carbon price schedule (CCPA, 2008b). This report itself was a frequent reference point for other actors and became instrumental in a general shift in environmentalist communication about the tax (see Pembina Institute, 2008b, 2009b, \& 2012a; Williams-Derry, 2010; Durning, 2009; Sustainable Prosperity, 2011; Sierra Club et al., 2012).

Furthermore, this same report continued a long line of communication questioning the value of revenue-neutrality in tax design (cf. Marshall, 2000; M. Lee, 2006, \& 2007). As mentioned previously, many environmentalists did not initially

\footnotetext{
${ }^{95}$ One variant of this storyline was the notion that the carbon tax was not a "silver bullet" when it came to addressing climate change, but that it was an important constituent part in a more wide-ranging government approach to climate change policy (see Sierra Club BC et al., 2012; Home, 2012b; cf. Burrows, 2009).

\% See Pembina Institute (2008b) for an early articulation (cf. Pembina Institute, 2009b).
} 
prioritize revenue-neutrality in their advocacy efforts and instead were more concerned with the overall combination of funding for climate programs (see BCSEA et al., 2008b, p. 5; Pembina Institute, 2007, p. 13; BCSEA, 2007; cf. David Suzuki Foundation, 2007). Sodero (2011, p. 1478) notes that despite environmentalist petitioning, the design of the tax was crafted largely in-house with the guidance of the Premier's office. Still, many environmental actors did focus on revenue-neutrality as a benefit to the policy design. However, this too would shift with the significant proportion of actors and groups in the research sample eventually rallying around a narrative that emphasized revenue hypothecation. There may be many possible reasons for this change, one of the most obvious being the persistent advocacy efforts of the CCPA. Furthermore, the end of the NDP "Axe the Tax" campaign, which for its part had previously focused its attack on the Liberal policy for its lack of "fairness", opened important political space. The new carbon tax narrative, which underscored policy reform that was "fair and effective", offered a political modification for the NDP with relatively few negative consequences.

The Liberals too suggested they would reconsider the tax's revenue-neutrality, though the sincerity of these gestures remained unclear (Clark, 2011; British Columbia Ministry of Finance, 2012, p. 66; cf. Lake, 2012). Other important factors included calls by Metro Vancouver mayors to use carbon tax revenue to fund regional transit initiatives under TransLink (Loy, 2009; Lupick, 2009), and the perceived failure of revenueneutrality to do its political communication work convincing the populace of its value (Sodero, 2011, p. 1478; Gunster, 2010, pp. 194 \& 198-202). Additionally, a number of public opinion polls indicated that by connecting carbon tax revenues to climate initiatives support increased, offering a politically attractive way to fill funding gaps for a 
variety of climate mitigation efforts (see Saxifrage, 2011; Pembina Institute, 2008a, \& 2011 b; Pembina Institute \& Energy and Materials Research Group, 2012).

The final policy point involved extending coverage of the carbon tax to noncombustion emissions, largely from industry, including the cement, aluminum and oil and gas sectors. Emissions from these sources were originally anticipated to be covered under the regional cap-and-trade system known as the Western Climate Initiative, a market system the province would eventually back away from. Still, prior to this change, environmentalists had pushed for these emissions to be covered under the carbon tax regime (see Pembina Institute, 2008b). Meeting the provincial climate targets began to seem further out of reach as natural gas development continued to boom in the Northeast of the province and the Liberal government moved the financial fortunes of the sector closer to the heart of its economic agenda. The inclusion of non-combustion emissions under the carbon tax therefore became an important policy point for advocacy, but one in a larger suite of options to stem the onslaught of emissions from the natural gas industry. Environmentalists would attempt to grapple with these issues throughout the 2010 period onwards, as they increasingly came to define the parameters of provincial climate policy. 


\section{Chapter Six}

\section{Conclusion}

We might ask a number of questions given some of the preceding considerations. What were some of the effects of ecological modernization discourse in British Columbia and how did its expression affect communicative practice with respect to climate politics? Why did communication matter in the fight over the carbon tax, at least within the environmental community? How might it have worked to change the balance of political power within the province? What were some of its broader repercussions for democratic culture more broadly?

I have attempted to show that climate politics was animated as a battle over definition, as different actors struggled to influence the terms on which the fight against global warming was conceived. This in turn inspired a host of conflicts over the broader order of societal power relations often implicit in visions for the future that were articulated across various media-spheres. In each case, one could reflect on how each expression worked to position its own particular understanding of the relevance of climate change for "everyday life" in various interpretive communities and consequently how it should be dealt with collectively. Similarly, we might examine how different patterns of communication worked to frame various actors and institutions as responsible for the societal effects of global warming and hence its mitigation. At whose foot was the mantle of climate action placed and to what effect?

These are important questions, in part because how the environmental community collectively made sense of these issues presumably contributed to both the reflexive 
potential and political power of green discourse on wider scales through different public spheres in broader society. In this respect, the strength of eco-modernist discourse expressed is no small matter. In weaker variants, the terms of discourse were generally constrained by the limitations given by dominant institutional actors whose concerns helped define the boundaries for realistic or practical action. Consequently, climate advocates attempted to work for societal change within discursive contexts that reinforced hegemonic social hierarchy, largely setting aside oppositional interrogation that might challenge the legitimacy of various state imperatives. One of the most salient concerns then, as mentioned earlier, becomes the threat of cooptation of environmentalist discourse and depletion of civil society (Dryzek et al., 2003; Torgerson, 1997).

However, there remains a more complicated story to tell here with respect to the carbon tax in British Columbia. One could argue that ultimately the environmental movement failed to attach its defining interest to the core of the state. The climate change agenda withered from the public limelight soon after the 2009 provincial election; ${ }^{97}$ the government failed to commit to further bold climate action past its initial surge of initiatives in 2007 and 2008; and commitments to complete the original Climate Action Plan, following the Climate Action Team recommendations, were not honoured in their entirety. Environmental advocates themselves have struggled to keep the carbon tax an official political priority in their attempts to expand and strengthen its design. Despite a ceasefire between groups with respect to ROR hydro power, concerns still remain over

\footnotetext{
${ }^{97}$ Indeed, both Harrison (2012) and Gunster (2010) suggests this was the case even during the election as the global economic recession began to take precedence in polling data. Etchell \& Hoberg (2009) found both the Liberals and the NDP lessened their attention on the carbon tax throughout the campaign, though they also suggest media coverage of the policy remained a priority. Harrison (2012, pp. 399-400) also notes that neither the environment nor climate change were part of the "Six Pillars" identified as Liberal Party priorities during the election run. A search on Canadian Newstand Complete shows that from January 1, 2010 through Aug 31, 2012, only 79 records were found for a search of "British Columbia" and "carbon tax". This compares to 84 records found for 2009,359 records for 2008 . This also fits with Sodero's (2011, p. 1479) assessment of lower levels of media coverage for 2010 and 2011 .
} 
the lack of public input and environmental efficacy of renewable energy policy in the province (Shaw, 2011). Furthermore, the expansion of a booming natural gas industry in the province has become a foundational pillar in the Liberal government's economic strategy and is predicted to overwhelm legally binding carbon reduction targets.

From this retrospective, intensive fossil fuel exploitation appears to have moved even closer to the heart of the provincial government's economic agenda. What may have initially seemed to be a rather promising and comprehensive climate plan, at least to many environmental advocates, has gradually been sidelined to the political margins, deferent to the powerful appeal of putative market opportunities for liquefied natural gas in Asian economies, among other policy priorities of the Liberal government. With these points in mind, it seems the Liberal climate agenda and carbon tax offered only a partial-and questionable_opportunity to connect an ecological imperative to an economic one. If we accept this interpretation, we can ask whether it was wise for movement actors to align themselves with the government in such a supportive fashion. Indeed, this is what much struggle in the environmental community had centered on. Yet, there is clearly more to say here regarding the practicalities of heeding the forewarning of Dryzek et al. (2003) that "movements ought to think long and hard before accepting inclusion on such limited terms" (p. 153; cf. Gonzalez, 2009). In particular, the B.C. case raises further questions about how one might assess the likelihood that such political opportunities offer "real" chances at affecting substantial policy change. How might advocates make prudent practical evaluations when identifying what constitutes an opportunity based on "limited terms" and what does not? Dryzek et al. (2003) offer their theoretical framework between active and passive inclusion or exclusion in the state as a 
more flexible alternative to the literature on political opportunity structures, allowing movement activists more choice in their strategic positioning in relation to official institutions of power. Yet such a choice can quickly become complicated by the burden of an ambiguous political context and require a certain kind of savvy and practical judgment that may not lend itself to easy analysis or instruction.

The avowed eco-modernist position of the provincial government in B.C. may have indeed seemed a strategic bargain too good to give up for many actors, ${ }^{98}$ especially considering opposition from the NDP. Similarly, the explosion of natural gas production in the province, largely facilitated by the technological advance of horizontal drilling and hydraulic fracturing, seems to have caught a number of analysts by surprise. Furthermore, a substantial portion of emissions from heavy industry, including the natural gas sector, were originally set to be covered under the cap-and-trade system of the Western Climate Initiative. Assessing exactly what constitutes a "real" political opportunity for inclusion in this context may defy straightforward appraisal.

In this respect, condemnations about the failure of environmentalists to collectively realize the true nature of their political situation should be further qualified. I have tried to reinforce that debates about climate policy had different consequences for different actors, but that generally these differences tended to cluster around two poles of ecological modernization discourse. Exactly how these factions might have come to a working political arrangement to push for stronger policy given the political landscape in B.C. is a matter for further debate. It is not clear how choosing a more oppositional stance or a "dual strategy" (Dryzek et al., 2003, pp. 131-163), might have come to a more

\footnotetext{
${ }^{98}$ This point seems to be reinforced by the larger number of groups initially joined in official coalition to support the Liberal climate agenda in 2008.
} 
mature point of development without forgoing the potential policy gains on offer by the

Liberal government. It is difficult to see how more promising results could have been achieved at the time given the lack of broad-based, bottom-up social movement politics rallying for deeper climate action. ${ }^{99}$ The Liberal climate agenda was a top-down initiative and this set an important political dynamic that the environmental community was forced to reconcile in some way.

Perhaps this point itself opens more productive territory for reflection. What is the value of professional policy advocacy without a base of critical democratic political action mobilized to support it or push for deeper change and dialogue? Groups looking to take advantage of the apparent political opportunity offered by the Liberals may have issued academically-vetted policy briefs and reports, and spoken the insider language of the administrative sphere with all the reasonableness of a more measured bureaucratic rationality, but it is not clear that this alone could hope to deliver meaningful political power. One could ask how this logic threatened to destabilize the carefully constructed legitimacy of the institutional practices that had thus far generated the risks of climate change in the first place. ${ }^{100}$ Climate change has been borne and exacerbated by the machinations of the modern provincial political economy in B.C., which is supported by

\footnotetext{
${ }^{99}$ This is not to minimize the importance of grassroots resistance to Liberal ROR policy or the Gateway project, and indeed these choices by advocacy groups to resist inclusion or support for the Liberal government reinforce Dryzek et al.'s (2003) broader point about political opportunities and agency.

100 This can be further related to Meyer's (2010) thoughts about the avoidance of "calling for" sacrifice in environmental politics. "Calling for" sacrifice is understood as a communicative act that proselytizes from a paternalistic, top-down relational stance and imposes a lack of agency on its audience and consequently inspires resistance to its call. This, says Meyer, is what much environmental communication tries to avoid. By contrast, "calling out" sacrifice acknowledges that sacrifices are always already happening, often involuntarily, and that contemporary society is not the best of all possible worlds. Hence, by highlighting the inadequacies of the present system of political arrangement, and by facing concerns that leaving industrialism behind requires the willful abnegation of things of cultural value, a more expansive social context for democratic action is brought to bear. The distinction here rests on one usage, which implies a lack of agency and a command forced upon its unwilling audience, and another that frames sacrifice as a potentially empowering and transformative choice to be willingly taken together. Calling out sacrifices means reframing these involuntary requirements of the cultural and political systems that are everywhere taken for granted, despite their ubiquity, and communicating from that context for future action.
} 
a panoply of related cultural assumptions that authorize its continued dominance. ${ }^{101}$

Without confronting the rationale that perpetuates this hegemony one is left largely at the mercy of those institutional players who, at best, attempt to initiate the structural transformations of society in transition to a carbon-neutral world in relative quiescence, apart from general public input and participation.

This is a key difference between strong and weak versions of eco-modernist discourse. By assuming deeper societal change can occur with little alteration in the dominant structural relationships of power in society, weak eco-modernism works from a truncated or constrained position of critique in a top-down fashion. This is not to assert that such assumptions are necessarily misguided in all cases, nor to suggest that professionalized counter-experts are not important parts of an overarching strategy for creating broader reflective engagement with climate issues. ${ }^{102}$ But without a vibrant and independent social movement founded primarily in civil society threatening to "storm the Bastille", as it were, it may be difficult to affect the political change necessary to reach a variety of different climate policy goals. This is part of the value of a "dual strategy" (Dryzek et al., 2003) that suggests varying degrees of emphasis on both insider and outsider strategies for climate advocacy depending on the political context. ${ }^{103}$

In the B.C. case, professionalized advocacy was often gripped by an uneasy tension with existing grassroots environmental politics. Perhaps most clearly, this tension could be found in the work of Tzeporah Berman, who tried to negotiate a very delicate

\footnotetext{
${ }^{101}$ This is clearly not a one-way street as many of these same cultural assumptions are reinforced by the dominance of the provincial political economy in a process of mutual support. Our ways of securing a living allow certain subject-positions to be occupied, which then helps reproduce ideological standpoints that reinforce and sustain these same ways of life.

${ }^{102}$ Certainly Dryzek et al. (2003) suggest so by acknowledging choices should be made by social movement actors faced with varying sets of circumstances and opportunities depending on the political context set by different governments. Likewise, Beck's process of reflexive modernization places a key role for "counter-experts" in the subpolitical process.

${ }^{103}$ Torgerson (1997 \& 1999) also suggests a similar orientation. More recently, Skocpal (2013) has stoked controversy in the American climate community with her assessment of the failure of cap-and-trade legislation in the United States. She likewise advocated a dual strategy combining insider and outsider politics (see Poole, 2013; Romm, 2013). The report itself is meant more for a lay audience and does not offer a comparable theoretical framework, but is noteworthy nonetheless.
} 
line, reformulating her past public identity as a grassroots campaigner with a new one that aimed at both working with the Liberal government and inspiring grassroots organization with PowerUP Canada. Other groups like Pembina Institute, David Suzuki Foundation and ForestEthics found themselves in a related struggle to reconcile their support for the Liberal government and the carbon tax with grassroots resistance.

These struggles proved to be a serious challenge for actors in their attempts to form a more united political front. I have expanded on a number of these dimensions where social negotiation proved to be a particularly difficult problem. These included issues related to the broader symbolic media value of the carbon tax, the so-called climate contradiction of Liberal policy, the "double ambivalence" held between social movements and the two political parties, and the notion of "climate leadership", among others. These areas of conflict I argue helped create and exacerbate a lack of understanding and trust between communicators. Perhaps such a discourse coalition would prove implausible given the political constraints on communicative action mentioned earlier. At times of division, actors seemed to be bounded by these limits, as they forcefully talked past each other, further intensifying an air of distrust, especially in the glare of the media spotlight during the 2009 election.

Indeed, herein lies a potential benefit of focusing on climate discourse by adopting the argumentative analytic approach of Hajer and others. It is instructive that despite previous articulations of mutual support for the government's climate program and the carbon tax, subsequent discursive clashes in the environmental community revealed a lack of shared definition of reality. The place of the carbon tax and climate action in the broader scope of environmental concerns, as well as their appropriate 
practical relation to institutions of government and media, indicated that earlier "worldmaking" could not sustain a shared sense of "credibility, acceptability and trust" (Hajer, 1995, p. 287). Though many environmental advocates may have at first expressed similar metaphors and storylines highlighting the value of ecological modernization in British Columbian climate policy, the differences in understanding exactly what those storylines had meant to each party changed during process of high-stakes environmental politics. The apparent discord became more pronounced as pressure mounted into the 2009 election, forcing different representatives and groups to balance their various socialpositions in a shifting social order. In this sense, storylines changed-as highlighted in the focus on "leadership" and the relative completeness or cohesiveness of Liberal environmental policy, for example-and so did the meaning of the carbon tax.

This did not spell the end for cooperative relations between groups, especially if we consider, as mentioned earlier, that divisions in the environmental community seemed to lessen, perhaps after personal or private communication between advocates helped ease hostilities. Still, following Hajer (1995), a more publicized deliberative environmental politics might have helped clarify the direction of ecological modernization and "produce a set of normative commitments that [were] widely shared by participants as well as to make clear where there [was] fundamental dissensus" (Hajer, 1995, p. 292). Similarly, Dryzek et al. (2003) and Torgerson (1999) focus on the deliberative potential of communication in constituting these reflexive political conditions, albeit with an emphasis on civil society and the green public sphere apart from the official institutions of government. ${ }^{104}$ In the B.C. case, the environmentalists

\footnotetext{
${ }^{104}$ Hajer's (1995) formulations of "societal inquiries" and "discursive law" are bound in a closer relationship to the formal institutions of governmental oversight.
} 
could have benefited from a more focused and wide-ranging public discussion on why different visions for the future of the province conflicted in such a visceral manner under the banner of climate action. A more reflexive debate should help clarify options and costs of policy choices in order to achieve better results in terms of problem closure (Hajer, 1995, p. 283).

This is admittedly a larger and more involved political and cultural endeavour that would have needed more sustained attention prior to the Liberal climate turnaround. Furthermore, it is a project that lacks guarantees on the outcomes of such public deliberations and involves embracing a certain type of "messiness" usually associated with democratic politics. Being open to dialogical interaction means that the results of discursive conflict are not predetermined and may well lead to ecologically inadequate or even destructive outcomes, though the likelihood of this prospect has been challenged (see Dryzek et al., 2003, pp. 5-6; Dryzek, 1997, pp. 200-201; Hajer, 1995, pp. 283-286; cf. Lövbrand \& Khan, 2010). Nonetheless, the project of improving the grounds for green discursive exchange is an important one in light of some of the limitations of provincial climate politics and the argumentative dynamics laid out in this study. It seems that many advocates together lacked a well-developed base for inter-discursive interaction on issues of environment and climate. As Dryzek \& Stevenson (2011) note, "A well-functioning public space should also feature engagement of discourses in such a way that induces critical reflection on the part of people articulating different discourses" (pp. 1869-1870; cf. Hajer, 1995, p. 281). ${ }^{105}$ By comparing different discourses against each other, the hope is to break down enclaves of like-minded individuals that tend to reinforce their

\footnotetext{
${ }^{105}$ In a similar fashion, Hajer (1995) has noted, "The challenge for reflexive ecological modernization lies much more in finding new institutional arrangements in which different discourses (and concerns) can be meaningfully and productively related to one another, in finding ways to correct the prevailing bias towards economization and scientification, and in active intersubjective development of trust, acceptability, and credibility..." (p. 281).
} 
own views in a self-referential loop, opening them up to a more creative engagement that challenges their foundational assumptions to better justify them in relation to others. Widening the scope of communication within a green public sphere could mean deeper reflexivity in argumentative practice, therefore offering the potential to enhance the political power of future eco-modernist discourse coalitions, as well as being a valuable creative and democratic exercise in and of itself. ${ }^{106}$

This is of course not to suggest that communication by environmental actors was entirely bereft of such interaction in B.C., but to suggest that these processes could have been more extensive and open. A more cohesive and organized set of spaces for such interaction could have benefited the project of environmental politics in British Columbia. This could have involved a reimagining of climate politics grounded in grassroots organization in civil society in connection with the more professionalized practices of advocacy. It could have involved a greater participatory role for a diversity of voices from different communities to broaden the scope of deliberative capacities and familiarity with the climate change as an issue of cultural relevance. But it also could have involved strengthening existing connections and commitments to networks of alternative media, as well as developing new ones. Throughout my investigation alternative media outlets offered important spaces for critical examination of environmental issues related to climate politics in B.C., and provided forums for a diverse array of activist voices to be held in contrast. This is in line with other scholarly work on the connection of alternative media and the potential for progressive politics (Gunster, 2011; Hackett \& Carroll, 2006). A more fulsome examination of some of these issues is

\footnotetext{
${ }^{106}$ See Torgerson's (1999) take on Hannah Arendt's conception of the performative and "fun" aspects of green political participation: "We witness a display of inventive and illuminative communicative skill, an exchange of opinions valued for its own sake. In this sense, political debate assumes the aspect of an infinite game, in which the players are committed to playing the game and keeping it going" (p. 157).
} 
beyond the scope of this thesis. However, future research could investigate some of these lines of study with the participation and input of advocates and media workers with practical experience in these areas. Scholarly inquiry might further consider connections between academic literature on strong ecological modernization discourse and the role of social media in creating the green public sphere (cf. Hier, 2008).

In some senses, the shape of environmental activism in B.C. has already made significant shifts in the past year in these directions, especially regarding the highly controversial Northern Gateway pipeline proposal from Alberta to B.C.'s coastal port in Kitimat. For example, in October, 2012, a coalition of groups under the name Defend Our Coast helped rally nearly 5,000 protesters, many of whom threatened acts of civil disobedience on the Legislature lawns in the provincial capital of Victoria. ${ }^{107}$ Nearly 70 community actions were also held across the province, primarily facilitated through an online campaign that centered on social media outreach. Concerns about climate change impacts for the Alberta tar sands have been important factors motivating mobilization, along with the environmental risks of an oil spill or pipeline leak. ${ }^{108}$ Additionally, much of the resistance has been led by First Nations groups who have opposed the project. This highlights a significant difference from previous debates about the carbon tax where aboriginal voices were virtually absent from public discussion. ${ }^{109}$

\footnotetext{
${ }^{107}$ The Defend Our Coast rallies were organized by Greenpeace, Truthfool, ForestEthics, Council of Canadians, Leadnow and Dogwood Initiative (Cox, 2012; Hong, 2012). Mark Jaccard was among the signees endorsing the act, as was Tzeporah Berman, David Suzuki, Bill Rees and others (Defend Our Coast, N.D.).

${ }^{108}$ It is also noteworthy that much of this activism resonates with well-worn environmentalist tactics confronting resource extractive industries. These clashes are often framed more as issues of confronting "dirty" energy production than about reducing greenhouse gas emissions (cf. Shaw, 2011). A smaller event held on May, 5, 2012, saw environmental advocates including Mark Jaccard and representatives from Dogwood Initiative and Voters Taking Action on Climate Change arrested for blockading a coal train in protest of plans to expand coal exports through the Lower Mainland (Saxifrage, 2012; Jaccard, 2013). This further suggests a shift in the practice of climate politics and communication towards more confrontational and grassroots action that disregards the standards of international carbon accounting to expand the moral context of climate advocacy towards a more international arena. In this case, the coal was mined in the United States and the protest aimed much of its message at American billionaire Warren Buffet, whose company Berkshire Hathaway owns the railway company Burlington Northern Santa Fe transporting the coal.

${ }^{109}$ There are many differences between the two cases that lend themseives to a more obvious participatory role for indigenous groups in the Northern Gateway case. For example, the proposed pipeline route traverses First Nations territory that was never settled by
} 
As I have argued, weak ecological modernization discourse played a dominant role in environmental communication about the B.C. carbon tax and climate change. The prospect of framing climate action as both economically and environmentally responsible allowed the Liberal government to adopt climate policy on the basis of terms that were consonant with conservative ideological tendencies. This opened up new opportunities for the creation of social and political effects in the province, as actors previously unacquainted with eco-modernist discourse were now able to partake in arguments for climate action in ways that complemented their own subject-positions and identities.

However, the prominence of appeals to this type of viewpoint and its storylines in the weak eco-modernist discourse coalition constrained the range of voices from different communities and cultural backgrounds in climate change discourse. It is notable, for example, that the limited role of public participation and input into government climate policy was an issue that was rarely raised by advocates as one of primary importance, at least with respect to the carbon tax. Key exceptions came from the Canadian Centre for Policy Alternatives who called for broader inclusion of marginalized or minority voices in public debate and deliberation on the design of climate policy itself (CCPA, 2008a; cf. BCSEA, 2007; cf. Washbrook, 2009). But the overall lack of diversity in participation in climate discourse in this manner left it a more exclusive enterprise led primarily by white, male environmentalists and suggests the role of public deliberation was not considered of central importance for affecting change in provincial climate politics. ${ }^{110}$ Future advocacy

\footnotetext{
official government treaty and many of the risks borne by an oil spill will directly affect these communities. However, First Nations communities would also be affected by issues related to climate policy and the carbon tax, as many groups reside in remote locations that depend on gas generators or motorized transport and are therefore vulnerable to large increases in a carbon price. Similarly, aboriginal communities and individuals are often affected by poverty and so have more at stake from a climate justice perspective than higher income individuals and families.

${ }^{110}$ It should be noted the second recommendation from the Climate Action Team was for broader public outreach and engagement on climate change. Additionally, the government had announced the creation of six regionally-focused groups called the Citizens' Conservation Council on Climate Action in the February, 2008, Speech from the Throne (British Columbia Office of the Premier and
} 
efforts could work towards ensuring different cultural perspectives are included and prioritized, both because egalitarian and democratic norms require a less insular politics, and because such inclusion could help expand the potential power of green politics throughout the province.

The challenge of climate politics rests in remaking industrial society in the image of climate change and its putative risks. How this process unfolds-its scope, pace, and social character-is an open empirical question which depends primarily on how power is established in the argumentative process of communication, as conflict over the meaning of these risks plays out rhetorically. I have attempted to show how debates about the B.C. carbon tax in the environmental community often acted as a stand-in for how climate change itself should be handled. How should we value local, grassroots participation in the processes of political change? Indeed, who are we? Who makes up the movement and how should it be organized? What is the role of the general public in deciding on future climate policy? How do we handle the international dimensions of a global problem at a regional level? How dire is the problem? How does ecology fit into climate policy? What is the role of government in relation to the market? And perhaps most fundamentally: what is "climate leadership"?

Actors and groups attempted to define their own concerns in relation to their vision for ameliorative action as foremost in the social negotiation of meaning over the carbon tax and climate policy. In this sense, the carbon tax is best viewed, not as a static or stable piece of legislative achievement, but as a complex object of argumentative struggle, which affected its design, implementation and enactment. The effects of these

Climate Action Secretariat, 2008; Province of British Columbia, 2009). My analysis shows that this outreach effort was not prioritized as an opportunity in environmentalist's public communication strategies. 
deliberative exchanges resonated beyond the environmental movement, as action in the green public sphere held the potential to either expand the dominant terms on which the risks of climate change were understood or reinforce them. The actual influence of any future climate movement in B.C. will therefore depend on how it understands the role of communication in its constitution. As Torgerson (1999) states:

The potential to escape the totalizing logic of instrumentalism in a green context depends (conceptually at least) on thinking not only in terms of a green movement, but also in terms of a green public sphere. Here the we would not be an instrument, but a space of appearance, a common world. The point would not be to achieve overall agreement—some final settlement of issues—but to make meaningful disagreement possible...The significance of the green public sphere resides not merely in reaching conclusions and resolving issues, but in sustaining a process of ecologically informed discourse that through its agenda, presuppositions, and cultural images challenges the monological administrative mind and the prevailing discourse of industrialism. (pp. 19-20)

From this view, addressing climate change depends more on clarifying the terms on which we communicate so as to better illuminate the issue as a social struggle that is embedded in cultural history. This is perhaps a more humbling political endeavour aimed first at supporting reflexive interaction. There will clearly be more said about the significance of the carbon tax in B.C. as it continues to be an important symbol in the environmental community and beyond. What it comes to represent—which social projects of change it carries forward-will ultimately depend on the way it is communicated and understood by those working to use it as a political tool in the 
ongoing process of defining and redefining the challenge climate change poses to modern society. 
Appendix One

Discourse Coalitions: Environmental Organizations and Actors

\begin{tabular}{|c|c|c|}
\hline $\begin{array}{c}\text { Strong Ecological } \\
\text { Modernization Discourse } \\
\text { Coalition }\end{array}$ & "Middle Ground" & $\begin{array}{c}\text { Weak Ecological } \\
\text { Modernization Discourse } \\
\text { Coalition }\end{array}$ \\
\hline $\begin{array}{l}\text {-Canadian Centre for Policy } \\
\text { Alternatives } \\
\text {-Raincoast Conservation } \\
\text { Foundation } \\
\text {-Wilderness Committee } \\
\text {-Dogwood Initiative } \\
\text {-Sierra Club } \\
\text {-VTACC } \\
\text {-BCSEA } \\
\text { - (Michael M'Gonigle) }\end{array}$ & -David Suzuki & $\begin{array}{l}\text {-Mark Jaccard } \\
\text {-Sustainable Prosperity } \\
\text {-David Suzuki Foundation } \\
\text {-Pembina Institute } \\
\text {-Sightline Institute } \\
\text {-ForestEthics } \\
\text {-Tzeporah Berman } \\
\text { (PowerUP Canada) }\end{array}$ \\
\hline
\end{tabular}

Supporting Rationale:

What follows are some of the reasons supporting the system of classification given above.

Strong Ecological Modernization Discourse Coalition

Canadian Centre for Policy Alternatives-B.C. Division (The Climate Justice Project):

As has been explained in much of the body of this report, the CCPA was a leading advocate of stronger ecological modernization and reform of the carbon tax along the 
four points that other advocates also espoused: increasing its price, making it progressive for low-income families, hypothecating revenues, and expanding it to cover noncombustion emissions. As a left-leaning think tank and proponent of "climate justice", the group consistently issued a detailed suite of policy reports that dealt with specific visions for the province, often sector-by-sector, on a wide range of issues, including transportation, land-use planning, food production, manufacturing, resource and energy development, forestry, and more (see CCPA \& Wilderness Committee, 2011; CCPA, 2010d \& c; CCPA, 2012a; CCPA et al., 2010). Often these recommendations focused on the effects of climate policy on income-inequality and stressed the importance of wider deliberative practices as key parts of successful climate change policy (see CCPA, 2008b, $2008 \mathrm{a}, \& 2010 \mathrm{a}$ ). They also crafted proposals that reoriented provincial economy activity around renewed local or regional communities, based on a "closed loop" systems, that depended on locally-sourced or recycled materials, energy efficiency and renewable energy. A leading figure at this group was senior economist, Marc Lee, who was the main media representative for the CCPA and its Climate Justice Project: a collaborative partnership with other universities, environmental organizations, and nongovernmental and community groups from across the province.

\section{Raincoast Conservation Foundation:}

The main actor representing this group was executive director, Chris Genovali. Raincoast Conservation Foundation is based on a remote island off the coast of the province and focuses primarily on conservation issues, scientific research related to advocacy priorities, and grassroots organization. Genovali himself published a number of op-eds that centered on climate change and the carbon tax. Many of these pieces were highly critical of the Liberal government's promotion of oil and gas subsidies and offshore oil drilling, and placed consideration of the carbon tax and climate policy in the context of this contradiction. Furthermore, the "drug addiction" storyline, mentioned in Chapter Five, found early expression here, which focused attention on the global context of emissions from oil and gas produced in B.C., but burned elsewhere (Genovali, 2008a). Genovali also expressed early support for carbon tax revenue to be directed to government spending on climate mitigation programs (Genovali, 2008b). Raincoast Conservation Foundation opposed Liberal policy on privatized run-of-river power based on ecological grounds, further arguing that "the unsustainable consumption of resources by a culture that believes in limitless economic and population growth will never be curtailed by continually meeting growing demand" (Genovali, Paquet, \& Macduffee, 2009). Actors here still voiced support for carbon taxation and carbon pricing more generally, but tended to couch their arguments for climate action in a broader suite of ecological concerns.

\section{Wilderness Committee:}

Wilderness Committee is a national, member-based, charitable organization headquartered in B.C., which is well known for their conservation efforts and role in the "War in the Woods" battles that characterized much environmental politics throughout the late 1980s and 1990s. The group has prioritized climate change advocacy and was supportive of the carbon tax, though some actors from this group expressed serious 
critique of other advocates that were laudatory of the Liberal climate plan (Holman, 2009a). Of all groups in the sample, Wilderness Committee was perhaps most closely connected to grassroots resistance to privatized ROR hydro policy and ran campaigns against the privatization of B.C. rivers (Wilderness Committee, 2009 \& N.D.). Deliberative engagement at a grassroots level was seen as a priority for effective environmental activism. Discourses expressed here tied together wilderness conservation and preservation storylines, alongside climate justice narratives. First Nations partnerships and engagement with Chinese Canadian communities on the Lower Mainland were also important priorities for the group (Western Canada Wilderness Committee, 2008 \& 2009; Wilderness Committee, $2008 \&$ 2012). The group was also affiliated with CCPA and collaborated on policy reports related to transportation and "complete communities", as well as sustainable forestry practices (CCPA \& Wilderness Committee, 2011; CCPA et al., 2010).

\section{Dogwood Initiative:}

Generally speaking, actors from this group tended to occupy stronger eco-modernist positions. Dogwood Initiative focused on environmental issues surrounding energy, land, and resource development in B.C., at times in partnership with First Nations communities, and through grassroots organization. Climate change was also a priority for the group, though often expressed in terms of opposition to the Alberta tar sands, the proposed Northern Gateway pipeline, and oil tanker traffic off the B.C. coast. Actors at Dogwood tended to express a more forceful rhetoric emphasizing catastrophic climate risks and questioning provincial climate policy in light of continued support for the oil and gas industry and unmitigated economic growth (see Horter, 2009b; Mann, 2008; Stainsby, 2009a \& b; cf. CCPA, BCGEU, \& Sierra Club, 2008). Alternative climate policies like cap-and-dividend policy also found support here, though the carbon tax was still an advocacy priority (see Dogwood, N.D.; cf. Stainsby, 2009a; and Horter, 2009a).

\section{Sierra Club BC:}

The inclusion of Sierra Club BC under the strong eco-modern coalition is largely based on communication and alignments that occurred post-2008, especially as former BC Government Employees Union president George Heyman took position as the Executive Director of the organization. Sierra Club climate communication related to the carbon tax took on a more "socialized" character, entailing a clearer focus on the impacts of the tax on low-income families and government spending. During the 2009 split over ROR development, Heyman tended to negotiate the group's position in line with support for grassroots member groups that were working to oppose privatized river development, especially that of Bute Inlet. Heyman himself had previously been critical of the carbon tax, especially its revenue-neutrality (National Union of Public and General Employees, 2008). Furthermore, Sierra Club BC commissioned a number of joint reports with the CCPA (CCPA, BCGEU, \& Sierra Club, 2008; CCPA \& Sierra Club BC, 2011) and reframed their prior commitment to the carbon tax as important for "raising public awareness", but ultimately inadequate on its own. A new policy solution was to be found in a cap-and-dividend proposal (Heyman \& Campbell, 2009). Prior to Heyman's 
appointment, Sierra Club communication about the carbon tax at times felt more closely aligned with some of the Liberal government's strategy (see Matthaus, 2007a \& b).

\section{Voters Taking Action on Climate Change (VTACC):}

Voters Taking Action on Climate Change is a volunteer-driven organization that focuses on citizen engagement, primarily in Vancouver and the Lower Mainland. The group was represented by one of its directors, Kevin Washbrook. Perhaps unsurprisingly, VTACC communication emphasized deliberative engagement as a priority for successful climate policy and took issue with Premier Campbell's top-down implementation style. Though the group promoted the revenue-neutrality of the carbon tax, Washbrook more often contextualized the carbon tax as one piece within a wider set of climate policy goals, which included greater government involvement and oversight in planning and consultation. Furthermore, the Liberal climate contradiction on oil and gas development was also highlighted as a serious challenge. For examples see Washbrook (2009 \& 2008) and Barrett (2008c).

\section{BC Sustainable Energy Association (BCSEA):}

BC Sustainable Energy Association is non-profit society dedicated to a broad-ranging vision of sustainable development that centers on issues related to renewable energy. The group has regional offices throughout the province and spent much energy engaging different local communities through grassroots education programs and events, often focusing on elementary and high school students. Further to this, BCSEA was active in submitting policy recommendations and comments on government policy related to carbon taxation, climate action and renewable energy. A number of their positions on issues related to climate policy emphasized the importance of broader public engagement in building social acceptability for initiatives (Dauncey, 2007 \& 2008; Hackney, 2010a \& b).

\section{Michael M'Gonigle:}

The inclusion of M'Gonigle as occupying a strong eco-modern actor role regarding carbon tax communication is debatable and a characterization that he himself might take issue with, as he is publicly opposed to the idea of ecological modernization (though the "ecological modernization" he critiques aligns more succinctly with weak versions of the discourse. See M'Gonigle, 2009b, for example). In this sense, the limited amount of articles he contributed to The Tyee are more properly classified as a variety of "green rationalism" (Dryzek, 1997, pp. 172-193), though one might make an argument that this discourse fits on the outer edges of a stronger articulation of ecological modernization. This may be especially so given his advocacy for B.C. to become a "showcase of a sustainable, just and practical economic model for the 21st century", which would include "energy-free economic growth" supported by technologies like light rail networks and smart meters, as well as energy exploration that "[follows] the dictates of the muchloved market, but a changed market that now works in the context of an energy-frugal, innovation economy" (M'Gonigle \& Anderson, 2009; M'Gonigle, 2009b). M'Gonigle 
helped found Greenpeace and Dogwood Initiative (he currently sits on their Advisory Round Table), among a number of other environmental groups.

\section{"Middle Ground"}

\section{David Suzuki:}

David Suzuki became a highly charged figure in public debate for his support of the Liberal carbon tax and critique of the NDP. However, my analysis has shown he did not directly participate in the B.C. carbon tax debate to any substantial extent, suggesting his status as an environmentalist celebrity-figure played a significant part in this polarization. Suzuki sat on the board of directors for the David Suzuki Foundation, a group I place in the "weak" eco-modern coalition. However, he is also well known for his commitment to more forceful brands of ecological discourse, which have prompted more conservative environmental actors to warn against "Suzukian prescriptions for Arcadian lifestyles" (Simpson, Jaccard \& Rivers, 2008, p. 251; cf. Suzuki \& Moola, 2010). In the context of environmental and climate debates in B.C., Suzuki negotiated a fine line, which I have interpreted here as occupying a middle space with respect to some of the tenets of ecological modernization discourse. He expressed lament that ecological issues were not at the centre of political debate and tried to balance support for a fulsome approach to climate action with concerns about ROR hydro projects at a local level (Suzuki, 2008; Suzuki \& Moola, 2009). He also highlighted the more extreme end of climate risks, emphasizing that "we face ecological, social, and economic catastrophe on a scale beyond anything we've experienced in modern times" and framed opponents as "industry shills and their followers" (Suzuki \& Moola, 2008). Yet he often promoted climate action on the basis of a narrative that appealed to dominant societal conventions, which underscored greater economic efficiency, technological innovation and expert-consensus.

\section{Weak Ecological Modernization Discourse Coalition}

\section{Mark Jaccard:}

Mark Jaccard was one of the most prominent advocates defending the carbon tax and climate policy in the province. The economic modeling developed by his consultancy, M.K. Jaccard and Associates, was widely cited by environmental groups and the provincial government. Generally speaking, Jaccard articulated climate change with a primary emphasis on economic efficiency - perhaps unsurprising for an economist-and addressed the public on terms that largely accepted a vision of political reality constituted by an uninvolved and self-interested public (Jaccard, 2009b; 2008a \& c). Moralistic environmentalist critique of government inaction was framed as unrealistic and insensitive to the political need for compromise with powerbrokers (Jaccard, 2009b). In this sense, deeper carbon reduction targets were portrayed as subservient to greater stipulations that climate policy should not adversely affect continued economic growth. 
Furthermore, he critiqued other advocates who challenged some of the cultural tenets of consumer society and economic growth by dismissing more radical policy action as draconian, politically naïve, and economically irresponsible (see Barrett, 2008a \& b; Jaccard, 2008a).

\section{Sustainable Prosperity:}

Sustainable Prosperity is a green think tank based in Ottawa that aims to "harness leading-edge thinking to advance innovation in policy and markets, in the pursuit of a greener, more competitive Canadian economy" (Sustainable Prosperity, N.D.). Many actors affiliated with this group had professional backgrounds in economics, law, business or academia. Discourse tended towards an emphasis on economic efficiency and the value of the carbon tax in B.C. as a "win-win" for the environment and the economy. In a national op-ed, and prior to founding Sustainable Prosperity, the group's present chair, Stewart Elgie, wrote,

"Modern capitalist markets are among the most amazing institutions humankind has ever created. They are mighty engines of innovation and wealth... But when it comes to conserving Earth's natural environment, our markets are badly broken... The underlying problem is that we don't pay the true environmental costs" (Homer-Dixon \& Elgie, 2008).

Actors associated with Sustainable Prosperity were important proponents of the B.C. carbon tax as a model for other jurisdictions and framed its accompanying tax cuts as an "economic boon" for taxpayers (Elgie, Rivers, \& Olewiler, 2010; Hume, 2009; Sustainable Prosperity, 2012). Actors most commonly associated with Sustainable Prosperity included Stewart Elgie, Nancy Olewiler, Nic Rivers, and Alex Wood.

\section{David Suzuki Foundation:}

David Suzuki Foundation actively supported the Liberal carbon tax and other government climate policies by contributing to coalitional statements, issuing various backgrounders, fact sheets, and media releases, and as a frequent source for journalists. Furthermore, members sat on both the Climate Action Team and the Green Energy Advisory Task Force. Actors from this group typically framed the carbon tax and climate change in terms of an efficiency narrative that drew from arguments about greater economic and environmental rationality at an aggregate level. Rationale for pricing carbon pollution was compared to paying to dump garbage into a landfill and was said to offer key competitive advantage for the provincial economy. The carbon tax itself was generally considered a key tool in creating the "low-carbon economy of the future" by sending powerful market signals that offered incentives for green technological innovation (Campbell, Bruce, \& Smith, 2009). Though the Foundation is well known for a host of advocacy issues related to biodiversity and other ecological concerns, storylines connecting these areas to the carbon tax or climate action more broadly were comparatively few (especially in comparison to texts from David Suzuki; cf. Robinson, 2009). Along with Pembina Institute, David Suzuki Foundation was among the most active groups constituting this coalition. For examples of the above see Bruce (2008); Campbell, Bruce \& Smith (2009); David Suzuki Foundation et al. (2008). 


\section{Pembina Institute:}

Representatives from Pembina Institute offered detailed policy analysis and commentary as frequent sources for media stories related to climate change policy and the carbon tax in British Columbia. Pembina Institute is a prominent national environmental think $\operatorname{tank}^{111}$ with a Vancouver office, and was one of the most active expert organizations in the B.C. carbon tax debate. As such, much communication about the carbon tax took shape through a technical language that focused on the structure of the tax itself and contextualized the policy in relation to other parts of the Liberal and NDP program. Storylines generally followed many of those detailed in Chapter Six (Horne, Bruce, \& Smith, 2012; Pembina Institute, David Suzuki Foundation, \& ForestEthics, 2009; Campbell, Bruce, \& Smith, 2009; Horne, 2011). The group was a key coalitional actor supporting Liberal climate policy, especially during the 2009 election writ drop, which exacerbated the split in the environmental community at the time. Matt Horne, the group's program director for climate change, sat on the Green Energy Advisory Task Force. Representatives often attempted to balance support for government policy with more forceful critique, and attempted to show support for the carbon tax through public polling data and expert consultation reports (Pembina Institute, 2011 a; Pembina Institute $\&$ Energy and Materials Working Group, 2012).

\section{Sightline Institute:}

Sightline Institute is an American environmental think tank based out of Seattle, Washington, formerly known as Northwest Environment Watch. In 1998, the group published Tax Shift: How to Help the Economy, Improve the Environment and Get the Tax Man Off Our Backs, an influential paper that helped lay the foundation for the carbon tax in B.C. (Durning \& Bauman, 1998; cf. Sodero, 2011). Most discourse from Sightline actors was somewhat removed from a B.C. context and addressed to an American audience, primarily in the Pacific Northwest region (cf. Bauman \& Hsu, 2012; cf. de Place \& Bauman, 2012). Still, discourse from Sightline actors generally stuck to the finer policy details of the tax, especially touting its revenue-neutrality, though this was tempered somewhat to suggest revenues could also be used for education, investment in clean energy research, and green jobs training (de Place, 2010b). The B.C. carbon tax was prized as a model for jurisdictions in the United States to follow suit (de Place, 2010b; Bauman \& Hsu, 2012), and in this respect, discourse attempted to address popular anxiety that the province was being put at competitive disadvantage for lack of similar carbon pricing policy elsewhere. Many blog posts focused on the potential for the tax to become regressive, largely in reference to work done by Marc Lee at the CCPA (de Place, 2010a). However, the potential role of broader public deliberation and engagement with respect to climate policy was generally non-existent and so discourse took on a more technocratic character.

\footnotetext{
111 The group also does consulting work, which makes up a significant part of the their annual revenue (over half of 2011 revenues; see Pembina Institute, 2012b).
} 


\section{ForestEthics:}

Texts from ForestEthics were not found frequently in the sample, though actors were sometimes represented as key sources in news stories. The group, co-founded by Tzeporah Berman, is well known for their mass media pressure campaigns on multinational corporations. I classify them here based primarily on their coalitional affiliations in B.C. with other weak eco-modernist actors, while recognizing, as is the case with all actors in the sample, that they may have occupied different positions in different political contexts (Pembina Institute, David Suzuki Foundation, \& ForestEthics, 2009). The group was a key part of the news conference prior to the drop of the writ in the 2009 provincial election that helped exacerbate the rift in the environmental movement at that time.

\section{Tzeporah Berman and PowerUP Canada:}

Tzeporah Berman and her organization PowerUP Canada were largely synonymous in the sample. PowerUP Canada was meant to inspire grassroots engagement in Canadian communities, but found short life as an advocacy endeavour, eventually dissolving after the 2009 provincial election in B.C. (Stobo Sniderman, 2012). I have detailed many of the social dynamics that affected Berman's contentious position as a leader in the environmental community in B.C., including her alignment with the Liberal Party through media spectacle and participation in official government roundtables. Her advocacy for privatized renewable energy put her in opposition to local concerns about ROR hydro power, and was met with strong backlash from the grassroots level. Generally speaking, she tended to dismiss these concerns as partisan, ideological, reactionary, or even cultish. That said, she frequently worked to frame climate change in more encompassing terms that pointed to its systematic and global character, often under the pretext of catastrophic risk. For example, she argued "Either we solve our carbon problem rapidly, or over the coming decades we will sentence millions of people to misery and dislocation, threaten half the world's species with extinction and leave our children to face rising food costs, shrinking clean water supplies and escalating national security issues" (Berman, 2009). I have classified Berman under the "weak" ecomodernist camp, primarily on the basis of the practical institutional context from which she positioned herself. Though the content of some of her communication may have resembled stronger eco-modern discourse, her practical alignment with dominant institutional actors, as well as the reaction from grassroots environmentalists, suggests she is more properly placed in the weak eco-modernist coalition. 


\section{Appendix Two}

\section{Search Terms}

The following is a list of search terms that were used to find relevant texts for discourse analysis throughout the search engines and websites previously detailed in the Chapter Four. Terms were used in any number of possible combinations to ensure as wide a sample as possible:

carbon tax; British Columbia; BC; B.C.; climate change; global warming; climate policy; revenue-neutral; revenue neutral; revenue-neutrality; revenue neutrality; tax shift; carbon pricing; carbon price; pricing carbon; price on carbon; Sierra Club B.C.; Sierra Club BC;

Lisa Matthaus; Pembina Institute; David Suzuki Foundation; David Suzuki; ForestEthics; Forest Ethics; Merran Smith; Sustainable Prosperity; Stewart Elgie; Nic Rivers; Nancy Olewiler; Alex Wood; David Green; PowerUP Canada; Power UP Canada; PowerUP; Power UP; Voters Taking Action of Climate Change; Kevin Washbrook; British Columbia Sustainable Energy Association; BCSEA; Guy Dauncey; Thomas Hackney; Canadian Centre for Policy Alternatives; CCPA; Marc Lee; Marjorie Cohen; Dogwood Initiative; Will Horter; Cliff Stainsby; Raincoast Conservation Foundation; Western Canada Wilderness Committee; Wilderness Committee; WCWC; Joe Foy; Andrea Reimer; run-of-river; run of river; Save Our Rivers; Livable Region Coalition; Bill Rees; William Rees; Alexandra Morton; Ingmar Lee; Save Greenpeace; Sightline Institute; Northwest Environment Watch; Alan Durning; Yoram Bauman; Conservation Voters of BC; Mark Jaccard; Michael M'Gonigle; Tzeporah Berman. 


\section{References}

Anderson, A. (2000). Environmental pressure politics and the 'risk society'. In S. Allan, B. Adam \& C. Carter (Eds.), Environmental Risks and the Media (pp. 93-104). London, UK: Routledge.

Anderson, A. (2003). Environmental Activism and News Media. In S. Cottle (Ed.), News, public relations and power (pp. 117-132). Sage: London, UK.

Anderson, A. (2009). Media, Politics and Climate Change: Towards a New Research Agenda. Sociology Compass, 3(2), 166-182.

Bäckstrand, K. \& Lövbrand, E. (2007). Climate Governance Beyond 2012: Competing Discourses of Green Governmentality, Ecological Modernization and Civic Environmentalism. In M. E. Pettenger (Ed.), The Social Construction of Climate Change: Power, Knowledge, Norms, Discourses (pp. 123-147). Burlington, VT: Ashgate Publishing Company.

Bäckstrand, K. \& Lövbrand, E. (2006). Planting Trees to Mitigate Climate Change: Contested Discourses of Ecological Modernization, Green Governmentality and Civic Environmentalism. Global Environmental Politics, 6 (1), 50-75.

Bailey, I. (2009, April 18). Suzuki decries NDP over plan to axe carbon tax. The Globe and Mail, $\mathrm{A} 8$.

Bailey, I. (2012, February 22). Liberals announce review of carbon tax. The Globe and Mail, S3.

Bailey, I., \& Stueck, W. (2012, June 22). Clark declares natural gas 'clean' energy. The Globe and Mail, S1.

Barrett, T. (2008a, March 6). Don't Call Him Mr. Carbon Tax: Hotshot eco-wonk Mark Jaccard, on what really works. The Tyee. Retrieved on April 9, 2013, from http://thetyee.ca/News/2008/03/06/Jaccard/.

Barrett, T. (2008b, March 7). Jaccard Rebuts Carbon Tax Critics: Advisor to the premier claims it's world-class policy. The Tyee. Retrieved September 1, 2012, from http://thetyee.ca/News/2008/03/07/JaccardAnswers/.

Barrett. T. (2008c, June 3). Enviros Wary of Campbell's Plans: Secret, conflicting climate change actions hurt support. The Tyee. Retrieved April 9, 2013, from http://thetyee.ca/News/2008/06/03/EnvirosWary/.

Barrett, T. (2009, April 27). Global Warming Debate Lost in Carbon Tax Fog: 'Partisan scrabbling' ruining chance to educate voters: VTACC's Washbrook. 
The Tyee. Retrieved September 1, 2012, from

$\mathrm{http} / / /$ thetyee.ca/News/2009/04/27/WarmingLost/.

Bauman, Y. \& Hsu, S. (2012, July 5). The Most Sensible Tax of All. New York Times, A19.

B.C. Climate Action Team. (2008). Meeting British Columbia's Targets: A Report from the B.C. Climate Action Team. Retrieved January 15, 2013 from www.env.gov.bc.ca/cas/mitigation/pdfs/CAT_FINAL_REPORT_July_23_2008. pdf.

BC Sustainable Energy Association. (2007, July 31). Climate Action Portfolio. Retrieved January 15, 2013 from http://www.bcsea.org/solutions/government/policy/climate-action-portfolio.

BC Sustainable Energy Association, Better Environmentally Sound Transportation, Canadian Parks and Wilderness Society- BC Chapter, Canadian Centre for Policy Alternatives, David Suzuki Foundation, Dogwood Initiative, ... Wildsight. (2008a, February 20). Climate Action Team Input. Retrieved January 15, 2013 from http://www.bcsea.org/solutions/government/policy/climate-action-team -input.

BC Sustainable Energy Association, Better Environmentally Sound Transportation, David Suzuki Foundation, Dogwood Initiative, ForestEthics, Lighthouse Sustainable Building Centre, ... West Coast Environmental Law. (2008b, October 6). Responses to the recommendations of the B.C. Climate Action Team from British Columbia environmental non-governmental organizations. Retrieved September 1, 2012, from http://www.bcsea.org/solutions/government/policy/comments-on-climate-action -team-report.

Beck, U. (1993). Risk Society and the Provident State. In S. Lash, B. Szerszynski, \& B. Wynne (Eds.), Risk, Environment and Modernity: Towards a New Ecology (27 43). London, UK: Sage Publications.

Beck, U. (1995a). Ecological Enlightenment: Essays on the Politics of Risk Society. New Jersey, NJ: Humanities Press International.

Beck, U. (1995b). Ecological Politics in an Age of Risk. Cambridge, UK: Polity Press.

Beck, U. (1999). World Risk Society. Cambridge, UK: Blackwell Publishers Ltd.

Beck, U. (2010). Climate for Change, or How to Create a Green Modernity. Theory, Culture \& Society, 27(2-3), 254-266. 
Beck, U., Bonss, W., \& Lau, C. (2003). The Theory of Reflexive Modernization: Problematic, Hypotheses and Research Programme. Theory, Culture \& Society, 20(2), 1-33.

Berman, T. (2009, May 22). This is the time to fire up a clean energy economy. The Vancouver Sun, A17.

Berman, T., \& Leiren-Young, M. (2011). This Crazy Time: Living Our Environmental Challenge. Toronto, ON: Alfred A. Knopf Canada.

Bernstein, S. \& Cashore, B. (2000). Globalization, Four Paths of Internationalization, and Domestic Policy Change: The Case of EcoForestry in British Columbia, Canada. Canadian Journal of Political Science, 33(1), 67-99.

Bill 17-2010: Clean Energy Act. (2010). $1^{\text {st }}$ Reading 2010, $39^{\text {th }}$ Parliament, $2^{\text {nd }}$ Session. Retrieved from Legislative Assembly of British Columbia website January 15, 2013 from http://www.leg.bc.ca/39th2nd/1st_read/gov17-1.htm.

Braun, B. (2002). The Intemperate Rainforest: Nature, Culture and Power on Canada's West Coast. Minneapolis, MN: University of Minnesota Press.

Brethour, P. (2012, July 4). On the carbon tax, Adrian Dix is tied. The Globe and Mail. Retrieved January 15, 2013 from http://www.theglobeandmail.com/news/politics/on-carbon-tax-and-more-adrian -dix-is-fit-to-be-tied/article4192599/.

British Columbia Ministry of Energy and Mines (2012). British Columbia's Natural Gas Strategy: Fueling B.C.'s Economy for the Next Decade and beyond. Retrieved January 15, 2013 from www.gov.bc.ca/ener/popt/down/natural_gas_strategy.pdf.

British Columbia Ministry of Environment. (2008). Climate Action Plan. Retrieved January 15, 2013 from www.env.gov.bc.ca/cas/pdfs/climate_action_21st_century.pdf.

British Columbia Ministry of Finance (2012, February 1). Budget and Fiscal Plan 2012/13 - 2014/15. Retrieved January 15, 2013 from www.bcbudget.gov.bc.ca/2012/bfp/2012_Budget_Fiscal_Plan.pdf.

British Columbia Office of the Premier and Climate Action Secretariat (2008, September 24). Premier Announces Regional Councils on Climate Action. Retrieved April 5, 2013 from http://www2.news.gov.bc.ca/news_releases_2005-2009/2008OTP0229001432.htm\#.

Bruce, I. (2008, November 13). Backgrounder: B.C. Carbon Tax. Retrieved on July 31, 2012, from http://www.google.ca/url?sa=t\&rct=j\&q=\&esrc=s\&source=web\&cd=2\&ved=0CG 
cQFjAB\&url=http://www.davidsuzuki.org/issues/climate change/Backgrounder\%2520BC\%2520carbon\%2520tax_April09.pdf\&ei=fZ0gUP 6JOMzpiQKhuIDoCA\&usg=AFQjCNGmKCcRxBCiOm94aXj_-Zi3WD5GOw.

Bruce, I., Campbell, K., \& Matthaus, L. (2007, March 12). Energy plan opens new field of debate: Mixed messages create doubts about the direction. The Vancouver Sun, A7.

Bruce, I., \& O'Connell, M. (2011, December 16). Better Future Fund: A solution to climate change within reach in B.C.. Retrieved January 15, 2013, from http://www.davidsuzuki.org/blogs/climate-blog/2011/12/better-future-fund--a -solution-to-climate-change-within-reach-in-bc/.

Brulle, R. J. (2008). The US Environmental Movement. In K. Gould \& T. Lewis (Eds.) 20 Lessons in Environmental Sociology. Cary, NC: Roxbury Press.

Brulle, R. J. (2009). Politics and the Environment. In C. T. Leicht \& J. C. Jenkins (Eds.). Handbook of Politics: State and Society in Global Perspective. New York, NY: Springer.

Brulle, R. J. (2010). From Environmental Campaigns to Advancing the Public Dialog: Environmental Communication for Civic Engagement. Environmental Communication: A Journal of Nature and Culture, 4(1), 82-98.

Brulle, R. J., \& Jenkins, J. C. (2006). Spinning our way to sustainability? Organization and Environment, 19(1), 82-87.

Bulkeley, H. (2000). Discourse coalitions and the Australian climate change policy network. Environment and Planning C: Government and Policy, 18, 727-748.

Bulkeley, H. (2001a). Governing Climate Change: The Politics of Risk Society?. Transactions of the Institute of British Geographers, 26(4), 430-447.

Bulkeley, H. (2001b). No regrets? Economy and environment in Australia's domestic climate change policy process. Global Environmental Change, 11, 155-169.

Burrows, M. (2009, April 17). Tzeporah Berman responds to critics in B.C. environmental movement. The Georgia Straight. Retrieved September 1, 2012, from http://www.straight.com/article-215030/tzeporah-berman-responds-critics -bc-environmental-movement.

Burrows, M. (2010, September 22). Mark Jaccard fears future premiers won't be as climate-friendly as Gordon Campbell. The Georgia Straight. Retrieved January 15, 2013 from http://www.straight.com/news/mark-jaccard-fears-future-premiers -wont-be-climate-friendly-gordon-campbell. 
Buttel, (2009). Ecological Modernization as Social Theory. In A. P. J. Mol, D. A. Sonnenfeld, \& G. Spaargaren (Eds.), The Ecological Modernization Reader: Environmental reform in theory and practice (123-137). New York, NY: Routledge.

Campbell, G. (2009, December 18). Climate change won't wait for consensus; Lack of agreement in Copenhagen doesn't mean we should shirk our duty as global citizens. The Vancouver Sun, A17.

Campbell, K., Bruce, I., \& Smith, M. (2009, April 15). Election question: Who will keep our future green? The Vancouver Sun, A13.

Canadian Centre for Policy Alternatives. (2008a, February 7). Searching for the Good Life in Carbon Neutral BC: Meeting BC's Greenhouse Gas Reduction Targets with Fairness and Equity. Retrieved September 1, 2012, from http://www.policyalternatives.ca/publications/reports/searching-good-life-carbon -neutral-bc.

Canadian Centre for Policy Alternatives. (2008b, October 30). Is BC's Carbon Tax Fair?: An Impact Analysis for Different Income Levels. Retrieved September 1, 2012, from http://www.policyalternatives.ca/publications/reports/bcs-carbon-tax -fair.

Canadian Centre for Policy Alternatives. (2008c, October 30). To be fair, BC's carbon tax needs work: Drop revenue-neutrality, increase credit to low-income families: study. Retrieved January 15, 2013, from http://www.policyalternatives.ca/newsroom/news-releases/be-fairbc $\%$ E2\%80\%99s-carbon-tax-needs-work.

Canadian Centre for Policy Alternatives. (2010a, April 22). By Our Own Emissions: The Distribution of GHGs in BC. Retrieved January 15, 2013, from http://www.policyalternatives.ca/publications/reports/our-own-emissions.

Canadian Centre for Policy Alternatives. (2010b, July 16). Peddling GHGs: What is the Carbon Footprint of BC's Fossil Fuel Exports? Retrieved January 15, 2013, from $\mathrm{http}: / / \mathrm{www}$.policyalternatives.ca/peddling-ghgs.

Canadian Centre for Policy Alternatives. (2010c, September, 30). Climate Justice, Green Jobs, and Sustainable Production in BC. Retrieved, April 9, 2013 from http://www.policyalternatives.ca/greenjobs.

Canadian Centre for Policy Alternatives. (2010d, November 2). Every Bite Counts: Climate Justice and BC's Food System. Retrieved, April 9, 2013, from http://www.policyalternatives.ca/everybitecounts. 
Canadian Centre for Policy Alternatives. (2011, February 23). Fix carbon tax by ending corporate tax breaks, using revenues for climate action and new tax credit: study. Retrieved January 15, 2013 from http://www.policyalternatives.ca/newsroom/news-releases/fix-carbon-tax.

Canadian Centre for Policy Alternatives. (2012a, June 20). Clean Electricity, Conservation and Climate Justice in BC: Meeting Our Energy Needs in a Zero Carbon Future. Retrieved April 9, 2013, from $\mathrm{http}: / / \mathrm{www}$.policyalternatives.ca/electricity-justice.

Canadian Centre for Policy Alternatives. (2012b, August 31). Building a Fair and Effective Carbon Tax to Meet BC's Greenhouse Gas Targets: Submission to the $B C$ Carbon Tax Review. Retrieved April 9, 2013, from http://www.policyalternatives.ca/publications/reports/ccpa-bc-submission-carbon -tax-review.

Canadian Centre for Policy Alternatives, B.C. Government Employees Union, \& Sierra Club BC. (2008, August 7). Greenhouse Gas Emission Reduction Scenarios for $B C$ : Meeting the Twin Objectives of Temperature Stabilization and Global Equity. Retrieved January 15, 2013, from http://www.policyalternatives.ca/publications/reports/greenhouse-gas-emission reduction-scenarios-bc.

Canadian Centre for Policy Alternatives, B.C. Government and Service Employee's Union, Communications, Energy \& Paper Workers Union, David Suzuki Foundation, Pulp, Paper and Woodworkers of Canada, Sierra Club BC, ... Western Canada Wilderness Committee. (2010, January 11). Managing BC's Forests for a Cooler Planet: Carbon Storage, Sustainable Jobs and Conservation. Retrieved, April 9, 2013, from http://www.policyalternatives.ca/coolforests.

Canadian Centre for Policy Alternatives, \& Sierra Club BC. (2011, February 23). Fair and Effective Carbon Pricing: Lessons from BC. Vancouver, BC; Lee, M.. Retrieved September 1, 2012, from http://www.policyalternatives.ca/publications/reports/fair-and-effectivecarbon-pricing.

Canadian Centre for Policy Alternatives \& Wilderness Committee. (2011, April 19). Transportation Transformation: Building complete communities and a zero emission transportation system in BC. Retrieved January 15, 2013, from $\mathrm{http}: / / \mathrm{www}$.policyalternatives.ca/transportationtransformation.

Caroll, W. K., \& Ratner, R. S. (2007). Ambivalent Allies: Social Democratic Regimes and Social Movements. BC Studies, 154, 41-66.

Carvalho, A. (2005). Representing the Politics of the Greenhouse Effect: Discursive 
Strategies in the British Media. Critical Discourse Studies, 2(1), 1-29.

Christoff, P. (1996). Ecological modernization, ecological modernities. Environmental Politics, 5(3), 476-500.

Clark, C. (2011, May 6). Open Letter to British Columbians from Premier Christy Clark: Building on B.C.'s Leadership in the Green Economy. Retrieved January 15, 2013 from http://www.newsroom.gov.bc.ca/downloads/Letter_to_editor_May6 -2011.pdf.

Colebourn, J. (2008, May 8). 69\% want cash redirected to transit, poll finds. The Province, A33.

Cottle, S. (1998). Ulrich Beck, 'Risk Society' and the Media: A catastrophic view? European Journal of Communication, 13(1), 5-32.

Cox, E. (2012, October 23). Defend Our Coast: A National Movement is Building. Rabble.ca. Retrieved on February 21, 2013 from http://rabble.ca/blogs/bloggers/ethan-cox/2012/10/defend-our-coast-national -movement-building.

Dauncey, G. (2007, July 31). Climate Action Portfolio. Retrieved April 9, 2013, from http://www.bcsea.org/solutions/government/policy/climate-action-portfolio.

Dauncey, G. (2008, April 29). BCSEA Position on Run-of-River Hydro Developments. Retrieved April 9, 2013, from http://www.bcsea.org/solutions/government/policy/bcsea-position-on-run-of -river-hydro-developments.

Dauncey, G., Horter, W., Smith, M., \& Berman, T. (2009, April 7). B.C. needs big energy changes; About three-quarters of our energy is produced by sources that emit greenhouse gases. The Vancouver Sun, A11.

David Suzuki Foundation. (2007, October 18). Re: David Suzuki Foundation Climate Protection Proposals for the 2008 B.C. Budget. Retrieved January 15, 2013, from www.davidsuzuki.org/issues/DSF_BC_budget_proposal_2008.pdf.

David Suzuki Foundation. (2008, October). Pricing Carbon: Saving Green-A Carbon Price to Lower Emissions, Taxes and Barriers to Green Technology. Retrieved January 15, 2013, from www.davidsuzuki.org/publications/downloads/2008/Pricing_Carbon_saving_gre en_eng.pdf.

David Suzuki Foundation. (2009, February 18). B.C. Budget maintains core climate strategy, but misses opportunity to invest in green economy. Retrieved January 
15, 2013, from http://www.davidsuzuki.org/media/news/2009/02/bc-budget -maintains-core-climate-strategy-but-misses-opportunity-to-invest-in-gr/.

David Suzuki Foundation, BC Spaces for Nature, BC Sustainable Energy Association, Canadian Parks and Wilderness Society, Cassiar Watch, ForestEthics, ... Wildsight. (2009, December 17). Recommendations for responsible clean energy development in British Columbia. Retrieved January 15, 2013, from www.davidsuzuki.org/media/news/Clean\%20Electricity\%20Recommendations. pdf.

David Suzuki Foundation, BC Sustainable Energy Association, Dogwood Initiative, Sierra Club BC, Western Canada Wilderness Committee, West Coast Environmental Law, \& Wildsight. (2008, June 26). The B.C. Carbon Tax: Myths and Realities. Retrieved September 1, 2012, from www.davidsuzuki.org/media/news/downloads/BC_Carbon_Tax_Reality_Check. pdf.

de Place, E. (2008, February 19). BC's Carbon Tax Shift: The best climate leadership comes from North Cascadia. Retrieved January 15, 2013, from http://daily.sightline.org/2008/02/19/bc-s-carbon-tax-shift/.

de Place, E. (2010a, April 23). BC's Carbon Inequality: New analysis connects income levels to carbon emissions. Retrieved April 9, 2013, from April 23, 2010 http://daily.sightline.org/2010/04/23/bcs-carbon-inequality/.

de Place, E. (2010b, June 17). Carbon Pricing in Washington: How a revenue-neutral carbon tax would work. Sightline Daily. Retrieved January 15, 2013, from http://daily.sightline.org/2010/06/17/carbon-pricing-in-washington/.

de Place, E., \& Bauman Y. (2012, July 10). Washington, Oregon should take cue from B.C.'s carbon tax. The Vancouver Sun, A11.

Defend Our Coast. (N.D.). It's Time to Defend Our Coast. Retrieved February 21, 2013 from http://defendourcoast.ca/about-us/.

DeLuca, K. M., \& Peeples, J. (2002). From Public Sphere to Public Screen: Democracy, Activism, and the "Violence" of Seattle. Critical Studies in Media Communication, 19(21), 125-151.

Dembicki, G. (2011, October 18). Gordon Campbell Slammed by Former Backer, EcoActivist Tzeporah Berman: Former BC premier's lobbying against clean fuel laws 'shocks' enviro who gave him award. The Tyee. Retrieved January 15, 2013, from http://m.thetyee.ca/News/2011/10/18/Campbell-Slammed-By-Berman/?size=large 
Dembicki, G. (2012, June 20). Canada's Oil Insiders Want a Carbon Tax: Surprising as that sounds, interviews reveal a business community consensus based on economics. Third in a Tyee Solutions Society series. The Tyee. Retrieved February 1, 2013, from http://thetyee.ca/News/2012/06/20/Carbon-TaxSupporters/.

Dogwood Initiative. (2011, September 1). BC's Dirty Secret: Big Coal and the Export of Global Warming Pollution. Retrieved January 15, 2013, from http://dogwoodinitiative.org/publications/reports/coalreport/view.

Dogwood Initiative. (N.D.) Working With Our Partners. Retrieved January 15, 2013, from http://dogwoodinitiative.org/archive/climatel/climate-approach/working -with-our-partners.

Doulton, H., \& Brown, K. (2009). Ten years to prevent catastrophe? Discourses of climate change and international development in the UK press. Global Environmental Change, 19, 191-202.

Dryzek, J. S. (1997). The Politics of the Earth: Environmental Discourses. Oxford, UK: Oxford University Press.

Dryzek, J. S., \& Stevenson, H. (2011). Global democracy and earth system governance. Ecological Economics, 70, 1865-1874.

Dryzek, J. S., Downes, D., Hunold, C., Schlosberg, D., \& Hernes, H. (2003). Green States and Social Movements: Environmentalism in the United States, United Kingdom, Germany \& Norway. Oxford, UK: Oxford University Press.

Durning, A. T. (2008, March 10). More on BC's Carbon Tax Shift: Oh, Canada! Retrieved January 15, 2013, from http://daily.sightline.org/2008/03/10/more-on bc2019s-carbon-tax-shift/.

Durning, A. T. (2009, April 14). Will BC Elections Turn on Carbon Tax Shift? Disheartening distortions from the New Democrats. Sightline Daily. Retrieved January 15, 2013, from http://daily.sightline.org/2009/04/14/will-bc-elections -turn-on-carbon-tax-shift/.

Durning, A. T., \& Bauman, Y. (1998, March 21). Tax Shift: How to Help the Economy, Improve the Environment and Get the Tax Man Off Our Backs. Retrieved January 15, 2013, from www.sightline.org/wp-content/plugins/download monitor/download.php?id=89.

Elgie, S., Rivers, N., \& Olewiler, N. (2010, July 28). B.C.'s carbon tax a winner; the shift has been an economic boon for the province's taxpayers and is projected to lower greenhouse gas emissions by five per cent. The Vancouver Sun, B2. 
Etchell, A. \& Hoberg, G. (2009, May 14). British Columbia Election 2009: The Role of the Carbon Tax. GreenPolicyProf. Retrieved January 15, 2013, from http://greenpolicyprof.org/wordpress/?p=199.

Fischer, D. (2013, January 2). Climate coverage dominated by weird weather, falls further in 2012. The Daily Climate. Retrieved February 1, 2013, from http://wwwp.dailyclimate.org/tdc-newsroom/2013/01/2012-climate-change -reporting.

Fogel, C. (2007). Constructing Progressive Climate Change Norms: The US in the Early 2000s. In M. E. Pettenger (Ed.), The Social Construction of Climate Change: Power, Knowledge, Norms, Discourses (123-147). Burlington, VT:Ashgate Publishing Company.

Galloway, G. (2012, September 17). Conservatives call it a carbon tax. NDP call it cap and trade. Which is it? Globe and Mail: Ottawa Notebook. Retrieved February 1, 2013, from http://www.theglobeandmail.com/news/politics/ottawanotebook/conservatives-call-it-a-carbon-tax-ndp-call-it-cap-and-trade-which-isit/article4549758/.

Gamson, W. A., \& Wolfsfeld, G. (1993). Movements and Media as Interacting Systems. The Annals of the American Academy of Political and Social Science, 528(1), 114-125.

Genovali, C. (2007, March 19). Governator, Gordinator differ on offshore ban. TimesColonist, A11.

Genovali, C. (2008a, February 21). Oil subsidies undermine tax. Times-Colonist, A11.

Genovali, C. (2008b, July 13). Campbell caught in a carbon-tax contradiction; Premier claims to embrace California's green shift - but only when it suits him. Times -Colonist, C3.

Genovali, C. (2009, May 22). BC Liberals show a paler shade of green; Idea that Liberal victory was due to climate policy is just plain silly. Times-Colonist, A11.

Genovali, C., Paquet, P., \& Macduffee, M. (2009, May 3). Con: Water diversions will hurt environment. Times-Colonist, D2.

Gitlin, T. (1980). The Whole World is Watching: Mass Media and the Unmaking of the New Left. Berkeley, CA: University of California Press.

Glave, J. (2009, November 1). Tzeporah Berman's Green Idea: The original tree hugger has a big, pragmatic agenda. Meet Canada's next generation of climate-warrior. Vancouver Magazine. Retrieved January 15, 2013, from 
http://www.vanmag.com/News_and_Features/Tzeporah_Berman_s_Green_Idea ?page $=0 \% 2 \mathrm{C} 0$.

Gonzalez, G. A. (2009). Democratic Ethics and Ecological Modernization. In A. P. J. Mol, D. A. Sonnenfeld, \& G. Spaargaren (Eds.), The Ecological Modernization Reader: Environmental reform in theory and practice (207-225). New York, NY: Routledge.

Green, D. (2007, November 1). Why 70 Economists Urge BC Carbon Tax: Premier asked for support, we supplied some. The Tyee. Retrieved January, 15, 2013, from http://thetyee.ca/Views/2007/11/01/CarbonTax/print.html.

Green, D., Harrison, K., Richards, J., \& Olewiler, N. (2008, June 24). We shouldn't 'axe' B.C.'s carbon tax: The issue should be helping people to adjust to higher fuel prices and to reduce their dependence on fossil fuels. The Vancouver Sun, A11.

Green Energy Advisory Task Force. (2010). Green Energy Advisory Task Force Report. Retrieved January 15, 2013, from http://www.empr.gov.bc.ca/EAED/Documents/GreenEnergyAdvisoryTaskForce pdf.

Greenberg, J. \& MacAulay, M. (2009). NPO 2.0? Exploring the Web Presence of Environmental Nonprofit Organizations in Canada. Global Media Journal Canadian Edition, 2(1), 63-68.

Greenberg, J. \& Knight, G. \& Westersund, E. (2011). Spinning climate change: Corporate and NGO public relations strategies in Canada and the United States. International Communication Gazette, 73, 65-82.

Griffin Cohen, M. (2008, January 22). Will BC's Carbon Tax Actually Reduce Emissions? rabble.ca. Retrieved September 1, 2012, from $\mathrm{http} / / / \mathrm{rabble} . c a /$ news/will-bcs-carbon-tax-actually-reduce-emissions.

Gunster, S. (2010). Self-Interest, Sacrifice and Climate Change: (Re)-Framing the BC Carbon Tax. In M. Maniates \& J. M. Meyer (Eds.), The Environmental Politics of Sacrifice (187-215). Cambridge, MA: The MIT Press.

Gunster, S. (2011). Covering Copenhagen: Climate Change in BC Media. Canadian Journal of Communication, 36, 477-502.

Hackett, R. A., \& Carroll, W. K. (2006). Remaking Media: The struggle to democratize public communication. New York, NY: Routledge.

Hackney, T. (2010a, January 7). Green Energy Advisory Task Force Submission. Retrieved April 9, 2013, from 
http://www.bcsea.org/solutions/government/policy/green-energy-advisory-task -force-submission.

Hackney, T. (2010b, April 16). Broad energy vision would engage us all. The Vancouver Sun, A15.

Hajer, M. A. (1993). Discourse Coalitions and the Institutionalization of Practice: The Case of Acid Rain in Britain. In F. Fischer and J. Forester (Eds.), The Argumentative Turn in Policy Analysis and Planning (43-76). Durham, NC: Duke University Press.

Hajer, M. A. (1995). The Politics of Environmental Discourse: Ecological Modernisation and the Policy Process. Oxford, UK: Oxford University Press.

Hajer, M. A. (1996). Ecological Modernisation as Cultural Politics. In S. Lash, S. Bronislaw, \& B. Wynne (Eds.), Risk, Environment \& Modernity: Towards a New Ecology (246-268). London, UK: Sage Publications Ltd.

Hajer, M. A. (2003) A frame in the fields: policymaking and the reinvention of politics. In M. A. Hajer \& H. Wagenaar (Eds.), Deliberative Policy Analysis: Understanding Governance in the Network Society (88-110). Cambridge, UK: Cambridge University Press.

Hajer, M. A., \& Versteeg, W. (2005). A decade of discourse analysis of environmental politics: Achievements, challenges, perspectives. Journal of Environmental Policy and Planning, 7(3), 175-184.

Harrison, K. (2012). A Tale of Two Taxes: The Fate of Environmental Tax Reform in Canada. Review of Policy Research, 29(3), 383-407.

Harvey, D. (1999). The Environment of Justice. In M. A. Hajer \& F. Fischer (Eds.), Living With Nature: Environmental Politics as Cultural Discourse (153-185). Oxford, UK: Oxford University Press.

Hier, S. P. (2008). Transformative democracy in the age of second modernity: cosmopolitanization, communicative agency and the reflexive subject. New Media and Society, 10(1), 27-44.

Heyman, G., \& Campbell, C. (2009, May 7). Towards an effective and fair carbon reduction strategy. Retrieved September 1, 2012, from http://www.sierraclub.bc.ca/media-centre/press-clips/towards-an-effective-and fair-carbon-reduction-strategy.

Hoberg, G. (2010, April 29). British Columbia's New Clean Energy Act: A Preliminary Analysis. GreenPolicyProf. Retrieved April 5, 2013, from http://greenpolicyprof.org/wordpress/?p=427 
Holman, S. (2009a, April 13). Foy: “... why in the Hell would you support that or pander to it in this way?". Public Eye Online. Retrieved January 15, 2013, from http://www.publiceyeonline.com/archives/003788.html.

Holman, S. (2009b, April 14). Fields: "It stands to alienate them from other groups...". Public Eye Online. Retrieved January 15, 2013, from http://www.publiceyeonline.com/archives/003798.html.

Homer-Dixon, T., \& Elgie, S. (2008, August 6). We must green the market. The Globe and Mail, A17.

Hong, B. (2012, October 22). Highlights: Defend Our Coast protest in Victoria. Retrieved February 21, 2013, from http://www.vancouverobserver.com/sustainability/highlights-defend-our-coast -protest-victoria.

Horne, M. (2007, November 26). BC's 2020 Emissions Reduction Target: How Do We Get From Here to There? Retrieved January 15, 2013, from http://www.pembina.org/op-ed/1558.

Horne, M. (2010, February 8). Encana's $\$ 31$ million free-pass: why we need to put a price on pollution. Retrieved January 15, 2013, from http://www.pembina.org/blog/321.

Horne, M. (2011, December 1). Looking to Canada's Economic Past for Wisdom on Climate Change. Retrieved April 9, 2013, from http://www.pembina.org/op -ed/2293.

Horne, M. (2012a, February 15). Claims of climate leadership in B.C.'s Natural Gas Strategy leave much to be desired. Retrieved January 15, 2013, from http://www.pembina.org/blog/611.

Horne, M. (2012b, July 4). Let the evidence speak for evidence on the effect of carbon taxes. The Vancouver Sun, A11.

Horne, M., Bruce, I., \& Smith, M. (2012, February 28). Carbon tax review could to lead to better future for B.C.. The Vancouver Sun, A13.

Horne, M., Bruce, I., Glave, J., \& Dauncey G. (2012, August 16). British Columbians Imagine a Better Future. Retrieved January 15, 2013, from http://www.pembina.org/mediarelease/2366.

Horter, W. (2009a, April 28). Carbon Politics and Pricing Tools. Blogwood. Retrieved January 15, 2013, from http://dogwoodinitiative.org/blog/carbon-politics-pricing -tools. 
Horter, W. (2009b, May 6). What is Required to Survive. Blogwood. Retrieved January 15, 2013, from http://dogwoodinitiative.org/blog/what-is-required-to-survive.

Hulme, M. (2009). Why We Disagree About Climate Change. Cambridge, UK: Cambridge University Press.

Hume, M. (2008, April 4). Independent power group slams NDP over inquiry call. The Globe and Mail, S2.

Hume, M. (2009, April 30). Province's carbon tax rated the top policy in Canada. The Globe and Mail, S1.

Hunter, J. (2012, May 14). Green goals may give way to LNG plans. The Globe and Mail, S1.

Hsu, S., \& Bauman, Y. (2012, July 5). The Most Sensible Tax of All. The New York Times, A19.

International Monetary Fund. (2012, June 12). Economy Faces Triple Threat to Sustainable Future, says Lagarde. Retrieved February 1, 2013, from http://www.imf.org/external/pubs/ft/survey/so/2012/NEW061212A.htm.

Jaccard, M. (2008a, January 16). Climate change policy, transportation reality. The Vancouver Sun, A11.

Jaccard, M. (2008b, April 10). It's time to pay up; Public policies based on voluntarily reducing carbon emissions have failed to change behaviour. The Vancouver Sun, A17.

Jaccard, M. (2008c, July 3). The NDP's Plan: Axe the tax, or max the tax?. The Vancouver Sun, A15.

Jaccard, M. (2009a, April 22). Voters being misled on climate policy; One system of emission reduction is more politically palatable, but is it the most effective? The Vancouver Sun, A11.

Jaccard, M. (2009b, December 14). Environmentalists, businesses see eye to eye on climate change solutions; Government needs to set realistic policies and frameworks as well as support clean technology. The Vancouver Sun, A11.

Jaccard, M. (2010, July 28). B.C.'s dishonesty on climate change; The province's promise to cut emissons by $33 \%$ by 2020 is at odds with its lax standards on shale-gas development. The Vancouver Sun, A11. 
Jaccard, M. (2011, April 12). Campbell's hidden \$200 million tax cut. The Vancouver Sun, A11.

Jaccard, M. (2013, March 1). The Accidental Activist: How an energy economist, Nobel laureate, and former government advisor found himself blocking a coal train. The Walrus, 10(2), 24-28.

Jaccard, M., Rivers, N., \& Kieth, D. (2007, November 21). Taxes beat red tape; Carbon tax propelled Norway to global leadership. National Post, FP17.

James, C. (2008, January 13). NDP leader says another gas tax is a bad way to fight climate change. The Province, A18.

Kimmett, C. (2009a, April 7). BC's Clashing Shades of Green: How 'run of river' and global warming are splitting enviros this election. The Tyee. Retrieved September 1, 2012, from http://thetyee.ca/News/2009/04/07/ShadesOfGreen/.

Kimmett, C. (2009b, December 16). COP Copenhagen Climate Award given to Campbell. The Tyee. Retrieved January 15, 2013, from http://thetyee.ca/Blogs/TheHook/Environment/2009/12/16/TaxPraised/.

Knight, G., \& Greenberg, J. (2011). Talk of the Enemy: Adversarial Framing and Climate Change Discourse. Social Movement Studies, 10 (4), 323-340.

Lake, T. (2012, July 4). NDP's Unrealistic Carbon Tax Policies Will Kill Jobs. Retrieved January 15, 2013, from http://governmentcaucus.bc.ca/news/ndps-unrealistic -carbon-tax-policies-will-kill-jobs/.

Lakoff, G. (2010). Why it Matters How We Frame the Environment. Environmental Communication: A Journal of Nature and Culture, 4(1), 70-81.

Langley Times. (2007, March 30). Gateway opponents gather. Langley Times, 12.

Lavoie, J. (2009, April 24). Eco-group urges voters to shun James. Times-Colonist, B1.

Lee, I. (2009, December 19). Climbing the Pole for ForestEthics. Pacific Free Press. Retrieved January 15, 2013, from http://www.pacificfreepress.com/news/1/5232-climbing-the-pole-for-forest -ethics.html.

Lee, M. (2006, September 28). Tax shifting: a gimmick with legs. The Progressive Economics Forum. Retrieved January 15, 2013, from http://www.progressive economics.ca/2006/09/28/tax-shifting-a-gimmick-with-legs/. 
Lee, M. (2007, September 25). Carbon Tax Shifting. The Progressive Economics Forum Retrieved on July 31,2012 , from http://www.progressive economics.ca/2007/09/25/carbon-tax-shifting/.

Lee, M. (2008, April 3). Is Infinite Economic Growth Possible? The Progressive Economics Forum. Retrieved January 15, 2012, from http://www.progressive-economics.ca/2008/04/03/is-infinite-economic-growth -possible/.

Lee, M. (2009, April 15). BC's Carbon Tax Clash. Policy Note. Retrieved January 15, 2013, from http://www.policynote.ca/bcs-carbon-tax-clash-2/sd.

Lee, M. (2010a, February 5). About that Copenhagen award. The Progressive Economics Forum. Retrieved September 1, 2012, from http://www.progressive economics.ca/2010/02/05/about-that-copenhagen-award/.

Lee, M. (2010b, March 16). Peddling GHGs: How much does BC export? Policy Note. Retrieved January 15, 2013, from http://www.policynote.ca/peddling-ghgs-how -much-does-bc-export/.

Lee, M. (2011, February 23). Look to Europe for next phase of B.C.'s carbon tax. The Vancouver Sun, A15.

Litfin, K. (1994). Ozone Discourses: Science and Politics in International Environmental Cooperation. New York, NY: Columbia University Press.

Litfin, K. (2000). Advocacy Coalitions Along the Domestic-Foreign Frontier: Globalization and Canadian Climate Policy. Policy Studies Journal, 28(1), 236 252.

Littlemore, R. (2009, June 11). BC NDP Leader Accepts Carbon Tax (Bravo! Carole James). DeSmogBlog.com. Retrieved January 15, 2013, from http://www.desmogblog.com/bc-ndp-leader-accepts-bc-carbon-tax-bravo-carole -james.

Lövbrand, E., \& Khan, J. (2010). The deliberative turn in green political theory. In K. Bäckstrand, J. Khan, A. Kronsell, \& E. Lövbrand (Eds.), Environmental Politics and Deliberative Democracy: Examining the Promise of New Modes of Governance (pp. 47-65). Cheltenham, UK: Edward Elgar Publishing Limited.

Lovell, H. (2004). Framing Sustainable Housing as a Solution to Climate Change. Journal of Environmental Planning and Policy, 6(1), 35-55.

Loy, I. (2009, April 22). Campbell to Metro mayors: Hands off the carbon tax. The Tyee. Retrieved January 15, 2013, from 
http:/thetyee.ca/Blogs/TheHook/BC-Politics/2009/04/22/Campbell-Mayors-No Carbon-Tax-Transit/.

Lupick, T. (2009, April 24). Whether carbon tax should remain revenue-neutral is matter of debate. The Georgia Straight. Retrieved January 15, 2013, from http://www.straight.com/article-216151/whether-carbon-tax-should-stay revenueneutral-matter-debate.

M'Gonigle, M. (2009a, April 20). Tapping Our Wild Rivers Can't Fix Climate Change: Veteran enviro says 'no' to Tzeporah Berman's PowerUP logic. The Tyee. Retrieved January 15, 2013, from http://thetyee.ca/Views/2009/04/20/PowerDown/.

M'Gonigle, M. (2009b, December 8). The Elephants of Doom in Copenhagen: What people there should be talking about, and why then won't. The Tyee. Retrieved April 5, 2013, from http://hetyee.ca/Opinion/2009/12/08/ElephantsOfDoom/.

M'Gonigle, M. \& Anderson, B. (2009, April 30). Beyond the Carbon Tax: Two enviros argue it's 'fluff' and 'blackmail' and no real fix for climate change. The Tyee. Retrieved on July 31, 2012. http://thetyee.ca/Views/2009/04/30/CarbonTax/.

Mann, G. (2008, September 2). Oil Industry Injustice. Blogwood. Retrieved January 15, 2013 from http://dogwoodinitiative.org/blog/bulletin.2008-09-02.8425574454.

Marshall, D. (2000, October 26). Shifting Ground: A CCPA-BC Policy Brief on the Potential and Limitations of Environmental Tax Shifting. Retrieved January 15, 2013, from www.policyalternatives.ca/sites/default/files/uploads/publications/BC_Off ce_Pubs/shiftingground.pdf.

Mather, C., Olewiler, N. \& Elgie, S. (2007, November 29). B.C.'s carbon tax shift is smart public policy. The Globe and Mail, A21

Matthaus, L. (2006, September 12). Taking a Giant Leap Backwards. The Vancouver Sun, A11.

Matthaus, L. (2007a, October 3). Presentation to the Select Standing Committee on Finance and Government Services Regarding the BC Budget 2008. Retrieved on July 31,2012 , from http://www.sierraclub.bc.ca/publications/global-warming/sierraclub-bcspresentation-to-the-finance-committee.pdf/at_download/file.

Matthaus, L. (2007b, October 18). How Carole Taylor can go green; B.C. Budget has to back premier's goals with money. The Vancouver Sun, A17. 
Meyer, J. (2010). A Democratic Politics of Sacrifice? In M. Maniates \& J. M. Meyer (Eds.), The Environmental Politics of Sacrifice (13-32). Cambridge, MA: The MIT Press.

Mol, A. P. J. (1996). Ecological Modernisation and Institutional Reflexivity: Environmental Reform in the Late Modern Age. Environmental Politics, 5(2), 302-323.

Mol, A. P. J., Jänicke, M. (2009). The Origins and Theoretical Foundations of Ecological Modernisation Theory. In A. P. J. Mol, D. A. Sonnenfeld \& G. Spaargaren (Eds.), The Ecological Modernisation Reader: Environmental reform in theory and practice (17-27). New York, NY: Routledge.

Mol, A. P. J., Sonnenfeld, D. A., \& Spaargaren, G. (Eds.). (2009). The Ecological Modernisation Reader: Environmental reform in theory and practice. New York, NY: Routledge.

Mol, A. P. J., Spaargaren, G., \& Sonnenfeld, D. A. (2009). Ecological Modernization: Thee Decades of Policy, Practice and Theoretical Reflection. In A. P. J. Mol, D. A. Sonnenfeld \& G. Spaargaren (Eds.), The Ecological Modernisation Reader: Environmental reform in theory and practice (17-27). New York, NY: Routledge.

Mythen, G. (2007). Reappraising the Risk Society Thesis: Telescopic Sight or Myopic Vision? Current Sociology, 55(6), 793-813.

National Union of Public and General Employees. (2008, February 21). B.C.'s carbon tax not neutral for working, low-income people: Preferential treatment for corporations, says BCGEU. Retrieved April 9, 2013, from http://www.nupge.ca/news_2008/n21 fe08a.htm.

Oreskes, N., \& Conway, E. M. (2010). Merchants of Doubt: How a Handful of Scientists Obscured the Truth on Issues from Tobacco Smoke to Global Warming. New York, NY: Bloomsbury Press.

Palmer, V. (2008, April 29). 'Validators' endorse Liberals' tax bill even before public sees it. The Vancouver Sun, A3.

Peet, C. \& Harrison, K. (2012). Historical Legacies and Policy Reform: Diverse Regional Reactions to British Columbia's Carbon Tax. BC Studies, 173, 97-122.

Pembina Institute. (2007, November 14). Mind the Gap: A Blueprint for Climate Action in British Columbia, Summary and Full Reports. Retrieved January 15, 2013, from http://www.pembina.org/pub/1550. 
Pembina Institute. (2008a, May 26). Strong National Support for British Columbia's Carbon Tax: Survey; Poll also shows Canadians want carbon tax revenues invested in clean energy. Retrieved September 1, 2012, from http://www.pembina.org/media-release/1641.

Pembina Institute. (2008b, October 24). Submission to the British Columbia Select Standing Committee on Finance and Government Services: British Columbia's Carbon Tax: Strengths and Opportunities. Retrieved January 15, 2013, from http://www.pembina.org/pub/1800.

Pembina Institute. (2009a, April 15). Pembina Reacts: B.C. Liberal Platform Offers Nothing New on Climate Action. Retrieved September 1, 2012, from http://www.pembina.org/media-release/1813.

Pembina Institute. (2009b, October 16). Recommendations for a Low Carbon Economy in BC: Submission to the Select Standing Committee on Finance and Government Services. Retrieved January 15, 2013, from http://www.pembina.org/pub/1902.

Pembina Institute. (2011a, June 30). British Columbians support the carbon tax: poll. Retrieved September 1, 2102, from http://www.pembina.org/mediarelease/2234.

Pembina Institute. (2011b, September 14). Shale Gas in British Columbia: Risks to BC's climate objectives. Retrieved January 15, 2013, from http://www.pembina.org/pub/2264.

Pembina Institute. (2012a, August 31). Pembina Institute recommendations for B.C.'s carbon tax review. Retrieved January 15, 2013, from http://www.pembina.org/pub/2370.

Pembina Institute. (2012b, December 3). Pembina Institute Annual Financial Report 2011. Retrieved April 9, 2013, from http://www.pembina.org/pub/2397.

Pembina Institute \& Energy and Materials Working Group. (2012, June 25). British Columbia's Carbon Tax: Exploring perspectives and seeking common ground. Retrieved January 15, 2013, from http://www.pembina.org/pub/2352.

Pembina Institute \& David Suzuki Foundation. (2009, October 29). Climate Leadership, Economic Prosperity. Retrieved January 15, 2013, from http://www.pembina.org/pub/1909.

Pembina Institute, \& West Coast Environmental Law. (2009b, May 6). Groups Make Sense of Climate and Environment in B.C. Election. Retrieved September 1, 2012, from http://www.pembina.org/media-release/1828. 
Pembina Institute, David Suzuki Foundation, \& ForestEthics. (2009, April 13). B.C. Climate Change Policy: Media Backgrounder. Retrieved January 15, 2013, from http://www.pembina.org/pub/1810.

Pembina Institute, Sierra Club BC, Living Oceans Society, Wildsight, West Coast Environmental Law, David Suzuki Foundation, ... BC Sustainable Energy Association (2007, February 15). British Columbians Want a Sustainable Energy Future (Backgrounder). Retrieved January 15, 2013, from http://www.pembina.org/pub/1392.

Pembina Institute, BC Sustainable Energy Association, BC Spaces for Nature, Better Environmentally Sound Transport, David Suzuki Foundation, Dogwood Initiative, ... West Coast Environmental Law. (2008, October 10). Climate Action Team Moves Province One Step Closer to a Low Carbon Future. Retrieved September 1, 2012, from http://www.pembina.org/media-release/1711.

Pollon, C. (2011, November 23). Has B.C.'s Carbon Tax Worked? Experts are divided on what the levy has achieved and how it must evolve. The Tyee. Retrieved January 15, 2013, from http:/thetyee.ca/News/2011/11/23/BC-Carbon-Tax/index.html.

Poole, E. (2013, January 18). Why the climate bill failed: It's not that simple. Grist. Retrieved March 1, 2013, from http://grist.org/climate-energy/why-the-climate -bill-failed-its-not-that-simple/.

Province of British Columbia (2009, November 18). Citizens' Conservation Council on Climate Action: Final Progress Report. Retrieved April 5, 2013, from http://www.livesmartbc.ca/community/citizens.html.

Rabe, B. G., \& Borrick, C. P. (2012). Carbon Taxation and Policy Labelling: Experience from American States and Canadian Provinces. Review of Policy Research, 29(3), 358-382.

Rees, W. (2008, February 26). BC's Carbon Tax Shell Game: Economist who invented 'eco-footprint' analysis is not impressed. The Tyee. Retrieved January 15, 2013, from http://thetyee.ca/Views/2008/02/26/TaxShellGame/.

Robinson, P. (2009, May 6). Moving beyond the carbon tax in B.C.'s election. Retrieved September 1, 2012, from http://www.davidsuzuki.org/media/news/2009/05/moving-beyond-thecarbon-tax-in-bcs-election/.

Romm, J. (2013, January 18). What Theda Skocpol Gets Wrong About the Climate Bill Fight. ThinkProgress. Retrieved March 1, 2013, from http://thinkprogress.org/climate/2013/01/18/1448251/what-theda-skocpol-gets -wrong-about-the-climate-bill-fight/. 
Russill, C., \& Nyssa, Z. (2009). The tipping point trend in climate change communication. Global Environmental Change, 199, 336-344.

Sabatier, P. A. (1988). An advocacy coalition framework of policy change and the role of policy-oriented learning therein. Policy Sciences, 21, 129-168.

Salazar, D. J., \& Alper, D. K. (1999). Beyond the Politics of Left and Right: Beliefs and Values of Environmental Activists in British Columbia. BC Studies, 121, 5-34.

Saunders, D. (2011, August 5). Greenpeace: tactics not so clear cut anymore. The Globe and Mail. Retrieved September 1, 2012, from http://m.theglobeandmail.com/report-on-business/rob-magazine/greenpeace -tactics-not-so-clear-cut-anymore/article589576/?service=mobile.

Saxifrage, C. (2011, March 22). Christy Clark and the Carbon Tax. The Vancouver Observer. Retrieved January 15, 2013, from http://www.vancouverobserver.com/blogs/earthmatters/2011/03/22/christy-clark -and-carbon-tax.

Saxifrage, C. (2012, May 5). Thirteen arrested blocking BNSF coal train in White Rock. The Vancouver Observer. Retrieved February 21, 2013, from http://www.vancouverobserver.com/blogs/earthmatters/2012/05/05/fourteen -arrested-blocking-bnsf-coal-train-white-rock.

Shaffer, M. (2009a, April 17). Green Gods Abandoned by Godless Socialists? Policy Note: a progressive take on BC issues. Retrieved January 15, 2013, from http://www.policynote.ca/green-gods-abandoned-by-godless-socialists/.

Shaffer, M. (2009b, April 27). To Tax or Not to Tax - That is the Question! Policy Note. Retrieved January 15, 2013, from http://www.policynote.ca/to-tax-or-not-to-tax -that-is-not-the-question/.

Shaw, K. (2004). The Global/Local Politics of the Great Bear Rainforest. Environmental Politics, 13(2), 373-392.

Shaw, K. (2011). Climate deadlocks: the environmental politics of energy systems. Environmental Politics, 20(5), 743-763.

Sierra Club BC. (2006, September 22). Quebec's Climate Change Plan and B.C.: Media Backgrounder. Retrieved January 15, 2013, from http://www.sierraclub.bc.ca/media-centre/press-releases/quebec2019s-climate change-plan-and-b-c.

Sierra Club BC. (2011, September 30). The Real Story: B.C.'s Uncounted Greenhouse Gas EmissionsBackgrounder. Retrieved January 15, 2013, from www.sierraclub.bc.ca/publications/fact 
sheets/GHG\%20Press\%20Release\%20backgrounder\%20Sep\%202011.pdf/at_d wnload/file.

Sierra Club BC. (N.D.). Global Warming. Retrieved January 15, 2013, from http://www.sierraclub.bc.ca/our-work/global-warming/global-warming.

Sierra Club BC; BC Government and Service Employees Union; BC Sustainable Energy Association; Canadian Autoworkers Union; Communications, Energy and Paperworkers Union; Columbia Institute, Georgia Straight Alliance ... Wildsight. (2012, August 31). Joint Submission to the B.C. Ministry of Finance's Carbon Tax Review. Retrieved January 15, 2013, from www.sierraclub.bc.ca/publications/other/joint-submission-to-the-b.c.-ministry-of -finances-carbon-tax-review/at_download/file.

Simpson, J. (2008, February 20). B.C.'s carbon tax sets a new standard. The Globe and Mail, A17.

Simpson, J. (2009, January 3). Time for a little mea culpa (don't blame the editors). The Globe and Mail, A15.

Simpson, J., Jaccard, M. \& Rivers, N. (2007). Hot Air: Meeting Canada's Climate Change Challenge. Toronto, ON: McClelland \& Stewart Ltd.

Simpson, S. (2008, June 28). Carbon tax defenders blast critics; Public misled by opponents academics say. The Vancouver Sun, E1.

Skocpal, T. (2013). Naming the Problem: What it Will Take to Counter Extremism and Engage Americans in the Fight Against Global Warming. Retrieved March 1, 2013, from

http://www.scholarsstrategynetwork.org/sites/default/files/skocpol_capt rade_report january_2013_0.pdf.

Smart, G. (2011). Argumentation across Web-based organizational discourses: The case of climate change." In S. Sarangi \& C. Candlin (Eds.), Handbook of communication in organisations and professions (363-386). Berlin, Germany: Mouton De Gruyter.

Smart, G. (2013). The discursive production and impairment of public trust through rhetorical representations of science: The case of global climate change. In C. Candlin \& J. Crichton (Eds.). Discourses of trust: The discursive construction of 'trust' within applied linguistic research. New York, NY: Palgrave Macmillan.

Smith, A., \& Kern, F. (2009). The transitions storyline in Dutch environmental policy. Environmental Politics, 18(1), 78-98. 
Sodero, S. (2011). Policy in motion: reassembling carbon pricing policy development in the personal transport sector in British Columbia. Journal of Transport Geography, 19, 1474-1481.

Stainsby, C. (2009a, April 20). Ban Carbon Emissions, Don't Price Them: Why Cap and Dividend is the Best Approach. Blogwood. Retrieved on July 31, 2012, from http://dogwoodinitiative.org/in-depth/ban-carbon-emissions-don2019t-price them-why-cap-and-dividend-is-the-best-approach.

Stainsby, C. (2009b, April 28). Why Carbon Taxes Won't Work. Blogwood. Retrieved on July 31, 2012. http://dogwoodinitiative.org/in-depth/why-carbon-taxes-won2019t -work.

Stephenson, E., Doukas, D., \& Shaw, K. (2012). "Greenwashing gas: Might a 'transition fuel' label legitimize carbon-intensive natural gas development?'. Energy Policy, $46,452-459$.

Stobo Sniderman, A. (2012, March 23). Tzeporah Berman's last Canadian project could have changed Canada's climate policy. So why did it flop?. This Magazine.

Retrieved April 9, 2013, from http://this.org/magazine/2012/03/23/tzeporah-berman\%E2\%80\%99s-last canadian-project-could-have-changed-canada\%E2\%80\%99s-climate-politics-so -why-did-it-flop/.

Sustainable Prosperity. (N.D.). What We Do. Retrieved April 9, 2013, from http://www.sustainableprosperity.ca/What+We+Do+EN.

Sustainable Prosperity. (2011, July 21). Carbon Pricing and Fairness. Retrieved January 15, 2013, from http://www.sustainableprosperity.ca/article1626.

Sustainable Prosperity. (2012, June 27). British Columbia's Carbon Tax Shift: The First Four Years. Retrieved September 1, 2012, from http://www.sustainableprosperity.ca/article2864.

Suzuki, D. (2008, October 7). DAVID SUZUKI: We need to acknowledge our place in a delicate system. Victoria News, 1.

Suzuki, D., \& Moola, F. (2008, July 4). Let's clear the air on carbon taxes. Retrieved April 9, 2013, from http://www.davidsuzuki.org/blogs/science matters/2008/07/lets-clear-the-air-on-carbon-taxes/.

Suzuki, D., \& Moola, F. (2009, April 8). Energy puts enviro-groups at odds. Cowichan Valley Citizen, 7.

Suzuki, D., \& Moola, F. (2010, August 17). David Suzuki: Anti-environmentalists are stuck in the past. The Georgia Straight. Retrieved April 9, 2013, from 
http://www.straight.com/news/david-suzuki-anti-environmentalists -are-stuck -past.

Taylor, A., Jaccard, M. \& Olewiler, N. (1999). Environmental Tax Shift: A Discussion Paper for British Columbians. Retrieved January 15, 2013, from www.emrg.sfu.ca/media/publications/1999/EnvTaxShift5.pdf

Teräväinen, T. (2010). Political opportunities and storylines in Finnish climate policy. Environmental Politics, 19(2), 196-216.

The Canadian Press. (2009, April 24). BC environmentalist blasts supporters of Liberal carbon tax. Wire feed.

Thomas, K. \& Littlewood, S. (2010). A European Programme for Skills to Deliver Sustainable Communities: Recent Steps Towards Developing a Discourse. European Planning Studies, 18(3), 467-484.

Tieleman, B. (2009a, April 21). Furious Rebuke to Suzuki, Berman. The Tyee. Retrieved September 1, 2012, from http://thetyee.ca/Views/2009/04/21/SuzukiRebuke/.

Tieleman, B. (2009b, June 9). How I 'Demonized' David Suzuki. The Tyee. Retrieved January 15, 2013 from http://thetyee.ca/Views/2009/06/09/DavidSuzuki/

Toke, D. (2011). Ecological modernisation, social movements and renewable energy. Environmental Politics, 20(1), 60-77.

Torgerson, D. (1997). Policy Professionalism and the Voices of Dissent: The Case of Environmentalism. Polity, 29(3), 345-374.

Torgerson, D. (1999). The Promise of Green Politics: Environmentalism and the Public Sphere. Durham, NC: Duke University Press.

Torgerson, D. (2010). Policy discourse and public spheres: the Habermas paradox. Critical Policy Studies, 4(1), 1-17.

Van Huizen, P. (2011). Panick Park: Environmental Protest and the Politics of Parks in British Columbia's Skagit Valley. BC Studies, 170, 67-92.

Ward, D. (2009, April 17). Key supporter quits NDP over carbon tax; Environmentalist feels 'deeply betrayed'. The Vancouver Sun, A1.

Washbrook, K. (2008, June 26). Let's Create a Positive Climate-Carbon taxes and global warming: winning the battle, losing the war? The Tyee. Retrieved April 9, 2013, from http://hetyee.ca/Views/2008/06/16/ClimatePositive/. 
Washbrook, K. (2009, May 7). Kevin Washbrook: Let's have a citizens' assembly on climate policies. The Georgia Straight. Retrieved April 5, 2013, from http://www.straight.com/news/kevin-washbrook-lets-have-citizens-assembly -climate-policies.

Weaver, A. (2009, April 16). NDP's 'environmental plan' just a gimmick; Party's 'axe the-tax' campaign is pure political opportunism. Times-Colonist, A13.

Western Canada Wilderness Committee. (2008). Annual Report for the year end 30 April 2008. Retrieved April 9, 2013, from http://wildernesscommittee.org/sites/all/files/publications/wc_2008_annual_repo rt_web.pdf.

Western Canada Wilderness Committee. (2009). Annual Report for the year end 30 April 2009. Retrieved April 9, 2013, from http://wildernesscommittee.org/sites/all/files/publications/wc_2009_annual_repo rt_low-res-1.pdf.

Wilderness Committee. (N.D.). BC's Rivers at Risk. Retrieved April 9, 2013, from http://wildernesscommittee.org/rivers.

Wilderness Committee. (2008, September 4). 2008 Chinese Language Toxins Certificate Presentation Press Conference. Retrieved April 9, 2013, from http://wildernesscommittee.org/video/2008_chinese_language_toxins_certificate _presentation_press_conference.

Wilderness Committee. (2009, March 25). 10,000 Voices Flood Premiers Office Today. Retrieved April 9, 2013, from $\mathrm{http} / / /$ wildernesscommittee.org/press_release/quotation/10000_voices_flood_pr emiers_office_today.

Wilderness Committee. (2012, July 20). Walking the Green Tiger. Retrieved April 9, 2013, from http://wildernesscommittee.org/event/walking_the_green_tiger.

Willaims-Derry, C. (2010, July 12). BC Carbon Tax Shift: Not as good as it used to be? BC's landmark tax shift is falling more heavily on the poor. Sightline Daily. Retrieved January 15, 2013, from http://daily.sightline.org/2010/07/12/bc-carbon tax-not-as-good-as-it-used-to-be/.

Winkel, G., Gleißner, J., Pistorius, T., Sotirov, M. \& Storch S. (2011). The sustainably managed forest heats up: discursive struggles over forest management and climate change in Germany. Critical Policy Studies, 5(4). 361-390.

Wynne, G. (2004). Shall We Linger on Ambitionless? Environmental Perspectives on British Columbia. BC Studies, 142/143, 5-67. 
Young, N., \& Dugas, E. (2011). Representations of Climate Change in Canadian National Print Media: The Banalization of Global Warming. Canadian Review of Sociology, 48 (1), 1-22.

Zehr, G. (2009a, April 11). Job loss expected from NDP climate plan: study. The Tyee. Retrieved January 15, 2015, from http://thetyee.ca/Blogs/TheHook/Election -Central/2009/04/11/Study-Layoffs-NDP-Climate/.

Zehr, G. (2009b, April 16). BC Liberal climate plan falls short: Pembina, Suzuki. The Tyee. Retrieved January 15, 2013, from http://thetyee.ca/Blogs/TheHook/Election-Central/2009/04/16/Liberal-Climate -Plan-Reaction/.

Zehr, G. (2009c, April 17). Activist who 'quit' no longer NDP member. The Tyee. Retrieved January 15, 2013, from http://thetyee.ca/Blogs/TheHook/BC Politics/2009/04/17/Berman-not-current-NDP-member/.

Zelko, F. (2004). Making Greenpeace: The Development of Direct Action Environmentalism in British Columbia. BC Studies, 142/143, pp. 197-239. 